\title{
A Biometrical Study of Egg Production in the Domestic Fowl.
}

\author{
IV. Factors influencing the Size, Shape, and Physical Constitution \\ of $\mathrm{Eggs} 1$. \\ By \\ Maynie R. Curtis.
}

With 18 figures in text and plates VI-X.

Eingegangen am 10. Januar 1914.

\section{Contents.}

Introduction . . . . page

Part I. The individuality of the eggs of each bird in regard to shape, size

and proportion of parts. . . . . . . . . . . . . . . 222

1. The fact of individuality . . . . . . . . . . . . . . . . . 222

2. The measurement of individuality . . . . . . . . . . . . . 223

3. The individuality in respect to variability. . . . . . . . . 228

4. The relation of intra-individual to intra-racial variation . . . : 243

5 . The difference in the degree of variation shown by the several

egg characters............... . . . . . . 248

6. Correlation of egg characters with other characters of the individual 249

7. Summary . . . . . . . . . . . . . . . . . . 253

Part II. The interrelation of the dimensions, shape, size of egg and the size and proportions of the parts .............. . . 255

1. Correlation vetween dimensions and between each dimension and the egg weight. . . . . . . . . . . . . . . 256

a. Gross correlation . . . . . . . . . . . . 256

b. Partial correlation. . . . . . . . . . . . . . . . 264

2. Correlation between the parts of the egg . . . . . . . . 268

a. Gross correlation . . . . . . . . . . . . . . . . . 268

b. Partial correlation. . . . . . . . . . . . . . 268

3. Correlation between the dimensions and shape of the egg and the size of the parts. . . . . . . . . . . . . . . . 269

a. Gross correlation . . . . . . . . . . . . . . . . . . . . 269

b. Partial correlation. . . . . . . . . . . . 270

4. Summary . . . . . . . . . . . . . . 271

1) Papers from the Biological Laboratory of the Maine Agrienltural Experiment Station No. 50. 
Part III. An analysis of the variation among the eggs of the same bird. 273

1. The variation related to the age or maturity of the bird . . . 275

2. The variation related to the season of the year . . . . . 299

3. The variation related to the state of health . . . . . . . . 303

4. The relation of the size of the egg to its position in the litter . 310

5. The relation of the size of the egg to its position in the clutch 311

6. Summary ................... . . 313

Discussion of results. . . . . . . . . . . . . . . . . . 315

General summary .......... . . . . . . . . . 322

Zusammenfassung ................... . . 325

Explanation of plates .................. . . 326

\section{Introduction}

The first and second papers ${ }^{1}$ ) in this series, which form the logical basis of the study, deal with egg production as a mass phenomenon and confine their attention to the number of eggs produced annually and the seasonal distribution of their production. The material upon which they are based is trap nest records. All eggs are considered equivalent. This point of view is necessary at the beginning of the investigation but before it proceeds far one must recognize the fact that the study of the number of eggs produced is only one phase of the general study of the physiology of reproduction in the fowl, and that the complicated physiological processes involved in the production of an egg are so influenced by both heredity and environment that they result in quite unequal products. That is eggs are not equivalent but vary greatly in every character. Egg production can be measured only roughly by counting the discrete units (the number of eggs laid) for these units differ in both size and quality. The scientific and economic importance of these differences is obrious.

In Part III ${ }^{2}$ ) Pearl and Surface began an investigation of these differences by a study of the variation and the correlation in the physical characters of the eggs. For the most part this investigation is confined to a study of the dimensions, weight, shape and bulk of the eggs of homogencous flocks of birds of the same strain. A preli-

1) Pearl, R., and Surface, F. M., A Biometrical Study of Egg Production in the Domestic Fowl. I. Variation in Annual Egg Production. U. S. Dept of Agr., Bur. of Animal Ind. Bull. 110. 1909. pp. 1-80. II. Seasonal Distribution of Egg Production. Ibid. 1911. pp. $81-170$.

2) Pearl, R., and Surface, F. M., A Biometrical Study of Egg Production in the Domestic Fowl. III. Variation and Correlation in the Physical Characters of the Egg. (In press.) 
A Biometrical Study of Egg Production in the Domestic Fowl. IV. 219

minary unpublished investigation by Dr. Pearl has also shown that variation in the physical characters of the egg extends to the size and proportion of the parts of the egg. That a large part of the variation in the eggs of the flock is due to variation between the eggs of different individuals, and that different individuals show different degrees of variability, is clearly recognized by PearL and Surface.

The individuality and the variation of the eggs of the different birds was also clearly shown by the eggs used in the investigations on inheritance in poultry which have for several years been in progress in the Biological Laboratory of the Maine Agricultural Experiment Station. In this work the eggs of about two hundred birds of one breed are handled individually each season. The variation in these eggs is very great. The four following facts in regard to it are apparent:

1) The eggs of different individuals of the same strain vary in size, shape, color and markings.

2) The eggs of an individual are more like each other than they are like the eggs of other individuals of the same strain.

3) In spite of this resemblance between the eggs of the individual they nevertheless show a certain degree of variation in all their characters.

4) The first eggs laid by. the pullets are smaller than those laid by the same birds later.

An analysis of the factors underlying this individuality and variation in the quantitative characters of the egg offers a new point of attack in the study of the physiology of egg production. For several years I have been associated with Dr. PearL, especially in his work in this field. In the fall of 1910 at his suggestion and under his direction I undertook a study of these factors. It is a great pleasure to acknowledge my indebtedness to him for his constant interest and attention during the progress of the work and the preparation of this paper.

This investigation forms the fourth step in the biometrical analysis of egg production, since it deals statistically with the individuality and the variation in the eggs of the individual birds and is therefore here presented as Part IV of that general study. It is an investigation of the shape and size, both absolute and relative, and the proportion of parts of the snccessive eggs of each of a number of Barred Plymonth Rock birds. It includes a) a study of the indi- 
viduality of the eggs of each bird and the variation among them; b) a study of the relation of the individuality of the eggs to other facts known about the bird, such as body weight, relative size of the several visceral organs, age, number of eggs laid, and tendency to broodiness; c) the variation in egg characters in relation to the age of the bird, the seasonal reproductive cycles and the intensity of the reproductive activity, including the grouping of the successive eggs into clutches and litters, the size of these groups and the position of the eggs within them.

For this investigation twenty-two Barred Plymouth Rock pullets were used. They received the same care as the other birds in the laying house of this Station 1). Nineteen of these pullets began to lay the last of October or during November. The other three began to lay in February. Beginning with the first egg laid quantitative data were taken on all the eggs of each bird. These data ${ }^{2}$ ) included the length and breadth of the egg and the weight of the egg and of its several parts (albumen, yolk and shell). In order that the determinations might be accurate it was necessary to find a method first by which the egg could be preserved without loss of weight from the time of laying until the records could be taken ( 24 to 48 hours), second for the accurate separation of the parts. Such a method had been determined by preliminary experiments. The full discussion of these experiments has been published ${ }^{3}$ ).

The method then found satisfactory and used in the present investigation is as follows. As soon as possible after laying each egg was sealed in a half pint Lightning fruit jar containing a layer of absorbent cotton. Here the egg remained until the data were taken. The parts of the egg were separated fresh by a slight modification of the housewife's method. The egg is broken near the center and the albumen allowed to run into the receiving dish. The yolk is kept in one half of the shell, then turned into the other half. If the chalazae remain attached they are cut off by pushing them near their point of attachment against the edge of the shell or by snipping them

1) Pearl, R., and Surface, F. M., Poultry Notes. Ann. Rept., Me. Agr. Exp. Sta. 1910. pp. 66-124.

2) These-measurements were made with a micrometer caliper and the weights with a chemical balance. The measurements were taken to hundredths of a milli-: meter and the weights to hundredths of a gram.

3) Gurtis, M. R., An Accurate Method for Determining the Weights of the Parts of the Eggs of Birds. Ann. Rept. Me. Agr. Exp. Sta. 1911. pp. 93-112. 
A Biometrical Study of Egg Production in the Domestic Fowl. IV. 221

off with scissors. The yolk is then dried on a filter paper, placed in the balance pan and weighed. The shell is also dried with a filter paper and weighed. The difference between the sum of the weight of the yolk and shell and the weight of the whole egg is the weight of the albumen.

From the measurements of the length and breadth it was possible to obtain a measure of the shape by calculating the length-breadth index $\frac{(100 \times \text { Breadth })}{\text { Length }}$. That is the percentage which the breadth is of the length is the index. A long narrow egg therefore has a low index, and a short broad egg a high one.

From the weights of the whole egg and the separate parts the percentage of each part was calculated.

From November 23, 1910, to January 21, 1911, the body weight of each bird was taken weekly. These weights show no tendency to increase or decrease in any bird. They fluctuate irregularly to some extent, due to the amount of food and water present in the bird's digestive tract. The body weights used in Part I of this paper are the means of these nine weighings. The birds were weighed again in September 1911. Most of them showed little change in weight, although a few had gained and a few lost as much as 200 to 300 grams. The birds that completed the second year were weighed again at autopsy.

The original plan was to discontinue the investigation with the cessation of laying at the first fall moult, i. e., in the antumn of 1911. By that time sufficient data had accumulated for a study of the individuality of the eggs of each bird and for a study of interrelations of the quantitative characteristies of the egg. The egg data used in Parts $\mathrm{I}$ and $\mathrm{II}_{3}$ which deal with these subjects, are those collected from all the eggs laid up to the end of the first laying year. It was, however, apparent that a continuation of the investigation through the second laying year would be of interest in the study of the factors influencing the variation in the eggs of the same bird. Part III, which is an analysis of the variation of the eggs of the same bird, is based on data collected from all eggs laid during the first two laying years. At the end of the second laying year all the birds then alive were killed and data were taken on the visceral organs. 
Part I.

\section{The Individuality of the Eggs of each Bird in Regard to Shape, Size, and Size and Proportion of Parts.}

\section{The Fact of Individuality.}

It is not necessary to resort to mathematical calculations to demonstrate the fact that the eggs of different individual fowls vary considerably in respect to size and shape and also color and markings. The inter-individual variation is easily seen by comparing the eggs of different birds. Plates VI, VII and VIII are photographs of representative eggs of five of the birds used in this investigation. As previously stated these birds are from the Maine Agricultural Experiment Station strain of Barred Plymonth Rocks. The purity of this strain has been amply proved by breeding experiments. For each of these birds there is shown a series of five to seven consecutive eggs laid between the middle of December and January 4th of the pullet year (1910-1911). That is, these eggs were produced at the same season by different individuals of a single strain under the same general environmental conditions. Beside this series of consecutive eggs there are shown for some of the birds eggs laid somewhat earlier or later. These eggs emphasize the permanence of the individuality. The difference in shape between the long narrow eggs of bird No. 139 (Plate VI) and the nearly spherical ones of bird No. 478 (Plate VIII), or between either of these and the small pointed eggs of No. 446 (Pl. VI), or the large pointed ones of No. 212 (Pl. VII), scarcely needs comment. The differences in size are similarly apparent. For example, the- eggs of No. 205 (Plate VI) and No. 446 (Plate VII) are decidedly smaller than those of No. 478 (Plate VIII) or No. 212 (Plate VII). The present investigation deals primarily with the quantitative or measurable characters of the egg, but that the individuality of the different birds manifests itself also in certain qualitative characters is illustrated by a comparison of the color and markings of the eggs of the different birds shown in Plates VI, VII and VIII.

This inter-individual variation which is seen by a comparison of the eggs themselves is shown equally clearly by a comparison of the measurements of the characters. This variation is not confined to the externally visible characters (dimensions, shape and size) but extends to the size and the proportion of the parts which make up the egg. 
A Biometrical Study of Egg Production in the Domestic Fowl. IV. 223

\section{The Measurement of Individuality.}

Since the eggs of any bird vary among themselves it is necessary to determine from a fairly large number of eggs the mean for each character. The method of the determination for each bird of a characteristic or mean egg was influenced by a fact more fully discussed in Part III. This fact is that there is a seasonal variation in the eggs of each individual bird. Since not all the birds were laying throughont the year it might be expected a priori that the means for the different birds based on all the eggs laid in the year would not be comparable. The only season of the year during which all the birds were laying was the spring or breeding season. No bird produced less than 34 eggs during the spring months, March, April and May. The mean for each character was determined for the eggs laid during these months. Table 1 gives for each bird the spring mean and the first year mean of each egg character measured. The spring means are printed in Roman type and the first year means in italics. The table is arranged in the order of the 1st year mean egg weights.

The yearly means were determined from frequency distributions but the spring means were obtained directly from the sums of the measurements. The probable errors of the spring means have not been determined. These probable errors would be of the same order of magnitude as those of the yearly means since the smaller number of spring eggs would connterbalance a somewhat smaller standard deviation.

The remarkable similarity between the two sets of means shows the high degree of permanence in the individaality of the birds, in regard to egg characters. Such differences as exist between the spring means and first year means for the same character in an individual, depend on complicated factors, of which an important one is the seasons during which the bird laid.

Since a comparison of the spring means and the first year means shows that the objection to considering the yearly means of the different individuals comparable is largely theoretical, and since the probable errors of the yearly means have been calculated, the first year means are used in the inter-individual comparisons.

From these means the following points are to be noted:

1) There is a large difference between the highest and lowest mean of each character. This range of means varies greatly in the 


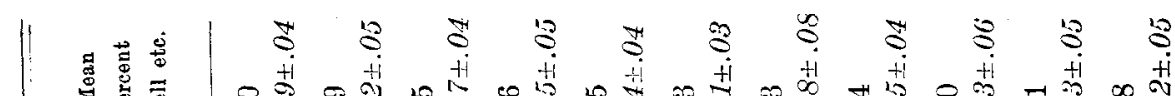

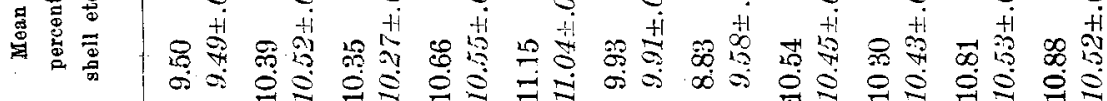

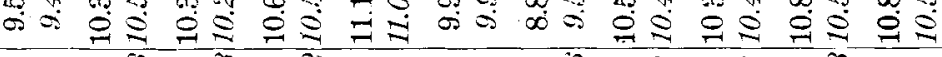

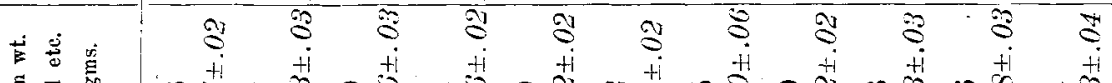

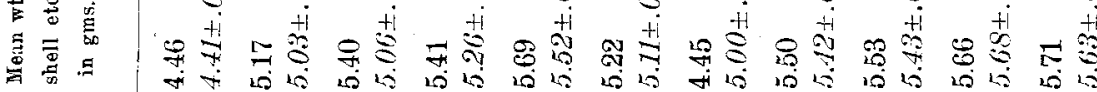
* से

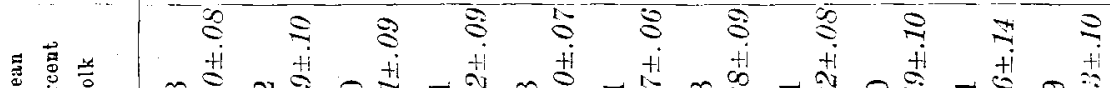
厸总

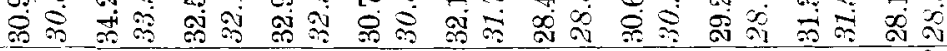

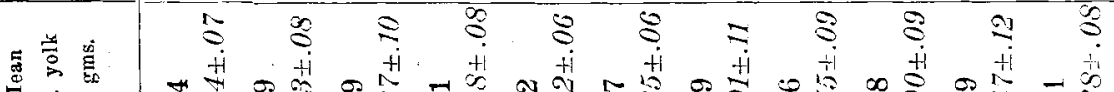

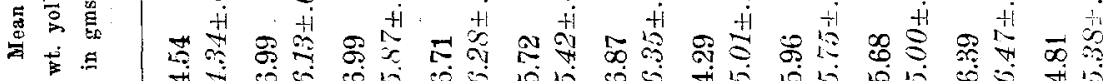

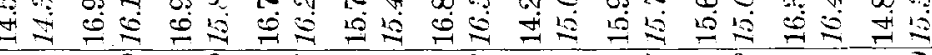

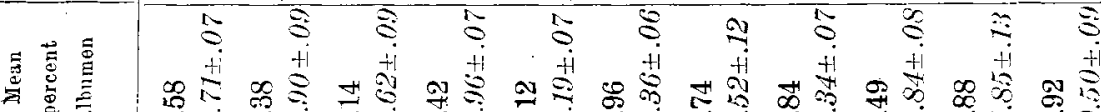

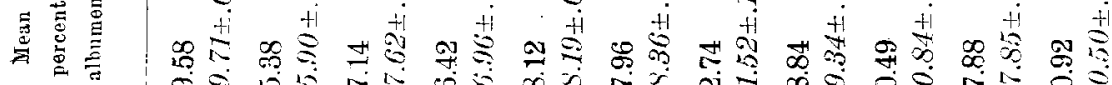

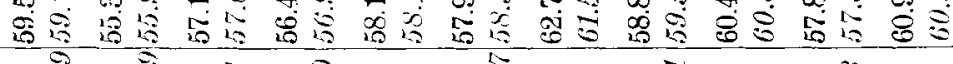

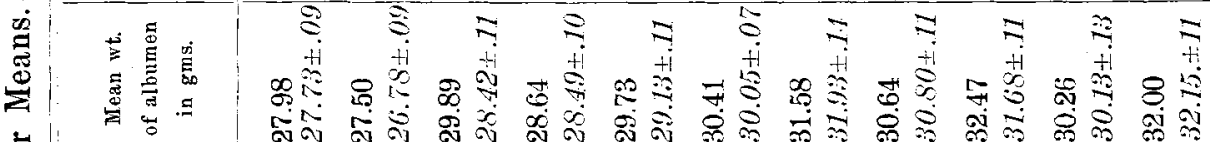
每1

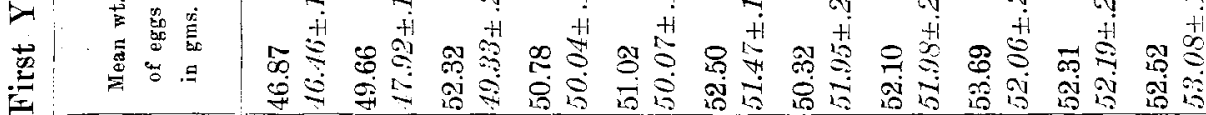
承 So| 造完| क

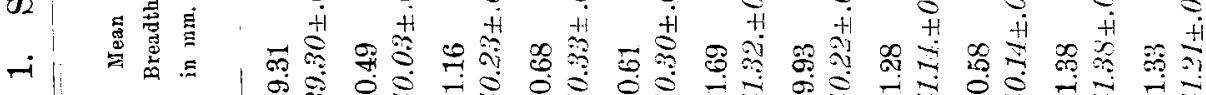

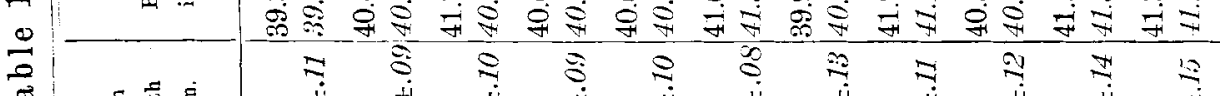
E

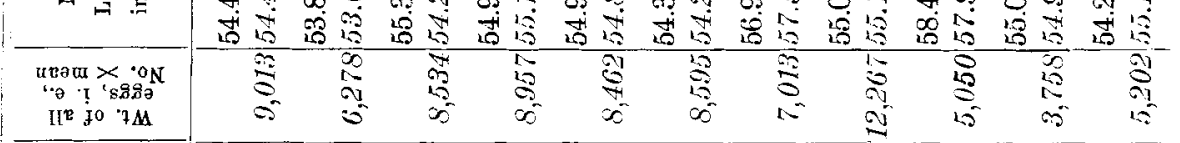

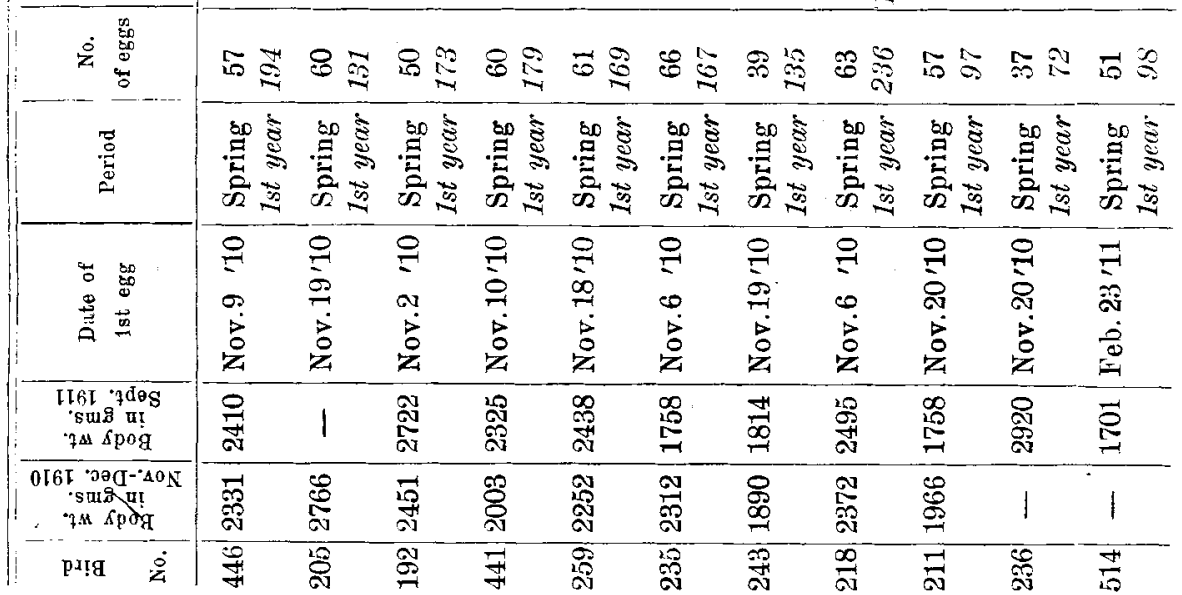




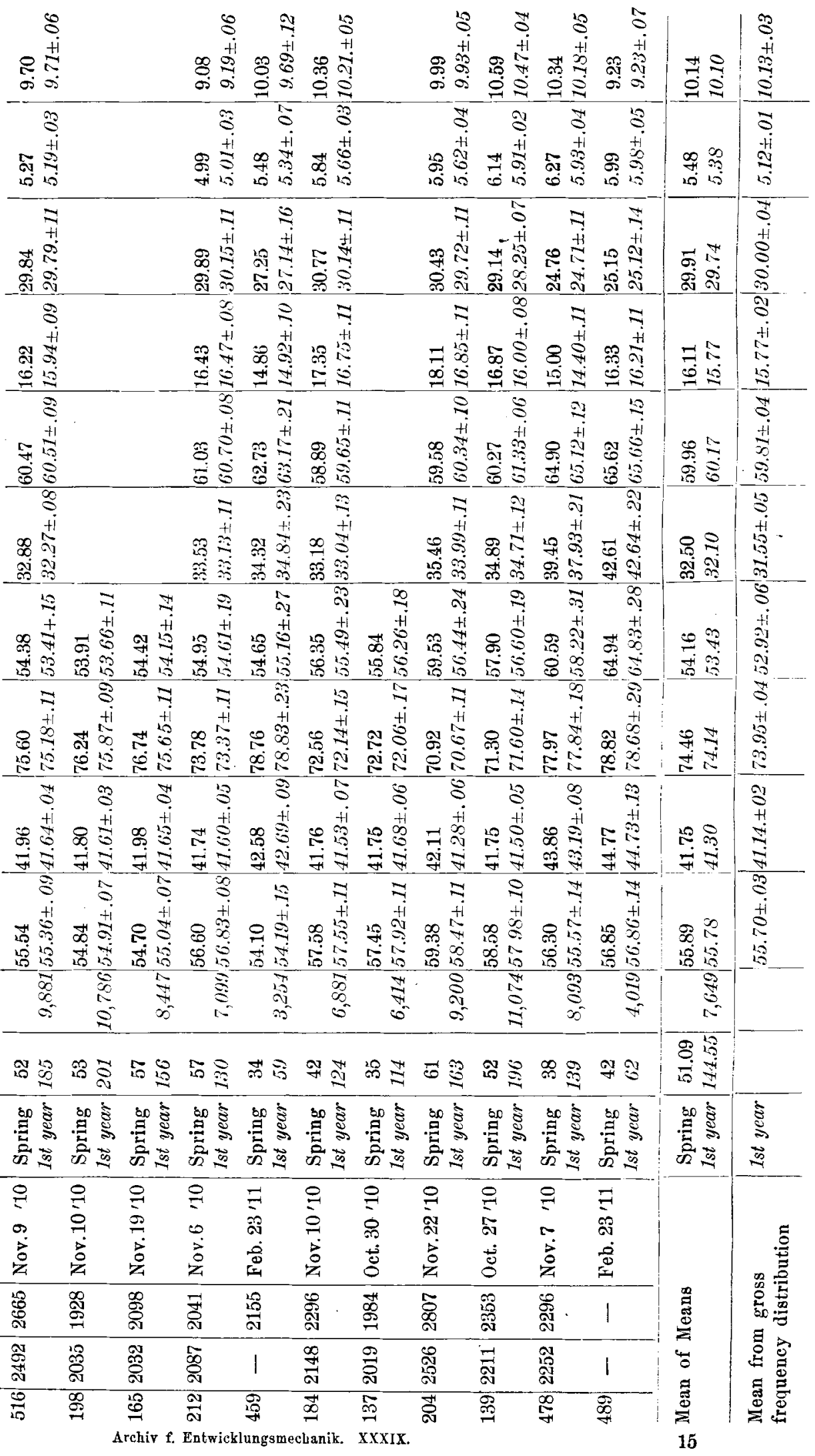




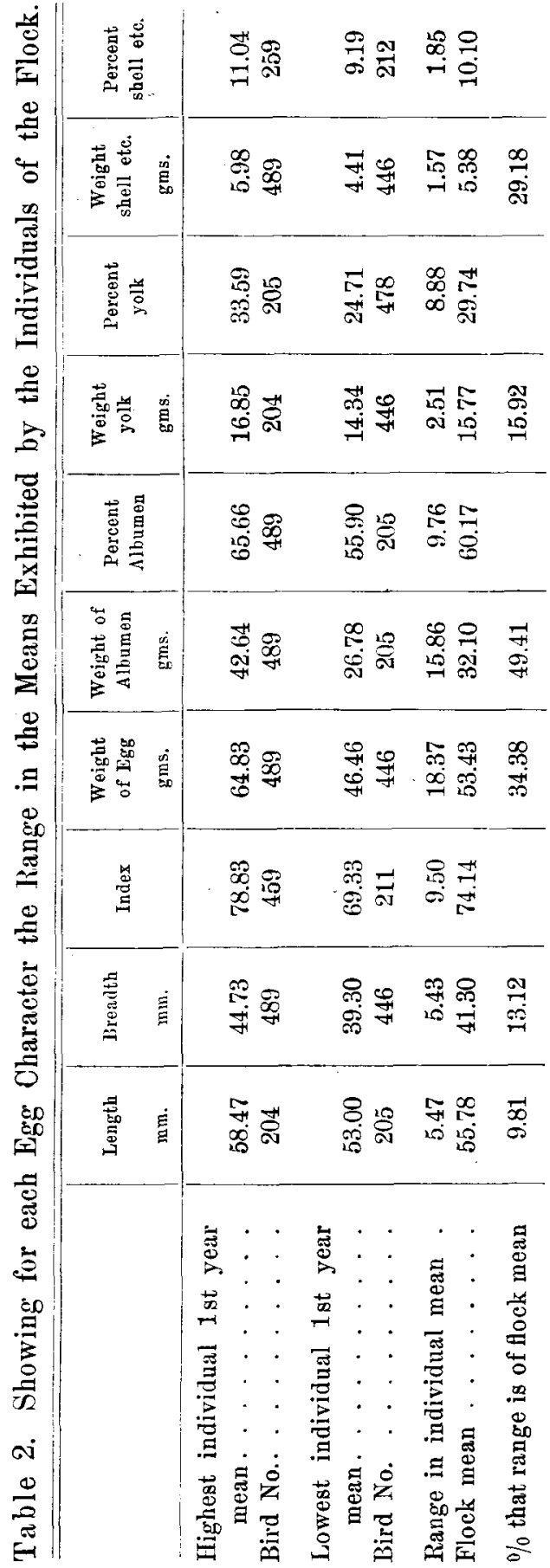

several characters. Table 2 shows for each character the highest and lowest mean; the range of the means; the flock mean and the percentage that the range in mean is of the flock mean.

According to these figures 1) the eggs of different individuals show less variation in either dimension than they do in weight. They are much more uniform in respect to the size of the yolk than they are in respect to the amount of albumen or shell present.

2) Table 1 also shows, as would be expected, that there is a general relationship between the characters. For example there appears to be a positive correlation between egg weight and all other characters except index, percentage or yolk and percentage of shell. A negative relationship between percentage of yolk and egg weight is apparent. From an inspection of the data

1) The same relative variation is shown if spring means are considered. The percentages that the range in the individual spring mean is of the flock spring mean are as follows: Length 9.95; Breadth 13.13; Egg weight 33.36; Weight of albumen 46.49 ; Weight of yolk 18.99; Weight of shell 33.21. 
A Biometrical Study of Egg Production in the Domestic Fowl. IV. 227

given in the table the significance of a relationship between the egg weight and index and between egg weight and percentage of shell is doubtfal.

3) In spite of this general and expected relationship between the characters, there is a strong tendency to an independent variation of the different characters. This may be illustrated by comparing the first year means for bird No. 236 and bird No. 218. The differences between the means of the several characters of the eggs of these two birds are as follows:

$\begin{array}{lr}\text { Length } & -.18 \pm .18 \\ \text { Breadth } & .24 \pm .08 \\ \text { Index } & .56 \pm .20 \\ \text { Weight } & .21 \pm .31 \\ \text { Weight of albumen } & -.67 \pm .17 \\ \text { Weight of yolk } & .72 \pm .15 \\ \text { Weight of shell } & .26 \pm .04 \\ \% \text { albumen } & -1.49 \pm .15 \\ \% \text { of yolk } & 1.34 \pm .16 \\ \% \text { of shell } & .08 \pm .06\end{array}$

The difference in weight is less than its probable error. The differences in breadth and index are however significant. The differences in the size of the parts are all from four to six times their probable error. The differences in percentage of albumen and percentage of yolk are in each case about nine times the probable error. We have here a compensatory difference in the weight and in the proportion of the several parts. The differences in the weight and also in the percentage of both yolk and shell are positive, while the differences in weight and percentage of albumen are negative. The eggs of these two birds then are practically equal in size but differ somewhat in shape. The slightly smaller egg of No. 218 has a disproportionately small yolk and large amount of albumen. This gives it a higher percentage of albumen and a lower percentage of yolk. In a preceding paragraph it was noted that in general the smaller the egg the higher the percentage of yolk. Many other illustrations might be eited from the table but the point is well brought out by considering the table as a whole. It is arranged in ascending order of the mean total egg weight. No other column is in such order. Due to the general relationship between the characters most of the columns show a tendency either to increase or decrase in value as 
one reads down the column but every column shows some values decidedly out of consecutive order. To rearrange the table for the mean of any other character would make radical changes in the position of the several birds and these changes would be different each time a different character was selected by which to rearrange the table.

\section{Individuality in Respect to Variability.}

The individuality of the birds in respect to each egg character may also be seen by a comparison of the maxima and minima of the character. Tables 3, 4, 6, 7, 8, and 9 give, each for one character, for each bird the maximum and minimum eggs with their dates of laying; the difference between these or the range of the character; the mean of the character; the percentage that the range is of the mean; the standard deviation; the coefficient of variation; and the percentage that the standard deviation of the individual is of the standard deviation of the flock. Tables $5,10,11$, and 12 give the same data except, the percentage that the range is of the mean and the coefficient of variation. The characters given in these tables are index, percentage of albumen, percentage of yolk and percentage of shell. The omitted data would not be significant in the case of these percentage characters.

The tables are based on the egg data for the entire first year and each table is arranged in the order of the value of the mean of the character on which it gives data.

By presenting the maxima and minima these tables furnish additional evidence that there is a great, and to a certain extent independent, variation in each egg character between the eggs of the different individuals. The data in these tables also sbow that the degree of variation exhibited by the eggs of the same bird is a definite and distinct characteristic of the individual. Some birds lay eggs that are quite uniform in respect to a given character, while other birds lay eggs which are decidedly more variable. The degree of intra-individual variation in the eggs is shown to a certain extent by the difference between the maximum and minimum, or the range, of a character. A rough comparison between the amount of variation in the several characters is possible by a comparison of the percentage that the range is of the mean. Since the frequency of large and small values of any character is small and since the distribution of the measurements for any character is 
A Biometrical Study of Egg Prodnction in the Domestic Fowl. IV. 229

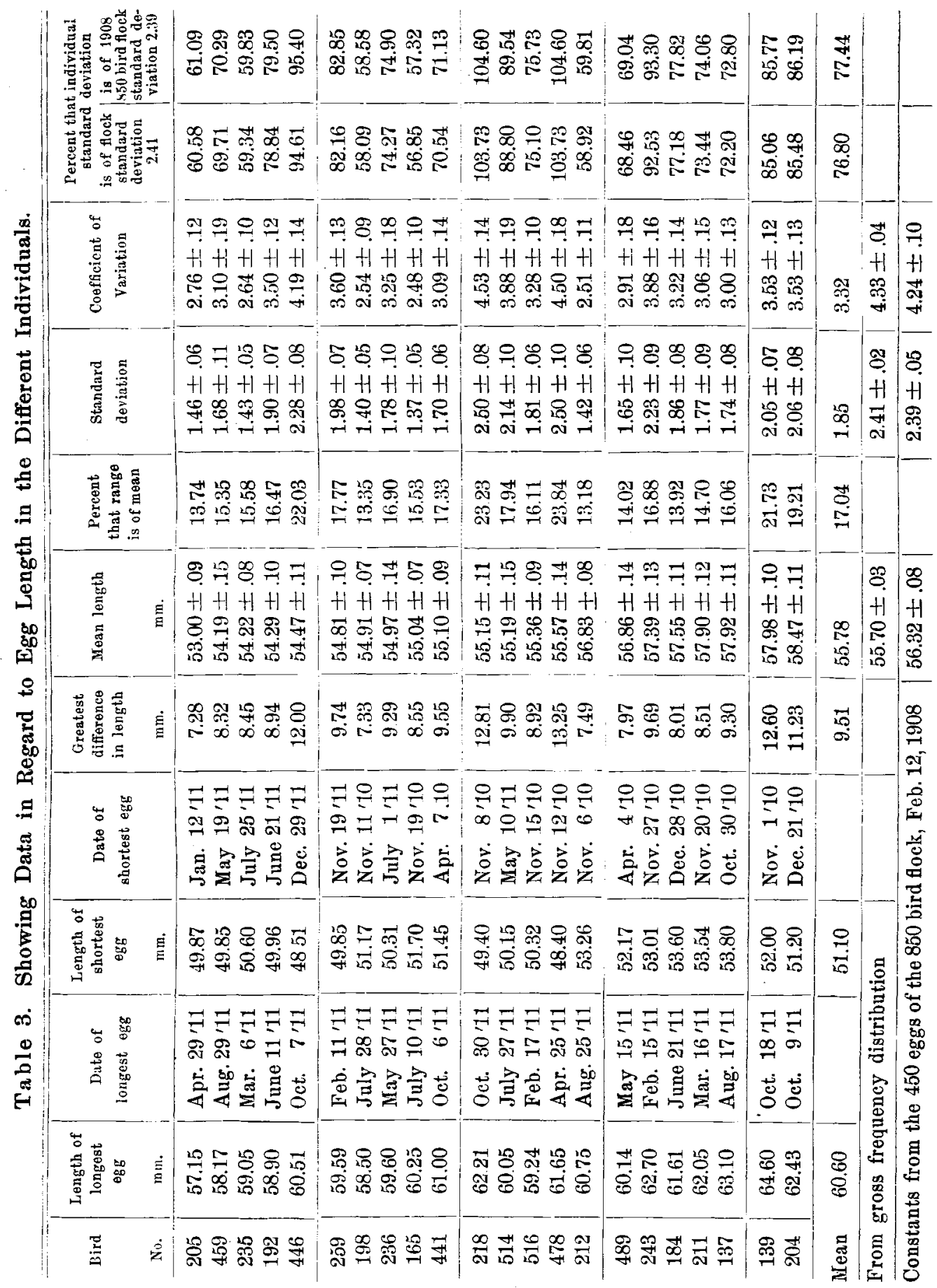


Maynie R. Curtis.

\begin{tabular}{|c|c|c|c|c|c|c|c|c|c|c|}
\hline & 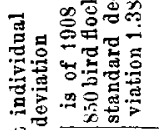 & 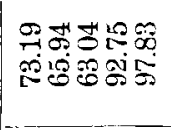 & 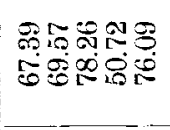 & 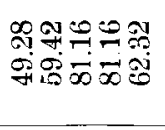 & 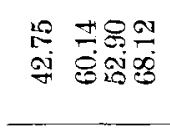 & $\underset{i}{0}$ & 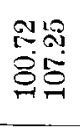 & $\stackrel{\text { F }}{\stackrel{5}{i}}$ & & \\
\hline & 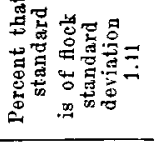 & 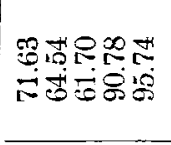 & 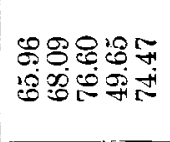 & 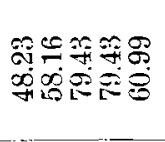 & 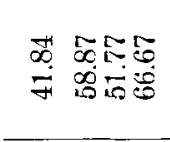 & $\begin{array}{l}8 \\
8 \\
8\end{array}$ & 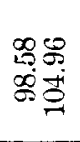 & $\begin{array}{l}0 \\
\infty \\
0 \\
B \\
0\end{array}$ & & \\
\hline$\ddot{Z}$ & 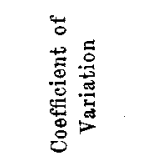 & 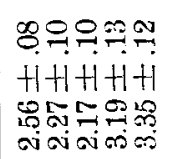 & 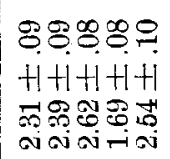 & 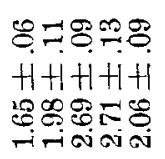 & 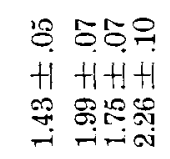 & $\begin{array}{l} \pm \\
+1 \\
+1 \\
\mathbb{N} \\
\text { oi }\end{array}$ & 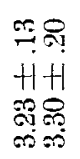 & 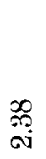 & $\begin{array}{l}8 \\
+1 \\
+1 \\
+4\end{array}$ & \begin{tabular}{l}
+1 \\
$\stackrel{g}{g}$ \\
\hdashline
\end{tabular} \\
\hline$\stackrel{D}{0}$ & 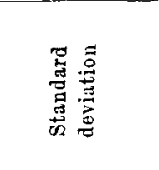 & 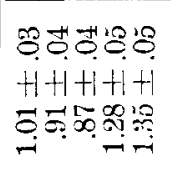 & 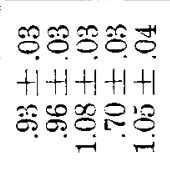 & 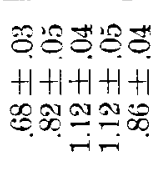 & 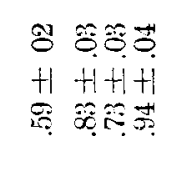 & $\begin{array}{l}\mathscr{8} \\
+1 \\
0 \\
0\end{array}$ & $\begin{array}{l}89 \\
81+1 \\
80 \\
80 \\
-7\end{array}$ & $\mathscr{8}$ & $\begin{array}{l}5 \\
0 \\
+1 \\
+1 \\
\rightarrow-1\end{array}$ & $\begin{array}{l}\infty \\
0 \\
+1 \\
\infty \\
\infty \\
\infty \\
-\infty\end{array}$ \\
\hline $\begin{array}{l}. \Xi \\
9\end{array}$ & 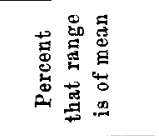 & 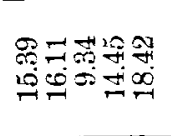 & 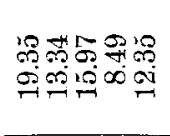 & 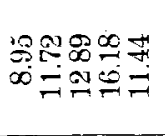 & 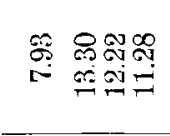 & $\underset{\infty}{\infty}$ & 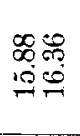 & $\stackrel{\Xi}{\stackrel{\Xi}{2}}$ & & \\
\hline 80 & 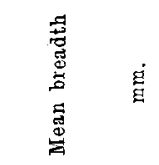 & 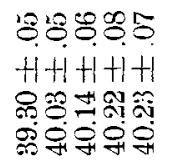 & 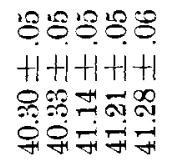 & 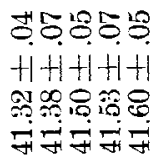 & 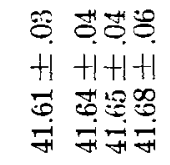 & $\begin{array}{l}8 \\
8 \\
+1 \\
8 \\
0 \\
\text { oj }\end{array}$ & 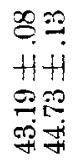 & 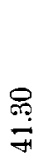 & $\begin{array}{l}8 \\
+ \\
+1 \\
+ \\
+\end{array}$ & 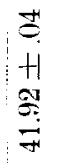 \\
\hline 茪 & 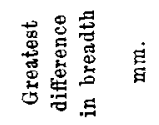 & 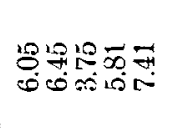 & 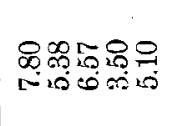 & 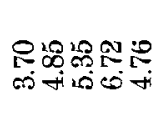 & 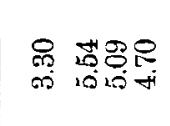 & $\stackrel{10}{\infty}$ & 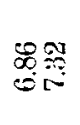 & $\underset{:}{\sharp}$ & & $\stackrel{\infty}{\stackrel{9}{9}}$ \\
\hline$\stackrel{\Xi}{\stackrel{5}{\leftrightarrows}}$ & 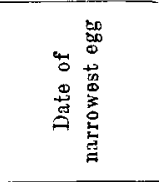 & 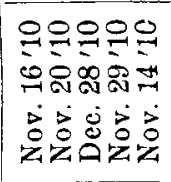 & 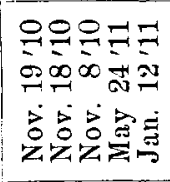 & 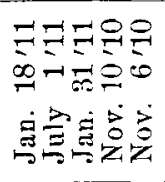 & 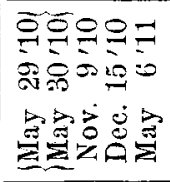 & $\begin{array}{l}E \\
\dot{E} \\
\dot{Z}\end{array}$ & 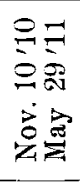 & & & 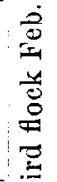 \\
\hline 胥 & 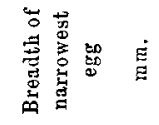 & 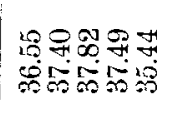 & 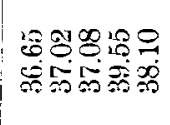 & 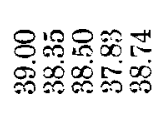 & 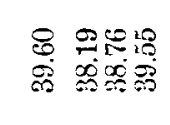 & $\stackrel{8}{8}$ & 我是 & $\begin{array}{l}5 \\
\infty \\
\infty \\
\infty\end{array}$ & z & $\begin{array}{l}10 \\
00 \\
0 \\
0 \\
=\end{array}$ \\
\hline$\stackrel{0}{2}$ & 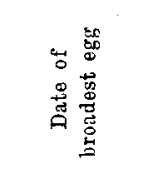 & 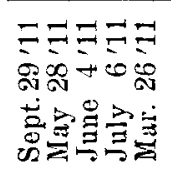 & 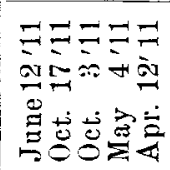 & 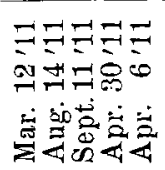 & 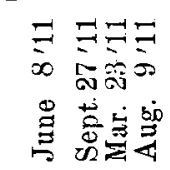 & 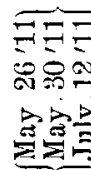 & 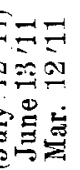 & & 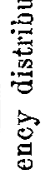 & $\begin{array}{l}0 \\
80 \\
80 \\
0 \\
0 \\
8 \\
8\end{array}$ \\
\hline & 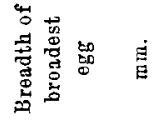 & 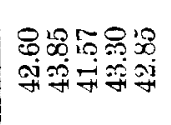 & 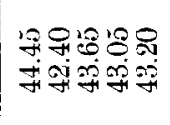 & 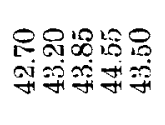 & 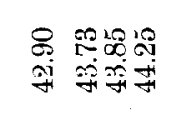 & 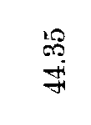 & 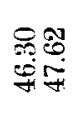 & 둠 & $\begin{array}{l}\vec{D} \\
\stackrel{D}{L} \\
0 \\
0 \\
0 \\
0\end{array}$ & $\begin{array}{l}\stackrel{9}{3} \\
\stackrel{3}{3} \\
\stackrel{3}{3}\end{array}$ \\
\hline & $\dot{2}$ & 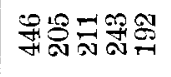 & 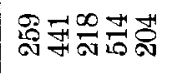 & 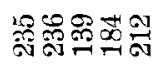 & $\underset{9}{0}$ & 要 & $\stackrel{\infty}{\stackrel{\infty}{\forall}}$ & 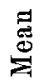 & $\underbrace{\Xi}_{0}$ & 蒡 \\
\hline
\end{tabular}


A Biometrical Study of Egg Produktion in the Domestic Fowl. IV. 231

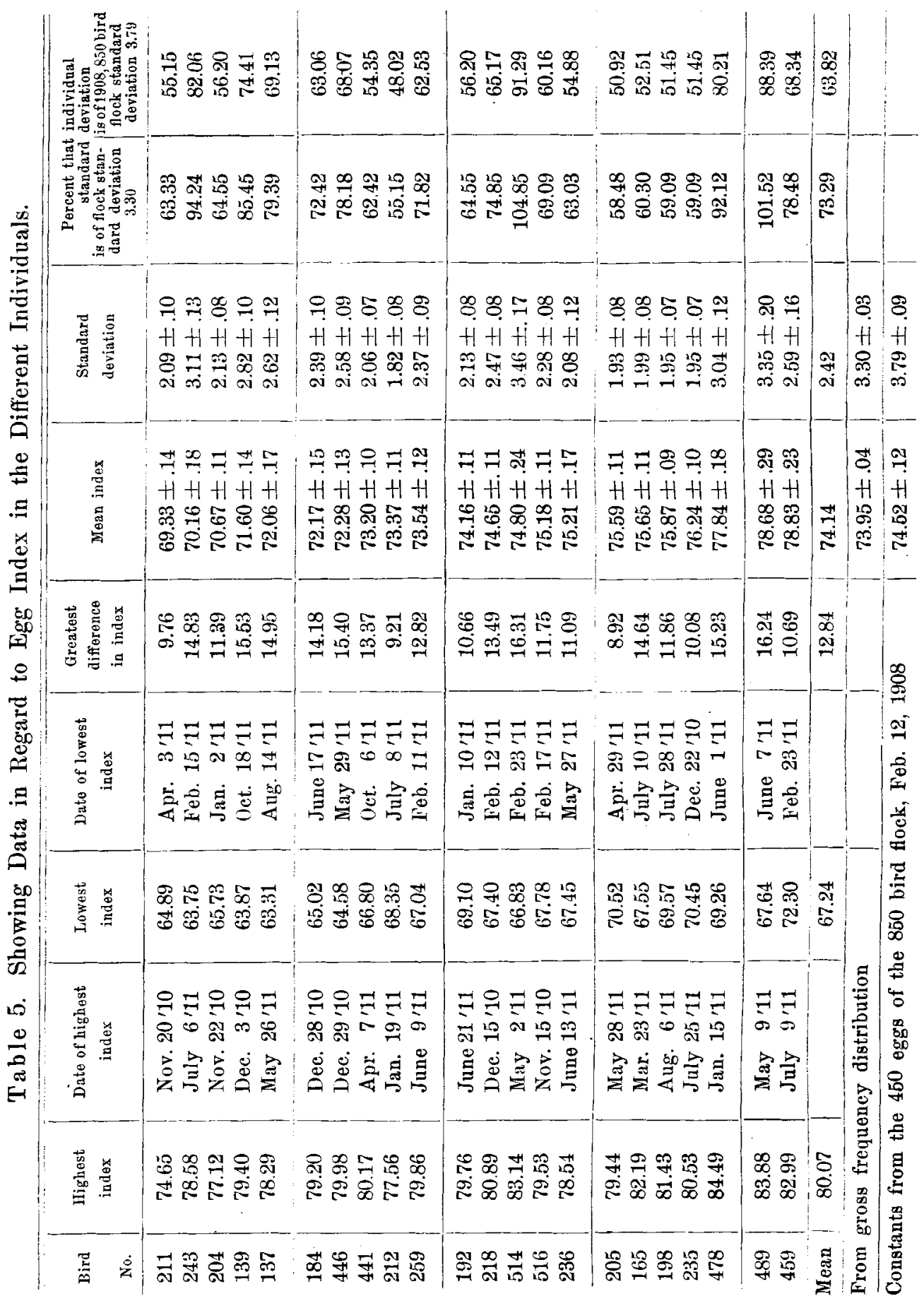




\begin{tabular}{|c|c|c|c|c|c|c|c|}
\hline 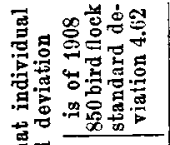 & 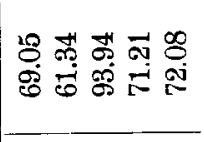 & 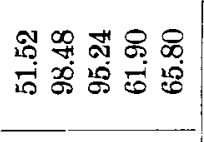 & 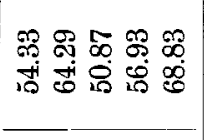 & 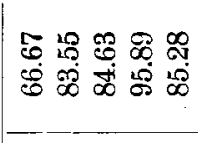 & 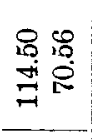 & 욤 & \\
\hline 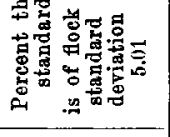 & 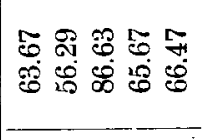 & 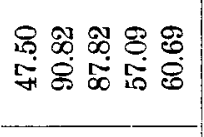 & 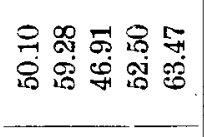 & 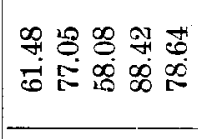 & 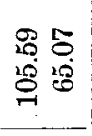 & 过 & \\
\hline 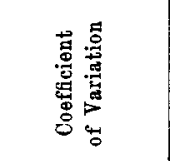 & 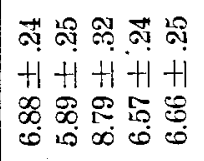 & 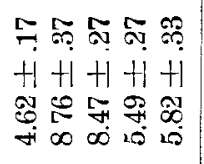 & 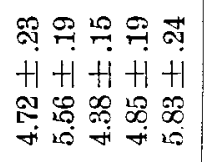 & 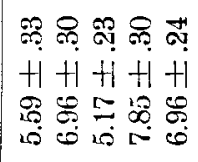 & 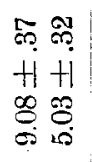 & 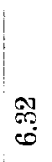 & $\begin{array}{l}\infty \\
0 \\
+1 \\
0 \\
0 \\
0\end{array}$ \\
\hline 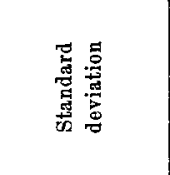 & 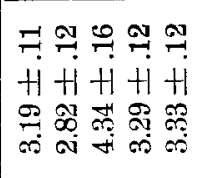 & 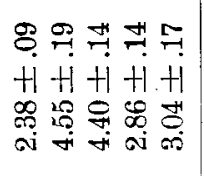 & 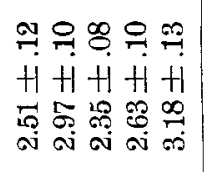 & 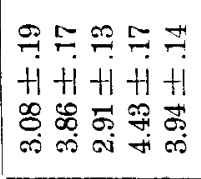 & 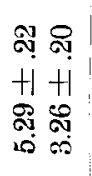 & $\underset{m}{\infty}$ & $\begin{array}{l}0 \\
0 \\
0 \\
0 \\
0\end{array}$ \\
\hline 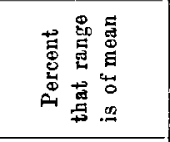 & 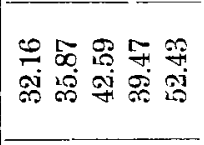 & 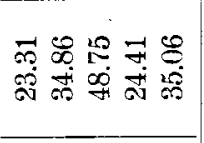 & 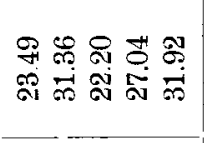 & 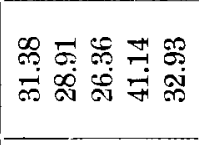 & 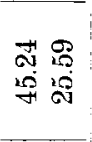 & $\stackrel{\infty}{\infty}$ & \\
\hline 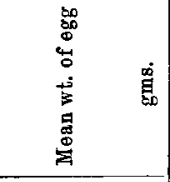 & 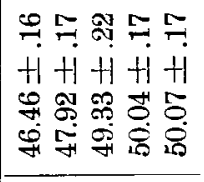 & 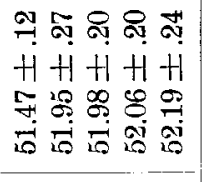 & 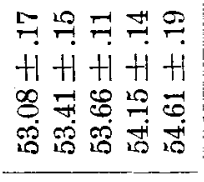 & 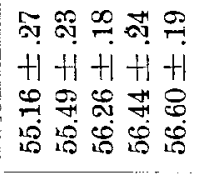 & 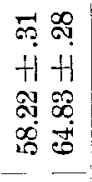 & 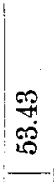 & 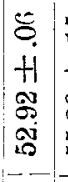 \\
\hline 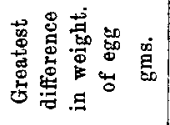 & 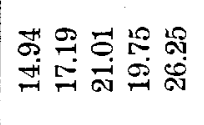 & 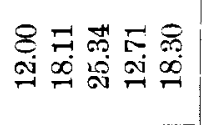 & 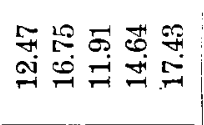 & 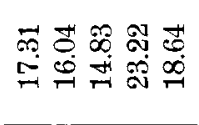 & 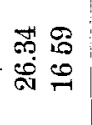 & 交 & \\
\hline 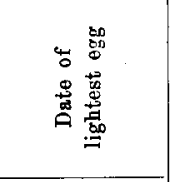 & 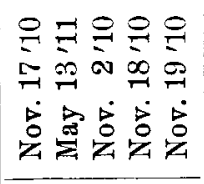 & 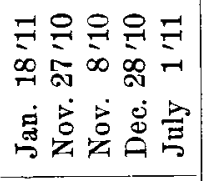 & 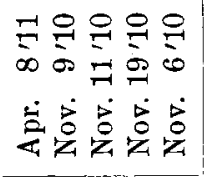 & 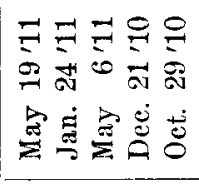 & 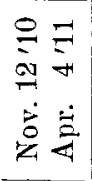 & & \\
\hline 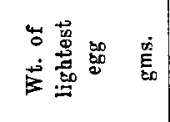 & 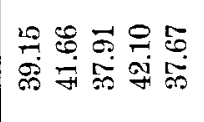 & 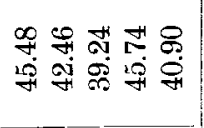 & 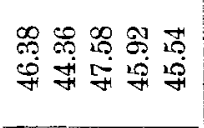 & 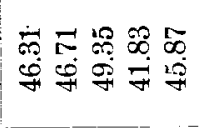 & 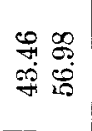 & $\stackrel{\vec{y}}{+}$ & \multirow{4}{*}{ 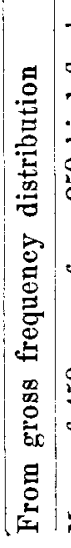 } \\
\hline 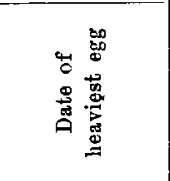 & 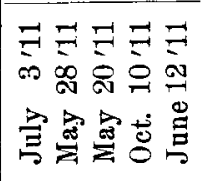 & 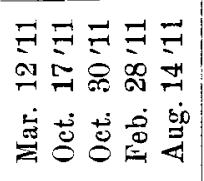 & 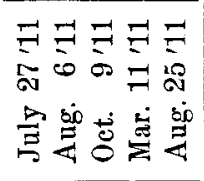 & 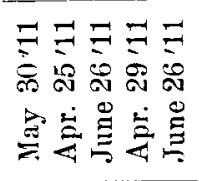 & 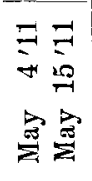 & & \\
\hline 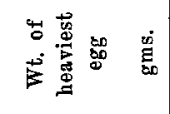 & 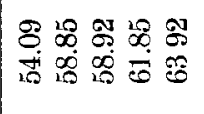 & 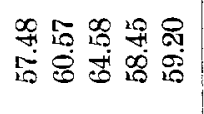 & 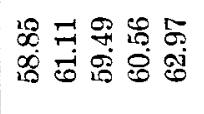 & 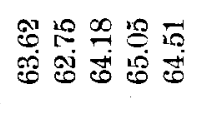 & $\begin{array}{l}\infty \\
\infty \\
\infty \\
0\end{array}$ & ô & \\
\hline$\dot{\check{z}}$ & 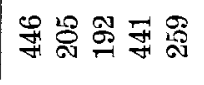 & 角学 & 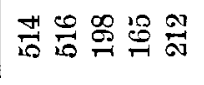 & 号架芯芯突 & 荣永 & 駌 & \\
\hline
\end{tabular}


A Biometrical Study of Egg Production in the Domestic Fowl. IV. 233

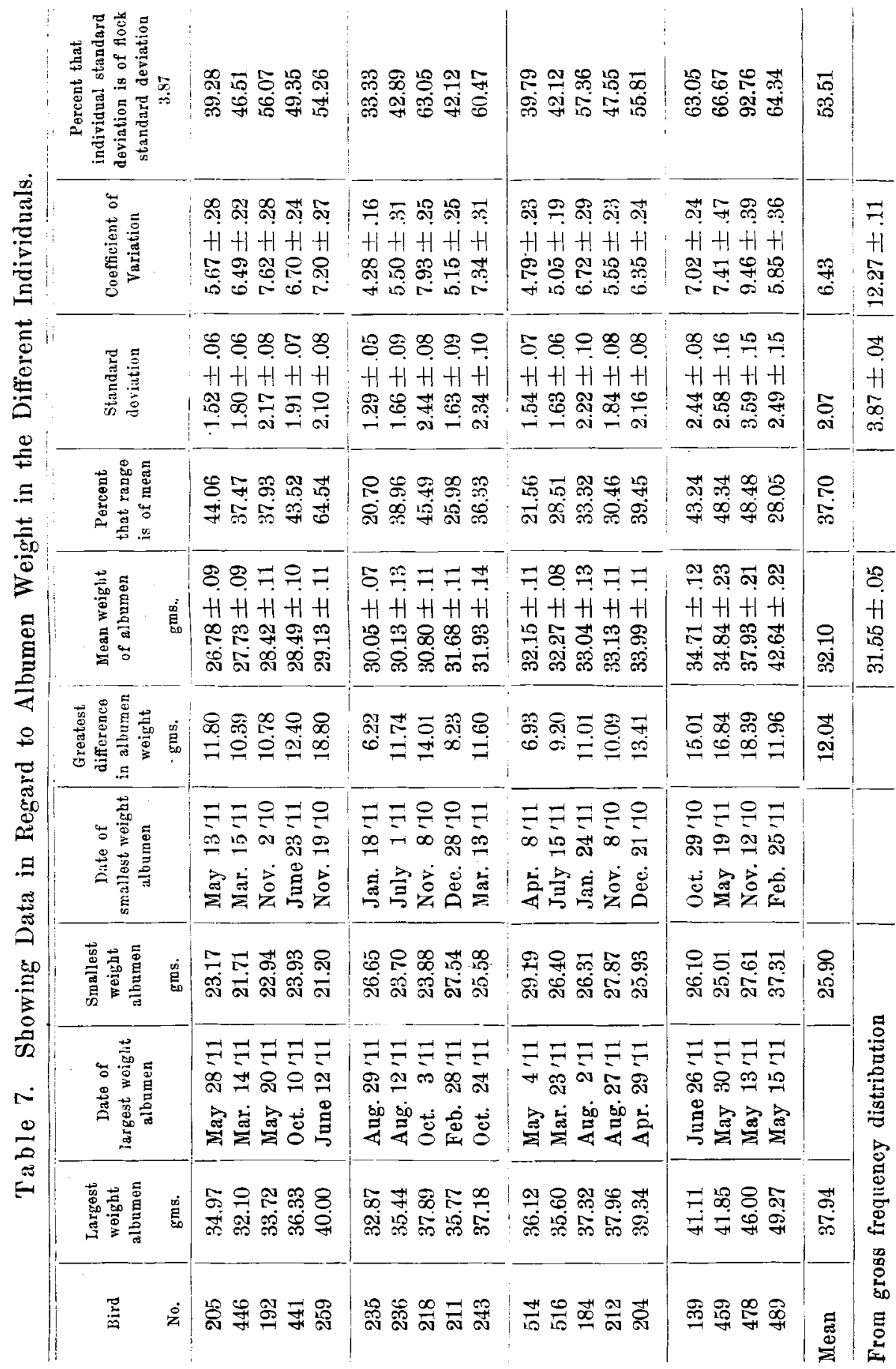




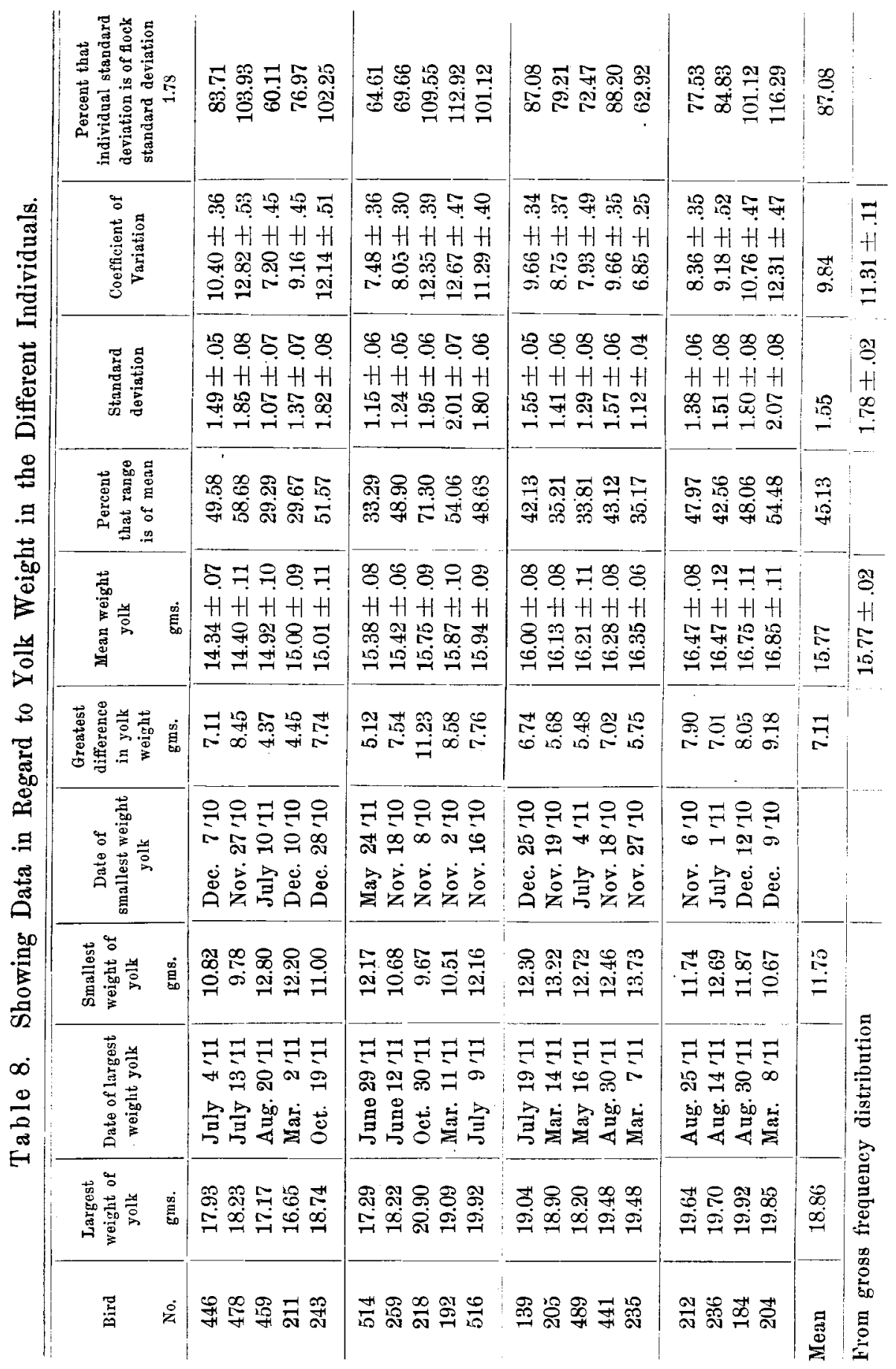


A Biometrical Study of Egg Production in the Domestic Fowl. IV. 235

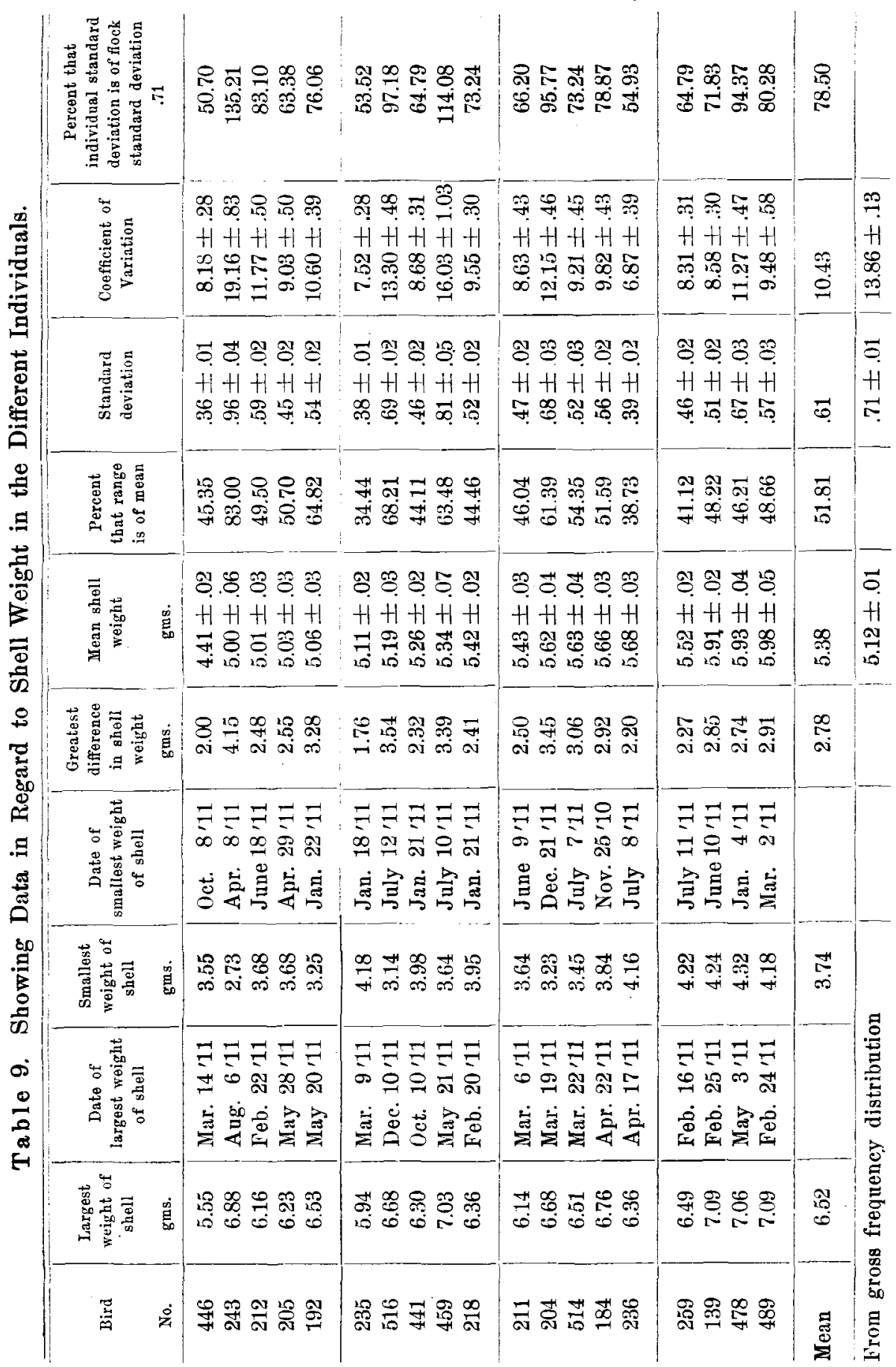




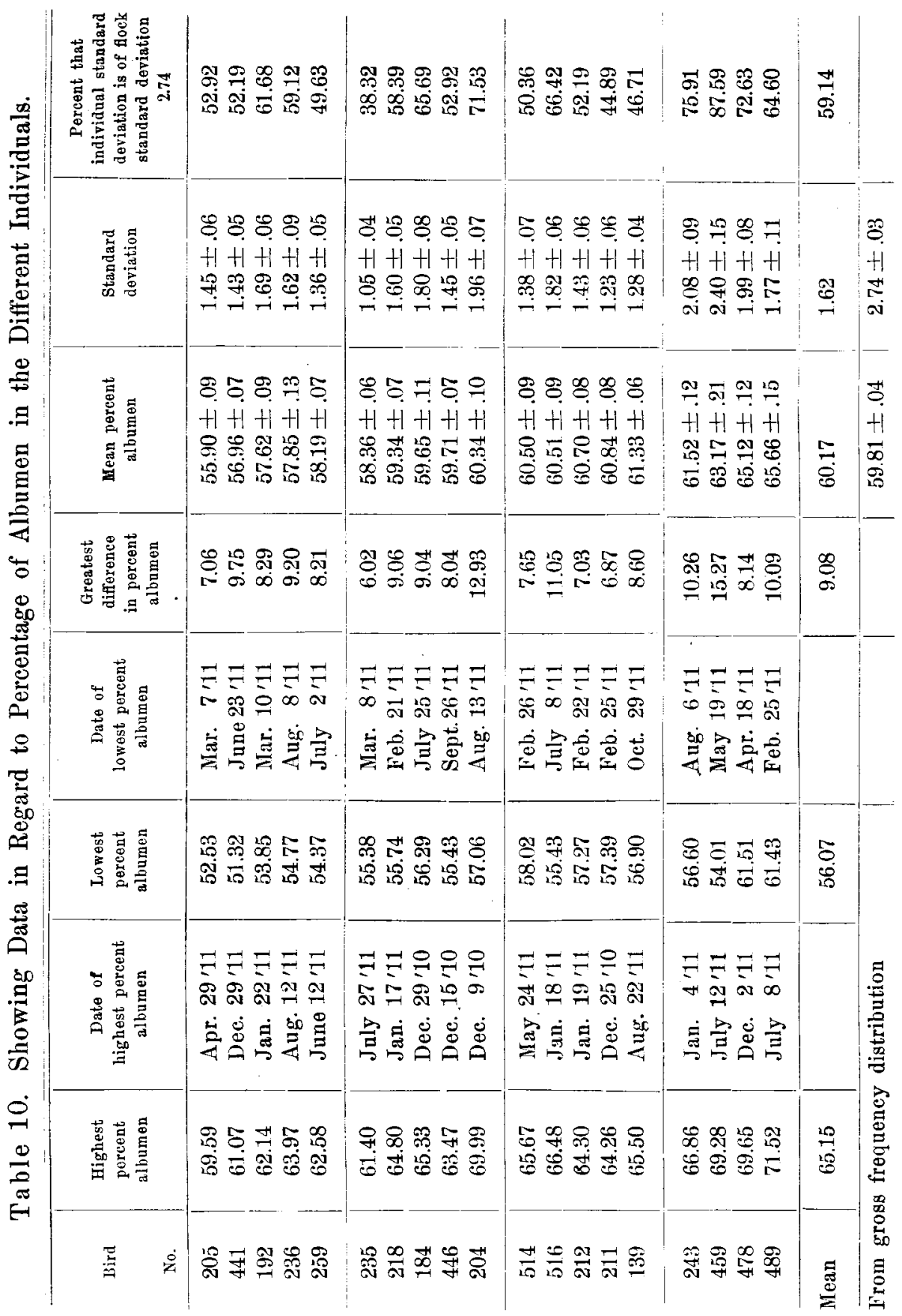


A Biometrical Study of Egg Production in the Domestic Fowl. IV. 237

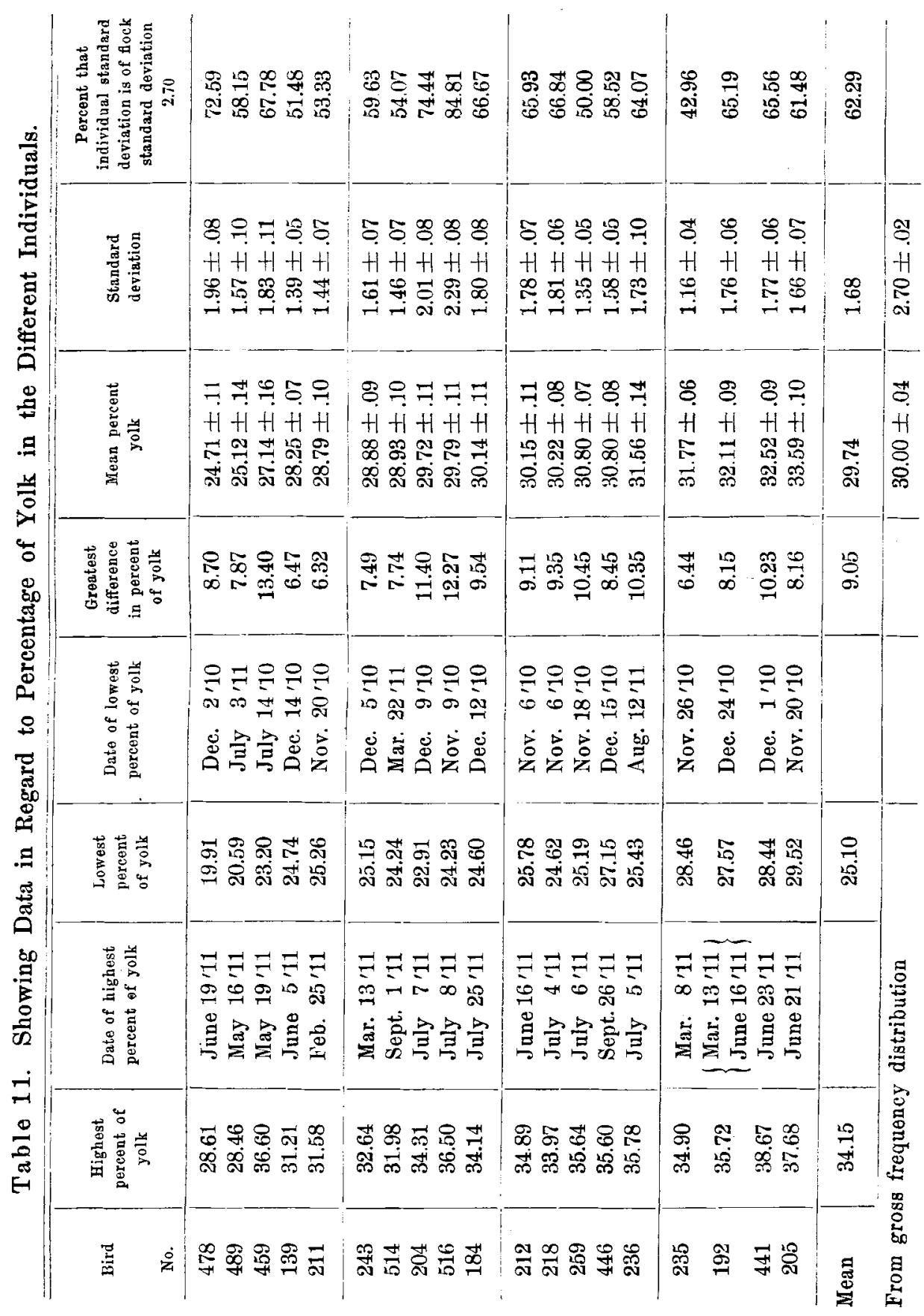




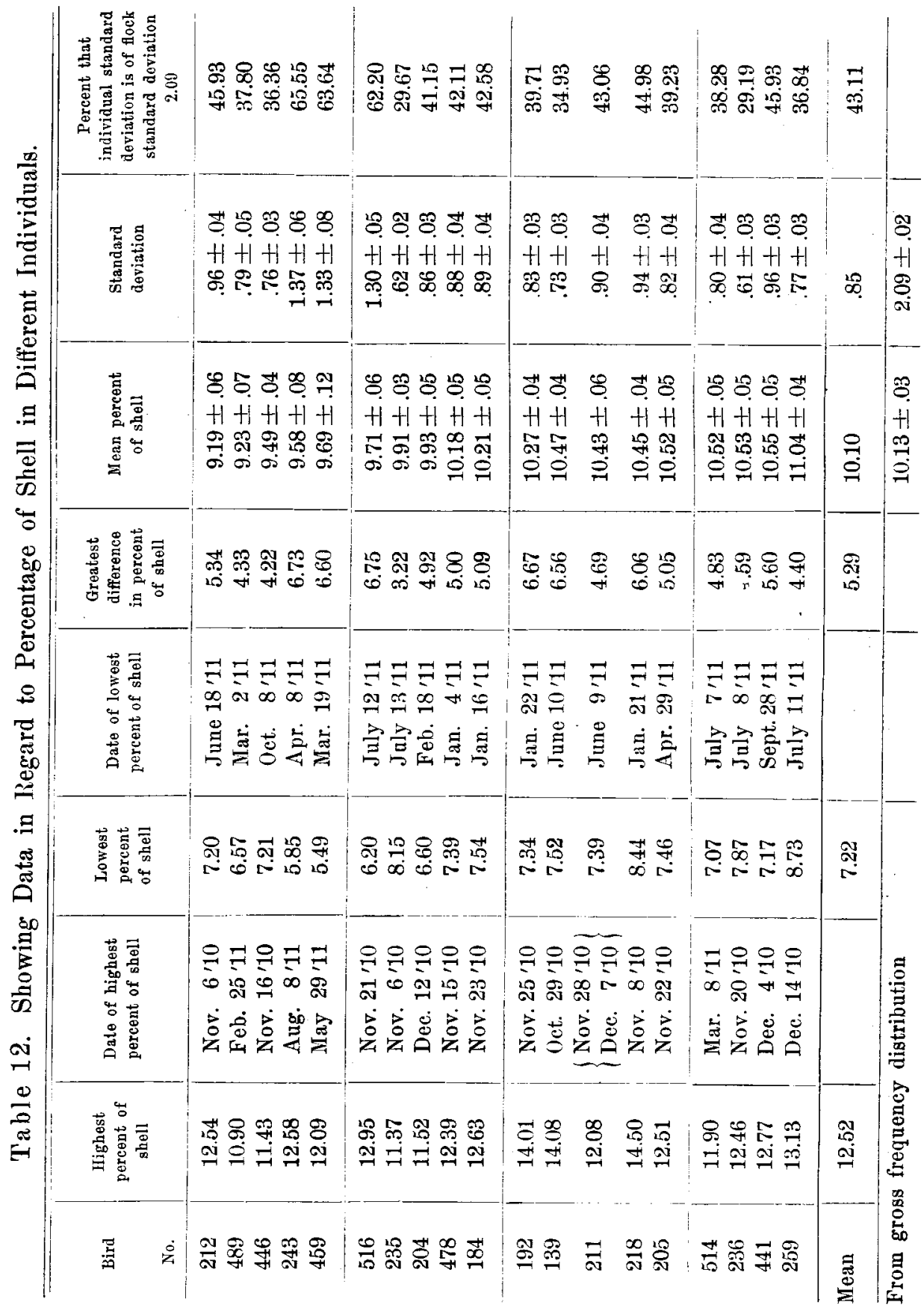


A Biometrical Study of Egg Production in the Domestic Fowl. IV. 239

not always similar in the different individuals, these quantities are subject to all the theoretical objections to considering the range a measure of variation 1 ), and no stress is to be laid upon the values tabled. From a physiological point of view, however, it is interesting to note the limits and the range of the separate characters in the individual birds, and to compare between the different characters the relation to the mean of the extent of actually occurring variation among the eggs of an individual bird. For this reason these data are given in the tables. The standard deviations and coefficients of variation which take account of the distribution of the separate measurements over the range are more accurate measures of the variation. The standard deviations for the same character are comparable between the birds, while the coefficients of variation or percentage that each standard deviation is of its own mean, are comparable also between the characters.

An examination of the standard deviations or of the coefficients of variation in any of the Tables 3 to 12 shows that for the given character there is considerable difference in the amount of variation exhibited by the eggs of different individual birds. The question arises whether the eggs of an individual tend to be variable or uniform in a similar degree in all the characters measured, or whether they exhibit radically different degrees of variation in the different characters. To determine this point the coefficients of variation are given in Table 13.

This table is arranged in ascending order of the coefficients of variation of egg weight. From this table it is readily seen that the eggs of the birds whose coefficients are given in the upper part of the table are much more uniform in all characters than those given at the bottom. For example the variation coefficients for bird No. 478 are much larger for every character than those for bird No. 235. The differences are as follows:

$\begin{array}{ll}\text { Length } & 1.86 \pm .21 \\ \text { Breadth } & 1.58 \pm .14 \\ \text { Egg weight } & 4.46 \pm .41 \\ \text { Albumen weight } & 5.18 \pm .42 \\ \text { Yolk weight } & 5.97 \pm .58 \\ \text { Shell weight } & 3.75 \pm .55\end{array}$

1) Yule, G. Udny, An Introduction to the Theory of Statistics. London, Chas. Griffin \& Co., 1912. p. 133. 


\begin{tabular}{|c|c|c|c|c|c|c|c|c|}
\hline 敂 & 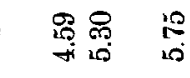 & 直题 & 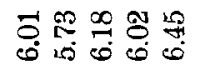 & 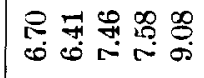 & 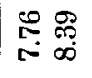 & : & & \\
\hline 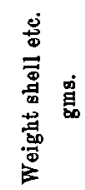 & 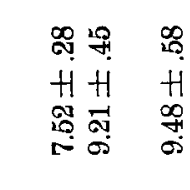 & 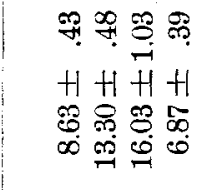 & 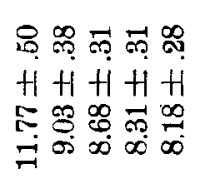 & 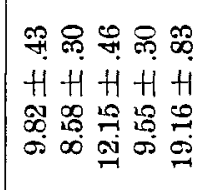 & 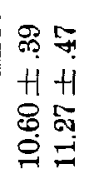 & $\stackrel{9}{\stackrel{9}{9}}$ & 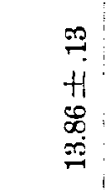 & \\
\hline 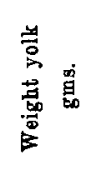 & 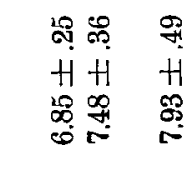 & 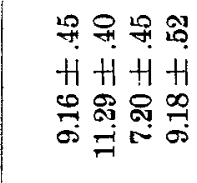 & 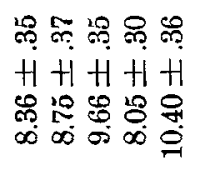 & 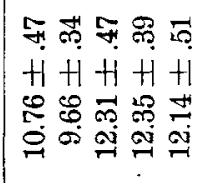 & 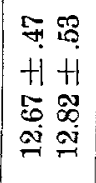 & $\mid$ & $\begin{array}{l}7 \\
+1 \\
+1 \\
\vec{m} \\
\vec{\sigma}\end{array}$ & \\
\hline 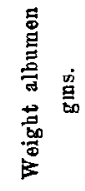 & 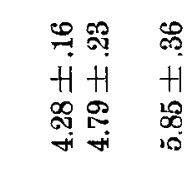 & 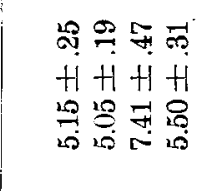 & 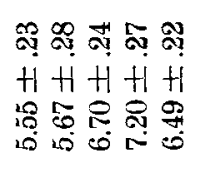 & 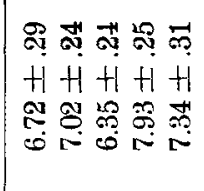 & 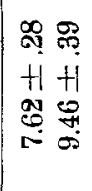 & 粱. & 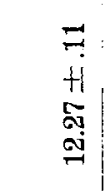 & \\
\hline 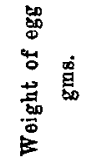 & 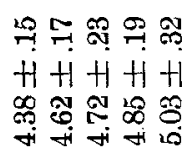 & 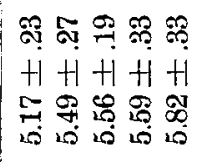 & 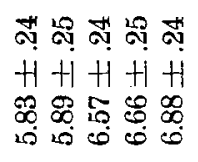 & 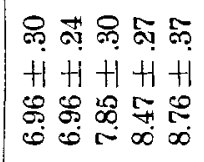 & 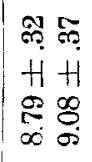 & 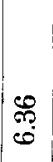 & $\begin{array}{l}o \\
0 \\
+1 \\
0 \\
1 \\
0\end{array}$ & $\begin{array}{l}\stackrel{P}{+} \\
\stackrel{H}{1} \\
\text { 足 } \\
\infty\end{array}$ \\
\hline 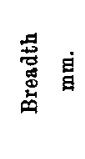 & 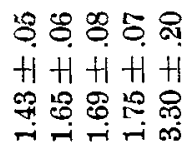 & 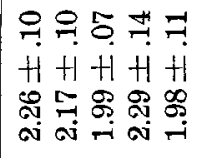 & 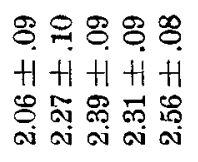 & 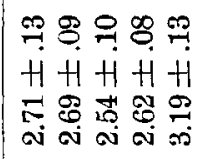 & 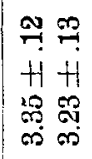 & $\begin{array}{l}\infty \\
\stackrel{\infty}{\infty} \\
\infty\end{array}$ & 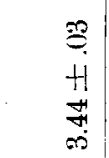 & 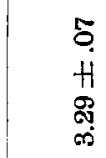 \\
\hline 密自 & 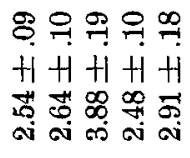 & 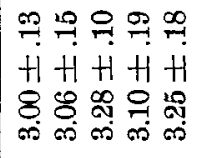 & 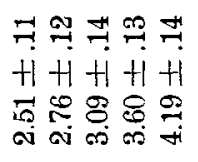 & 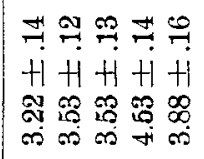 & 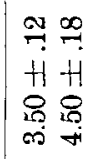 & i) & $\begin{array}{c}\overrightarrow{0} \\
+1 \\
\dot{0} \\
\ddot{m} \\
+i\end{array}$ & \begin{tabular}{l}
$\stackrel{9}{!}$ \\
+1 \\
$\vec{H}$ \\
\multirow{H}{*}{}
\end{tabular} \\
\hline 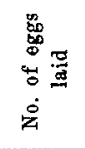 & 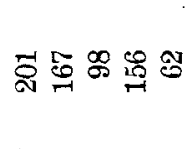 & 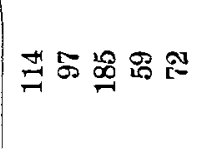 & 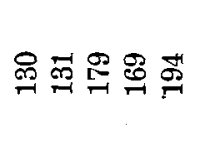 & 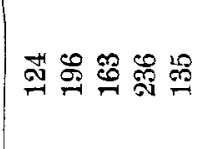 & 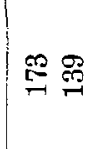 & & 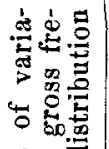 & 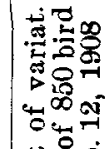 \\
\hline 吾离 & 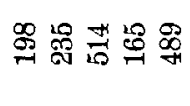 & 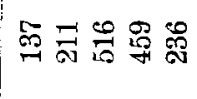 & 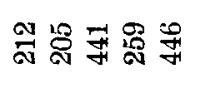 & 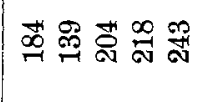 & 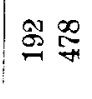 & & 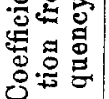 & 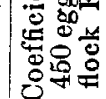 \\
\hline
\end{tabular}


A Biometrical Study of Egg Production in the Domestic Fowl. IV. 241

These differences in variability range from 5.8 (shell weight) to 12.3 (albumen weight) times their probable errors. That is the eggs of No. 478 are much more variable for every character than the eggs of No. 235.

Bird No. 139 and bird No. 184 each lays eggs which are moderately variable, but the eggs of the two birds are closely similar to each other in the degree of their variation. The following list shows the differences in the variation coefficients.

$\begin{array}{lr}\text { ILength } & .31 \pm .18 \\ \text { Breadth } & .02 \pm .16 \\ \text { Egg weight } & .00 \pm .38 \\ \text { Albumen weight } & .30 \pm .38 \\ \text { Yolk weight } & 1.10 \pm .58 \\ \text { Shell weight } & 1.24 \pm .52\end{array}$

The greatest difference for any character is that for shell weight and is only 2.3 times its probable error.

These cases show that the eggs of two birds may show strikingly similar degrees of variability in all their characters, or on the other hand they may show very different degrees of variability in all characters. A comparison of the differences of the variabilities of the eggs of No. 441 and No. 489 shows that the eggs of two birds may exhibit very similar degrees of variability in some characters and significantly different degrees of variability in others. These differences show also that the eggs of one of the birds may be more variable in certain characters and less so in others. The list of differences follows:

$\begin{array}{lr}\text { Length } & .18 \pm .23 \\ \text { Breadth } & -.91 \pm .22 \\ \text { Egg weight } & 1.54 \pm .40 \\ \text { Albumen weight } & .85 \pm .43 \\ \text { Yolk weight } & 1.73 \pm .60 \\ \text { Shell weight } & -.80 \pm .66\end{array}$

These differences show that the eggs of No. 441 are significantly more variable in egg weight, and possibly also in yolk weight, while they are significantly less variable in breadth.

Such comparisons as those above might be extended to all possible pairs of birds used in the investigation, but a general comparison of the variability in the different individuals is made in Table 14. 
The coefficients of variation for each character and the mean coefficients were arranged in order and the birds assigned the consecutive numbers from one to nineteen according to the values of the coefficients. The bird numbers are given in the ascending order of the value of the coefficients of egg weight. That is bird No. 235 has the smallest coefficient of variation for breadth, egg weight, weight of albumen, and weight of yolk, and the coefficients of variation for length and for shell weight are second in value for those characters.

Table 14. Relative Variability of the Birds in Regard to all Measured Characters.

\begin{tabular}{|c|c|c|c|c|c|c|c|c|}
\hline $\begin{array}{l}\text { Bird } \\
\text { No. }\end{array}$ & $\begin{array}{c}\text { No. } \\
\text { Eggs }\end{array}$ & Length & Breadth & $\begin{array}{l}\text { Weight } \\
\text { of Egg }\end{array}$ & $\begin{array}{c}\text { Weight } \\
\text { Albumen }\end{array}$ & $\begin{array}{l}\text { Weight } \\
\text { Yolk }\end{array}$ & $\begin{array}{l}\text { Weight } \\
\text { Shell etc. }\end{array}$ & $\begin{array}{c}\text { Mean } \\
\text { Variation }\end{array}$ \\
\hline 235 & 167 & 2 & 1 & 1 & 1 & 1 & 2 & 1 \\
\hline 514 & 98 & $16^{1 j}$ & 2 & 2 & 2 & 3 & 9 & 3 \\
\hline 489 & 62 & 4 & 18 & 3 & 8 & 4 & 10 & 6 \\
\hline 211 & 97 & 5 & 6 & 4 & 4 & 8 & 6 & 4 \\
\hline 516 & $18 \check{5}$ & 10 & 4 & 5 & 3 & 14 & 17 & 13 \\
\hline 459 & 59 & 7 & 8 & 6 & 16 & 2 & 18 & 14 \\
\hline 236 & 72 & 9 & 3 & 7 & 5 & 9 & 1 & 2 \\
\hline 212 & 130 & 1 & $\check{\delta}$ & 8 & 6 & 6 & 15 & 7 \\
\hline 205 & 131 & 3 & 7 & 9 & 7 & 7 & 8 & 5 \\
\hline 441 & 179 & 6 & 10 & 10 & 11 & 111 & 7 & 9 \\
\hline $2 \tilde{9} 9$ & 169 & 14 & 9 & 11 & 14 & $\delta$ & 4 & 8 \\
\hline 446 & 194 & 17 & 12 & 12 & 10 & 12 & 3 & 11 \\
\hline 184 & 124 & 8 & $1 \check{0}$ & 131) & 12 & 13 & 12 & 12 \\
\hline 139 & 196 & 121) & 14 & 14. 1) & 13 & $10^{1}{ }_{j}$ & 5 & 10 \\
\hline 204 & 163 & $131)$ & 11 & 15 & 9 & 16 & 16 & 15 \\
\hline 218 & 236 & 19 & 13 & 16 & 18 & 17 & 11 & 16 \\
\hline 243 & 135 & $151)$ & 16 & 17 & 15 & 15 & 19 & 19 \\
\hline 192 & 173 & 11 & 19 & 18 & 17 & 18 & 13 & 17 \\
\hline 478 & 139 & 18 & 17 & 19 & 19 & 19 & 14 & 18 \\
\hline
\end{tabular}

This table shows that while the eggs of an individual tend to be uniform or variable in all the characters, the eggs of some individuals may be in general uniform but may vary considerably in one or two characters 2). For example the eggs of bird No. 514 are very much more variable in length than in the other characters, while the eggs of bird No. 489 are more variable in breadth and shell

1) Variation coefficients equal.

2) This point may also be verified for these birds from the percentage that the individual variation is of the race variation shown in Table 15. 
A Biometrical Study of Egg Production in the Domestic Fowl. IV. 243

weight. On the other hand, the eggs of a bird may be variable in most characters and yet show a decided tendency toward uniformity in one or two characters. For example, the eggs of bird No. 204 are much more uniform in albumen weight than in the other characters.

Since there is a seasonal variation among the eggs of a bird it might be expected that the birds which are not laying steadily throughout the year would show less variation than those which are. In other words, is there a positive correlation between the number of eggs produced during the year and the amount of variation which they exbibit? A comparison of the coefficients of variation in Table 13, or of the relative variabilities in Table 14, shows that when birds lay less than $100 \mathrm{eggs}$ the eggs tend to be comparatively uniform, especially in respect to egg weight and yolk weight. In four of the five cases this was probably due to the fact that the birds did not lay during the early winter when the flock was laying small eggs with small yolks. The other case (bird No. 211) may be due to the fact that this bird did not lay after June 9 . That is she did not lay through the summer and early fall when the eggs of the flock were fluctuating in egg weight and in yolk weight.

In general the eggs of these five birds were remarkably uniform, but some of them showed a decided tendency to vary in one particular [No. 514 (length), No. 489 (breadth), No. 459 (albumen weight), No. 489 and No. 459 (shell weight)].

Where an individual laid 130 or more eggs, that is when the laying continued practically throughout the year, there is no relation between the number of eggs produced and the relative variation of the eggs.

\section{The Relation of Intra-individual to Intra-racial Variation.}

It has been shown that in all the characters measured the eharacteristic or mean egg of an individual differs from the characteristic eggs of other individuals. Also the eggs of some individuals show much more variation among themselves than the eggs of some other individuals. The question now arises: Are the eggs of an individual in general more like each other (i. e., more uniform) than are a random sample of the eggs of a number of individuals of the same strain, sufficiently large to be representative of the race or strain as a whole? 
The eggs of an individual form a series of $\gg$ undifferentiated * like parts (in the sense of Pearson) which show a high degree of variation. An individual furnishes enough such parts to make it possible to study the variation within that individual. The results of this study as tabulated in Tables 3 to 12 have just been discussed. In order to compare the variation in the individual with the variation in the strain or race it is necessary to measure the variation shown in a random sample of the eggs of the race. The whole flock of birds used in this study may be taken as a representative sample of the race of Barred Plymouth Rock fowls on the Station plant. On this basis the standard deviation and coefficient of variation for each character was calculated from gross frequeney distributions which included all the eggs laid by the twenty-two birds during the first year. These are given in Tables 3 to 13. Two objections may be raised to these constants as measures of variation in the strain. These are: 1) that although the number of eggs is large (3144) the number of birds is small (22), and 2) that different birds contribute different numbers of eggs, and therefore have unequal influence in determining the amount of variation shown in so small a flock.

Certain published data 1 ) collected in this laboratory however, make it possible to present for several egg characters variation constants not open to either of the above objections. These constants are based on $450 \mathrm{eggs}$ laid February 12, 1908, by an 850 bird flock of the same strain as the birds used in the present investigation. They are based on a large number of individuals, each individual furnishing only one egg. The characters used in the study referred to were length, breadth, index, and weight. Tables 3 to 6 and Table 13 shows also these general flock standard deviations and coefficients of variation.

A comparison of the results from the one day's egg production of a large flock, with the results obtained for the first year eggs of the small flock, shows that the difference between the racial or flock variation constants determined from the two sets of data is not significant in the case of length and breadth, but that there are significant differences in opposite directions in index and weight. The fact that the coefficient of variation in egg weight is larger for the year's

1) Pearl, R., and Surface, F. M., A Biometrical Study of Egg Production in the Domestic Fowl. III. Variation and Correlation in the Physical Characters of the Egg. (In press.) 
A Biometrical Study of Egg Production in the Domestic Fowl. IV. 245

eggs of the small flock is no doubt due to the seasonal variation in eggs in respect to this character.

The relation between the variation of each individual in respect to any egg character and the variation of the flock in respect to the same character is shown by the percentage that the individual standard deviation is of the flock standard deviation. These percentages give a method of testing (so far as egg characters are concerned) "the principle that the variation within the individual is less than that of the race", i. e., homotyposis, as defined by Pearson ${ }^{1}$ ).

The last columns of Tables 3 to 12 give for each character in each individual the percentage that the individual standard deviation is of the flock standard deviation. In Tables 3 to 6 the percentages are calculated both from the standard deviations of the small and the large flock. The two sets of percentages differ somewhat in absolute value, but the conclusions are the same whichever set of percentages is considered. Since the characters for which data are given in these tables are the only ones on which measurements were made in the large flock, the other Tables 7 to 12 give only one set of percentages. The percentages that the individual standard deviations are of the race standard deviations (as calculated from the data for the small flock) are brought together in Table 15 .

A consideration of the means given in this table shows:

1) That in different individuals the mean percentage which the individual variation is of the racial variation for all characters ranges from $47.49 \%$ in the case of bird No. 235 to $87.84 \%$ in No. 478 .

2) That the mean for different characters ranges from 43.11 percent in percentage of shell to 87.08 percent in yolk weight.

3) Thus whether we consider the matter from the standpoint of the mean variation of the several characters in a single individual, or from that of the mean for each character in the several individuals, the eggs of an individual show a smaller average percentage of the variation of the race than the leaves of the same tree, the pods on the same plant, or any of the other twenty-two cases of homotypic correlation investigated by Pearson ${ }^{2}$ ). The mean of the means for the separate characters is 67.13 percent. The mean for the 22 cases

1) Pearson, K., Homotyposis in the Vegetable Kingdom. Mathematical Contributions to the Theory of Evolution. IX. Philosophical Transactions of the Royal Society of London. Vol. 197 A. 1901. pp. 285-379.

2) Pearson, K., loc. cit. 


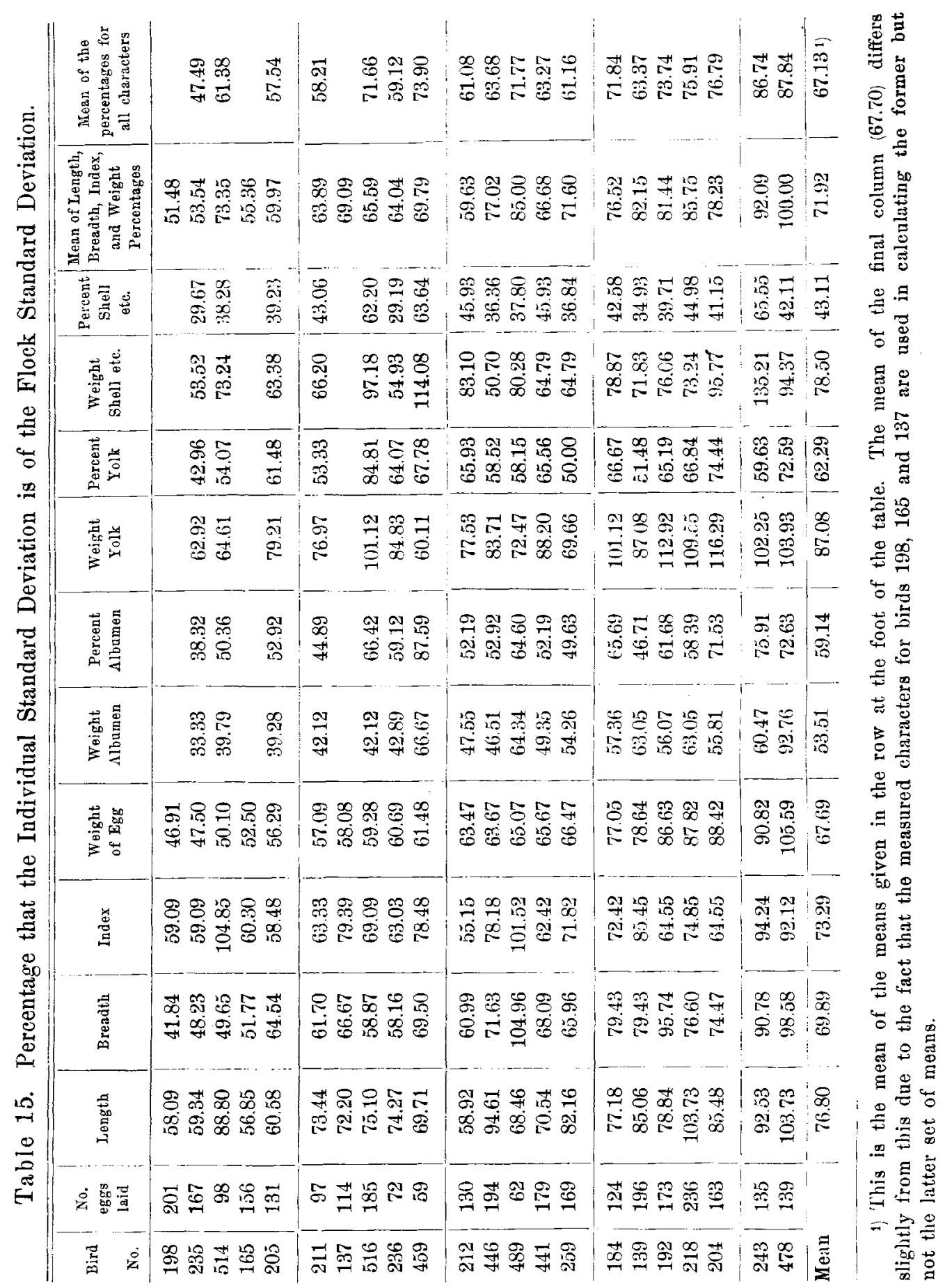


A Biometrical Study of Egg Production in the Domestic Fowl. IV. 247

in the vegetable kingdom studied by Pearson is 87.88 percent, which is very near the two maximum values given above. The eggs of an individual then resemble each other more closely than do eggs forming a random sample from other individuals of the same strain.

4) The individuals differ greatly in respect to the portion of the race variation shown. Some of the individuals which lay uniform eggs show less than 50 percent of the variation of the race while those that lay variable eggs may show nearly 90 percent.

5) Certain egg characters show a much larger percentage of race variation in the individuals than do other characters. It thus seems clear that the quantitative limits of homotyposis differ according to the choice of the egg character by which it is measured, and also according to the relative variability of the individuals which make up the population.

6) A consideration of the data given in the body of the table shows even more clearly that homotyposis cannot be thought of as a definitely limited relationship. 'For example a certain character may be relatively more variable in the individual than in the race. In fact there is, in the case of every character except albumen weight and the percentages of the parts, one individual or more showing an intra-individual variation which is more than 100 percent of the variation of the race. The more variable individuals (as No. 243 and No. 478) may show such a relationship for two or three characters. One character, yolk weight exhibits this relationship in seven of the nineteen individuals studied. There is then no necessary reduction of the race variation for any one egg character within a particular individual.

Egg characters like many, if not most, other characters, are evidently not entirely predetermined by heredity, but are determined by the combined action of hereditary and environmental factors. In the present study of variation in these characters no attempt has been made to measure separately the influence of these two groups of factors. It is evident from the above results that in some instances the interaction of these factors may produce in a certain character in a particular individual a variation relatively greater than the variation shown in that character by the race to which the individual belongs. 
5. The Difference in the Degree of Variation Shown by the Several Egg Characters.

From the data given in Table 13 the different degree of variation shown by the several egg characters is clearly seen. The means given at the foot of this table are the average individual variations for each character taking the group of birds as a whole. The four following relationship between the degree of variation in the separate characters are clearly demonstrated, either by comparing these means or by considering separately the several coefficients for each bird.

1) The egg varies more in respect to weight of shell and weight of yolk than in respect to any of the other characters. A few individuals show significant differences between the amount of variation in these characters. The eggs of some individuals vary more in respect to the one and some in respect to the other.

2) Egg weight and albumen weight are about equally variable. They are decidedly less variable than shell weight and yolk weight and much more variable than either leugth or breadth. The difference between the variation for these two characters is significant for very few individuals.

3) Both length and breadth are much less variable than any of the weight characters of the egg.

4) The egg is more variable in length than in breadth. In a few individuals the difference between the variation in these characters is not significant.

The following list arranges the egg characters in the order of their variability.

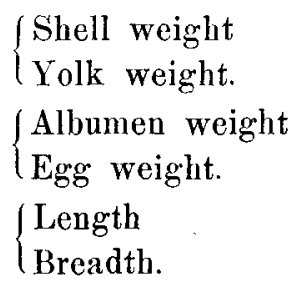

It is especially worthy of note that the variation coefficients for yolk and shell are much higher than that for the whole egg, and the coefficient for albumen weight is at least as high. There must then be a compensatory variation among the parts. The data given in Table 1 also show that in general the eggs of the breeding season have 
A Biometrical Study of Egg Production in the Domestic Fowl. IV. 249

disproportionately large yolks and a consequent smaller percentage of albumen than the eggs at other seasons.

The fact shown by Table 13 that within the eggs of an individual the yolk weight is much more variable than any other character except shell weight is interesting when compared with the fact (p. 226) that the mean yolk weight for the different individuals is more uniform than the mean weight of either of the other parts or of the whole egg.

\section{The Correlation of Egg Characters with Other Characters of the Individual.}

It has been shown that the several individuals differ in respect to egg characters. Like the individuals of any race they also differ in very many anatomical and physiological characters. The interindividual variation in egg characters must be related to the interTable 16. Showing Date of Hatching, Date of 1st Egg, No. of Eggs, Size of Eggs and Body Size.

\begin{tabular}{|c|c|c|c|c|c|}
\hline $\begin{array}{l}\text { Bird } \\
\text { No. }\end{array}$ & Date Hatehed & Date of 1 st $\mathrm{Egg}$ & $\begin{array}{c}\text { No. } \\
\text { of Eggs }\end{array}$ & $\begin{array}{c}\text { Spring Mean } \\
\text { Egg Weight } \\
\text { gms. }\end{array}$ & $\begin{array}{c}\text { Body Weight } \\
\text { gms. }\end{array}$ \\
\hline 165 & March 30 & Nov. $19^{\prime} 10$ & 156 & 54.42 & 2032 \\
\hline 137 & $-\quad 31$ & Oct. $30^{\prime} 10$ & 114 & 55.84 & 2019 \\
\hline 139 & $-\quad 31$ & $-\quad 2710$ & 196 & 57.90 & 2211 \\
\hline 198 & April $2 b$ & Nov. $10^{\prime} 10$ & 201 & o3.91 & 2035 \\
\hline 243 & $-\quad 26$ & $-\quad 19^{\prime} 10$ & $13 \check{5}$ & 50.32 & 1890 \\
\hline 192 & $\begin{array}{l}-\quad 27 \\
\end{array}$ & $2 ' 10$ & 173 & 52.32 & 2451 \\
\hline 212 & $-\quad 27$ & $-6 / 10$ & 130 & 54.95 & 2087 \\
\hline $23 \tilde{~}$ & $\begin{array}{l}-\quad 27 \\
-\end{array}$ & $-\quad 6 \prime 10$ & 167 & $\check{5} 2.50$ & 2312 \\
\hline 205 & - $\quad 28$ & $-\quad 19^{\prime} 10$ & 131 & 49.66 & 2766 \\
\hline 211 & $-\quad 28$ & $-\quad 20 \prime 10$ & 97 & 53.69 & 1966 \\
\hline 441 & May 9 & $-\quad 10^{\prime} 10$ & 179 & 50.78 & 2003 \\
\hline 446 & $-\quad 10$ & $-\quad 9 \prime 10$ & 194 & 46.87 & 2331 \\
\hline 204 & $-\quad 10$ & $-\quad 22 \prime 10$ & 163 & - 59.53 & 2526 \\
\hline 184 & $-\quad 11$ & $-\quad 10^{\prime} 10$ & 124 & 56.35 & 2148 \\
\hline 259 & $-\quad 11$ & $-\quad 18^{\prime} 10$ & 169 & 51.02 & 2252 \\
\hline 218 & $-\quad 19$ & $6^{\prime} 10$ & 236 & 52.10 & 2372 \\
\hline 478 & $\begin{array}{l}-\quad 19 \\
-19\end{array}$ & $7 ' 10$ & 139 & $60 . \tilde{a} 9$ & 2252 \\
\hline 516 & $\begin{array}{l}-\quad 19 \\
\end{array}$ & $-\quad 9 \prime 10$ & 185 & 54.38 & 2492 \\
\hline 514 & $-\quad 23$ & Feb. $23 \prime 11$ & 98 & 52.52 & 1701 \\
\hline 459 & June 1 & - $\quad 23^{\prime} 11$ & 59 & 54.65 & 2155 \\
\hline 236 & 2 & Nov. $20^{\prime} 11$ & 72 & $\tilde{5} 2.31$ & 2920 \\
\hline 489 & 2 & Feb. 23'11 & 62 & 64.94 & \\
\hline
\end{tabular}


individual variation in other characters of the bird. The number of birds used in the experiments is, however, too small to determine with certainty the correlation of egg characters with other anatomical and physiological characters of the individual. Such data as we have on the other characteristics of the birds used in this study are however of some interest. Table 16 shows for each bird the date of hatching, the date when the first egg was laid, the total number of eggs laid, the average weight of the egg, and the body weight.

It should be stated that birds used in this study were not chosen at random from the large flocks. It was not possible to begin this work until the last of October. At that time some of the early pullets had already been laying for two or three weeks and hence conld not be used. The birds selected at the beginning of the investigation were the first nineteen pullets which laid their first egg after 0ct. 26. For the sake of comparison, three birds which did not lay until Feb. 23 were added at that time. These were late hatched birds and were probably not fully matured at the beginning of the investigation. The body weights show that the birds hatched before May 19 were equally well grown, at least there is no relationship shown between the body weight and the date of hatching. In the comparison between the date of hatching and the date of the first egg it should be remembered that the birds were selected on the basis of the date of the first egg.

The comparison shows that most of the birds which began to lay in November (between the 2nd and 22nd) were hatched between the 26th of April and the 19th of May. Within these limits there is no relation between the date of the first egg and the date of hatching. The birds which did not lay until spring (February 23) were later hatched (May 23 to June 2). Bird No. 236, hatched June 2, laid her first egg Nov. 20, but did not lay her second egg until March 31 and should be considered a bird which began laying in the spring. The two birds which began to lay in October were hatched March 31. As would be expected the late hatched birds which did not lay until February laid fewer eggs during the year, but among the birds which began to lay between October 30 and November 22 there is no apparent relation between the number of eggs laid during the year and either the date of hatching or the date that the first egg was laid.

There is no apparent relation between the mean weight of the eggs (based on spring data, cf. p. 224) and the date of hatching or the date of the first egg. 
A Biometrical Study of Egg Prodnction in the Domestic Fowl. IV. 251

It is of importance to know whether there is any correlation between the size of a birds body and the size of her egg, the number of eggs produced or of the whole mass of material produced from her body as eggs. Also there might be a relationship between the size of the egg and the number of eggs laid. These correlations were calculated for the twenty-one birds of known body weight. In these calculations the following data, taken from Tables 1 and 15, are used: Mean body weight for November and December 1910 for all birds except the late hatched ones (birds No. 236, No. 514 and No. 459), for which the body weight in September 1911 was used: the mean spring egg weight; the whole number of eggs laid before cessation of laying at the first (1911) fall moult; and the whole amount of egg material produced, i. e., the number of eggs times the mean egg weight for the first year's eggs.

The constants are given in Table 17.

Table 17. Correlation Coefficients Between Body Weight, Spring Mean Egg Weight, Number of Eggs Laid the First Year and the Weight of all the Eggs Laid the First year.

\begin{tabular}{|c|c|c|c|c|}
\hline Character & Mean & Standart Deviation & $\begin{array}{l}\text { Coefficient of Corre- } \\
\text { lation Between this } \\
\text { Character and the } \\
\text { Body Weight }\end{array}$ & $\begin{array}{l}\text { Coefficient of Corre- } \\
\text { lation Between this } \\
\text { Character and the } \\
\text { spring Mean Egg } \\
\text { Weight }\end{array}$ \\
\hline $\begin{array}{l}\text { Body Weight } \\
\text { in grams }\end{array}$ & 2234 & $282.92 \pm 29.4 \check{~}$ & & $-.030 \pm .147$ \\
\hline $\begin{array}{l}\text { Spring Mean } \\
\text { Egg Weight } \\
\text { gms. }\end{array}$ & 53.65 & $3.17 \pm .33$ & $-.030 \pm .147$ & \\
\hline $\begin{array}{l}\text { No. of Eggs } \\
\text { Laid the } \\
\text { 1 st Year }\end{array}$ & 148.67 & $44.03 \pm 4.58$ & $-.129 \pm .145$ & $.062 \pm .147$ \\
\hline $\begin{array}{l}\text { Weight of all the } \\
\text { Eggs Laid the } \\
1 \text { st Year gms. }\end{array}$ & 7678.90 & $2275.43 \pm 236.83$ & $.004 \pm .147$ & \\
\hline
\end{tabular}

From this table we see that in this small group of birds none of these characters are significantly correlated, the coefficients in all cases being less than their probable errors.

The birds which completed their second year were autopsied. Table 18 gives the data taken at autopsy, together with the two 


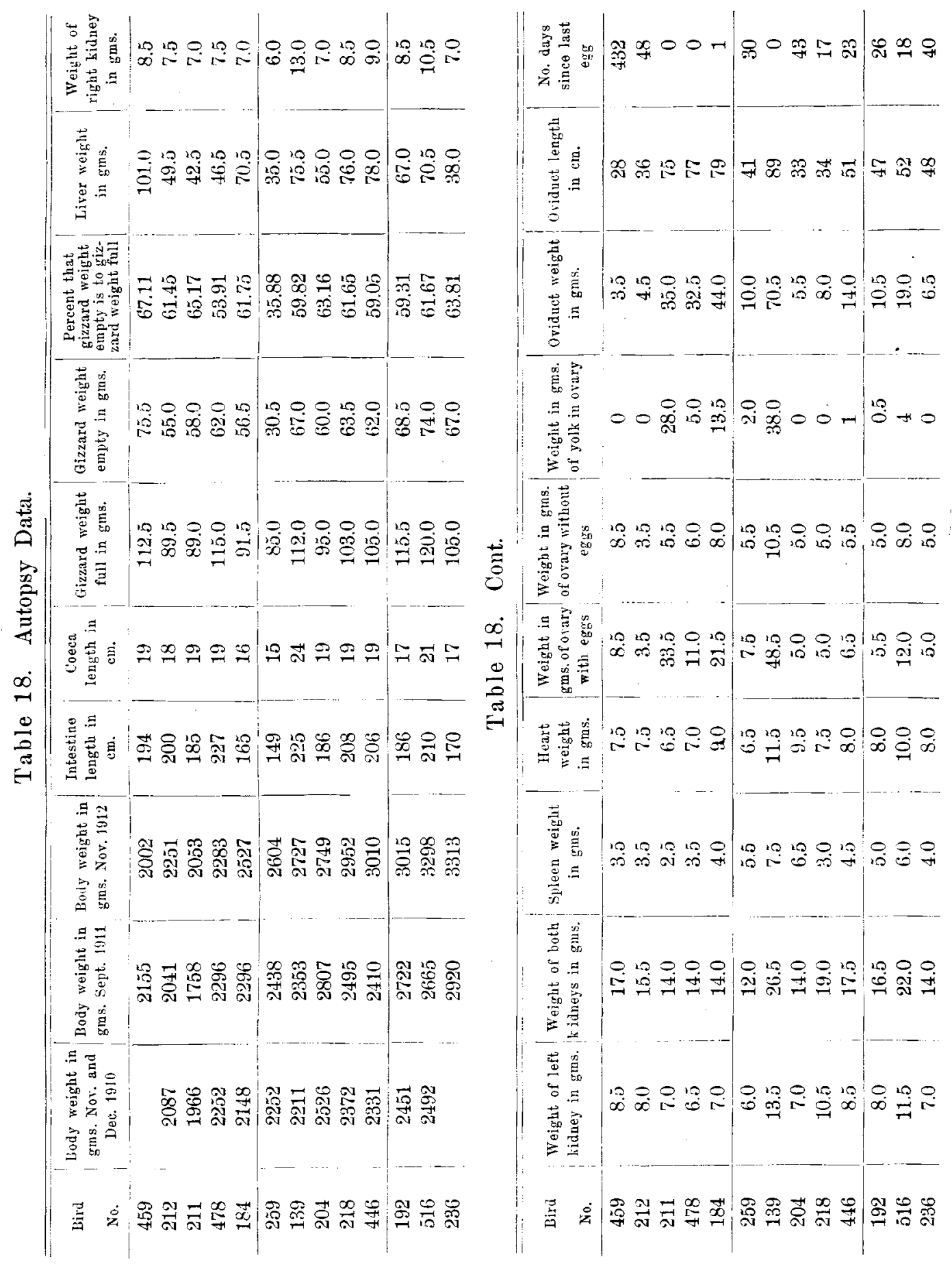


A Biometrical Study of Egg Production in the Domestic Fowl. IV. 253

previous body weights 1 ). These data are given in order to put on record the remainder of the facts known about the birds. The number of birds is too small for statistical comparison, either in respect to size of the body, size of the visceral organs, or the number of eggs produced. Attention may be called to the fact that in the birds which are not laying the weight of the oviduct is definitely related to the length of time since the last egg was produced and to the amount of yolk present in the ovary. In the four birds which are laying, the size of oviduct, especially as indicated by the length, appears to be related to the body weight (see Table 19). The weight of the active oviduct is very much influenced by the amount of the secretion present in the glands at the time of weighing and therefore is not a very good measure of the size of the duct unless all the weights are taken immediately after the passage of the egg down the duct. The four cases presented show one wide exception to a positive relationship between the size of the egg and the size of the active oviduct. These eases are of course too few on which to base general conclusions.

Table 19. Data Showing the Length and Weight of Oviduct, the Mean Weight of the Spring Eggs and the Body Weight for the Four Birds Killed While in Laying Condition.

\begin{tabular}{c|c|c|c|c|c}
\hline Bird & $\begin{array}{c}\text { Body weight } \\
\text { in grams }\end{array}$ & $\begin{array}{c}\text { Weight of } \\
\text { mean spring egg } \\
\text { in gms. }\end{array}$ & $\begin{array}{c}\text { Weight of } \\
\text { yolk in ovary } \\
\text { in gms. }\end{array}$ & $\begin{array}{c}\text { Length of } \\
\text { oviduct in em. }\end{array}$ & $\begin{array}{c}\text { Weight of } \\
\text { ovidnct in gms. }\end{array}$ \\
\hline No. & 2053 & 53.69 & 28.0 & 75.0 & 35.0 \\
\hline 411 & 2283 & 60.59 & 5.0 & 77.0 & 32.5 \\
184 & 2527 & 56.35 & 13.50 & 79.0 & 44.0 \\
139 & 2727 & 57.90 & 38.0 & 89.0 & 70.5
\end{tabular}

\section{Summary of Part I.}

1) The characteristic eggs of the different individuals show variation in all egg characters.

2) They differ more in size than in shape, and they differ more in the amount of albumen and shell than in the size of the yolk.

3) There is a general correlation between the various characters of the egg. That is, when a bird's eggs are large they are both long and broad and contain a large yolk with a large amount of al-

1) These are also given in Table 1. 
bumen and shell. The amount of yolk, however, is not proportionately large, so that the birds which lay large eggs lay eggs which have a relatively small percentage of yolk.

4) In spite of this general relationship the eggs of one individual may vary disproportionately in any one of the characters measured.

5) There is an evident individuality among the birds also in the amount of variation in the egg characters. The uniformity (or variability) of the egg characters of an individual tends to be general, but may manifest itself in different characters to quite different degrees.

6) The variation coefficients must be somewhat affected by the facts: a) that there is a seasonal change in the egg characters, and b) that not all the birds are laying thronghout the year. Yet the birds which are laying practically throughout the year show marked tendencies toward either uniformity or variability. In fact the extremes of the flock are found in the eggs of such birds.

7) A comparison of the relative degree of variation in the individual and in the race shows that in general the eggs of an individual resemble each other much more closely than do a random sample of the eggs of the same strain. The eggs of certain individuals, however, show a much higher percentage of the variation of the race than those of some of the other individuals. In certain egg eharacters there is a general tendency for the individual variation to approach more nearly the limits of the race variation than in other characters. Finally certain characters may display a variation relatively greater in a particular individual than in the race. This indicates that the egg characters are determined by an interaction of hereditary and environmental forces which may cause a particular character to reach or surpass the racial limits of variation within the eggs of one individual.

8) Whereas a comparison of the means for the different individuals shows that intra-racially the eggs are more uniform in yolk weight than in the weight of the other parts or of the whole egg, within the eggs of the individual the yolk weight is almost as variable as the shell weight and much more variable than the weight of the albumen or of the whole egg.

9) The intra-individual variations show a compensatory variation in the parts as the rariation in the weight of the egg is less than that in the parts. 
A Biometrical Study of Egg Production in the Domestic Fowl. IV. 255

10) The eggs of each individual as well as the means of the different individuals vary less in respect to the dimensional characters than in respect to weight. The eggs must vary simultaneously in both dimensions.

11) The factors which bring about the individuality in the eggs of the different birds are too complex for analysis from the data in hand. All the other facts known about the birds are presented and a few of them are investigated to discover possible relationships between the variation in egg characters with variation in other characters.

12) The early hatched birds laid earlier in the fall than those hatched during the middle of the season while the late batched birds did not lay until spring.

13) Among the birds which began to lay in the fall there is no relation between the number of eggs laid and the time of hatehing or the exact date of the first egg.

14) Among the whole flock there is no relation between the size of the egg and either the time of hatching or the time of laying the first egg.

15) Correlations calculated between body weight and number of eggs and size of eggs, and between number of eggs and size of eggs were all significantly zero.

16) The autopsy data are given for the thirteen birds which completed their second year. The number of birds is too small for statistical analysis. They show an apparent relationship between the size of the inactive oviduct and the time which has elapsed since the last egg and the amount of yolk present in the ovary. The size of the active oviduct appears to be related to the body size. .

17) It is not possible to determine whether or not there is a relationship between the size of the active oviduct and the size of the egg.

\section{Part II.}

The Interrelation of the Dimensions, Shape, Size of Egg, and the Size and Proportions of the Parts.

The individuality of the birds in respect both to the mean size and to the amount of variation of each egg character was discussed in Part I. In this dicussion it was noted that there was a general relationship between the various characters; that is, when an indi- 
vidual laid large eggs her characteristic egg was both long and broad and each one of the component parts was relatively large. It was also noted that the eggrs of an individual evidently varied coincidently in both diametral dimensions since they were less variable in either dimension than in size. It was further noted that within an individual there was a compensatory variation in the size of the parts since the variation in the whole egg is less than the variation in the parts.

The purpose of the present part of the paper is to show the interrelation, or more strictly correlation, of the various egg characters within the eggs of each of the several individuals. Evidence will be presented to show that while there is a general tendency amongst all individuals for a particular character to be either, a) closely related, or b) slightly related, or c) unrelated to another character; yet there are great individual differences in the different birds in regard to the degree of correlation shown between any two characters.

The correlation coefficients for each pair of egg characters for each individual are given in Table 20.

\section{Gross Correlation Between the Dimensions and Between Each Dimension and Egg Weight.}

The first three lines of Table 20 show the following relations of the dimensions to each other and to the weight of the egg.

1) Length and breadth are positively correlated. The correlation varies in the different individuals from $.671 \pm .024$ (Bird No. 218) to practically zero (Birds No. 137, No.514, No. 4891) and No. 459). It is significant for eighteen of the twenty-two individuals, but the variation among the individuals in the degree of the relationship is great.

2) Length and weight are positively correlated to a high degree for each of the twenty-two individuals. The lowest coefficient is .548 \pm .044 for bird No. 137. The coefficients for the eggs of the different individuals vary in a nearly evenly graded series from this to the high coefficient $.889 \pm .009$ for bird No. 218. The difference between these extremes is $.341 \pm .045$. That is the eggs of bird No. 218 show a very much closer association between length and weight than do the eggrs of No. 137. While this represents the ex-

1) See p. 260 . 
A Biometrical Study of Egg Production in the Domestic Fowl. IV. 257

\begin{tabular}{|c|c|c|c|c|c|c|c|}
\hline & 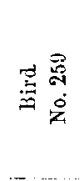 & 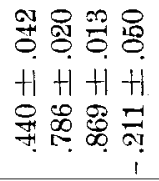 & 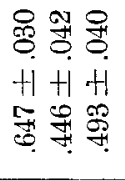 & 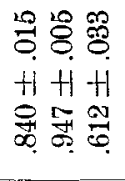 & 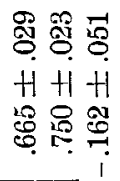 & 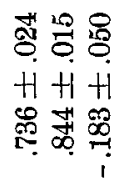 & 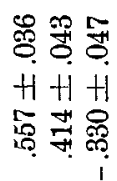 \\
\hline$\frac{\dot{D}}{\stackrel{D}{ \pm}}$ & 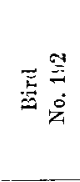 & 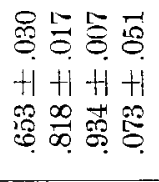 & 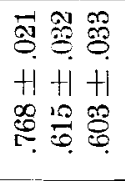 & 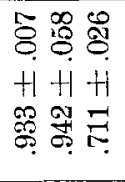 & 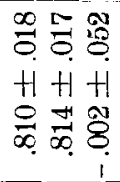 & 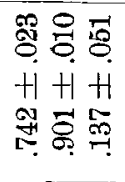 & 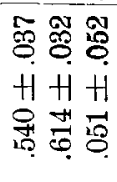 \\
\hline 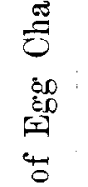 & 涪 & 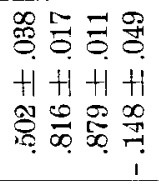 & 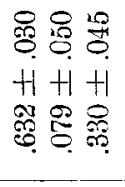 & 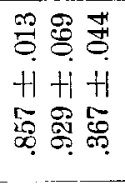 & 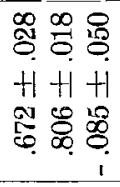 & $\begin{array}{l}\text { go } \\
8 \\
\end{array}$ & 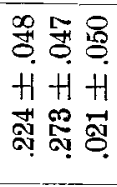 \\
\hline 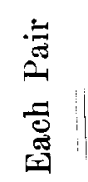 & 音蓄 & 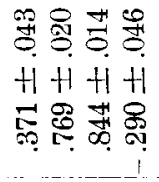 & 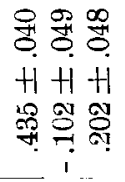 & 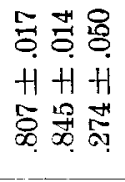 & 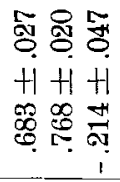 & 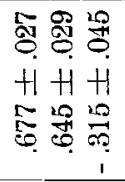 & 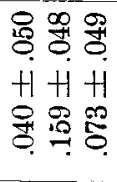 \\
\hline 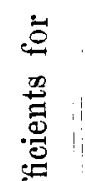 & & 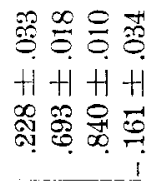 & $\begin{array}{l}\infty \\
0 \\
0 \\
0 \\
+1\end{array}$ & 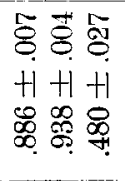 & 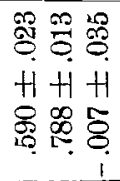 & 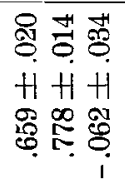 & 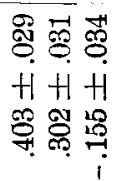 \\
\hline 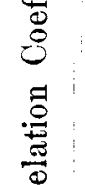 & 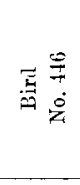 & 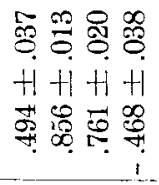 & 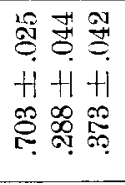 & 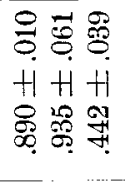 & $\begin{array}{l}0 \\
0 \\
0 \\
\end{array}$ & $\begin{array}{l}\infty \\
0 \\
0\end{array}$ & 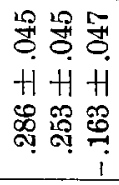 \\
\hline 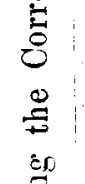 & 壳总 & 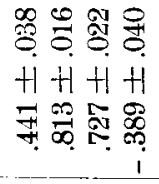 & & & & & \\
\hline 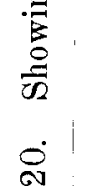 & 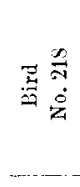 & 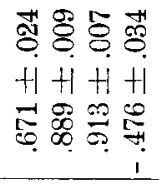 & 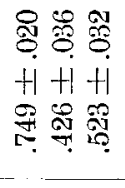 & 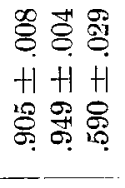 & 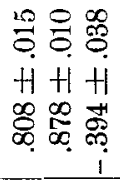 & 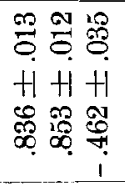 & 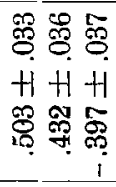 \\
\hline$\frac{\stackrel{0}{\sigma}}{E}$ & & 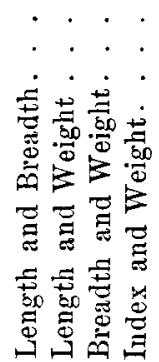 & 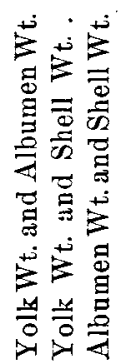 & 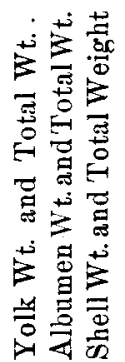 & 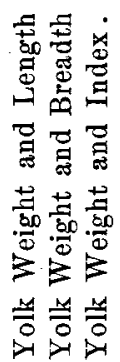 & 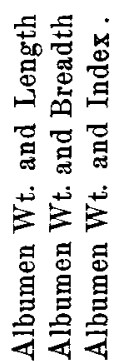 & 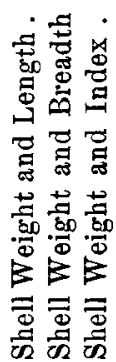 \\
\hline
\end{tabular}




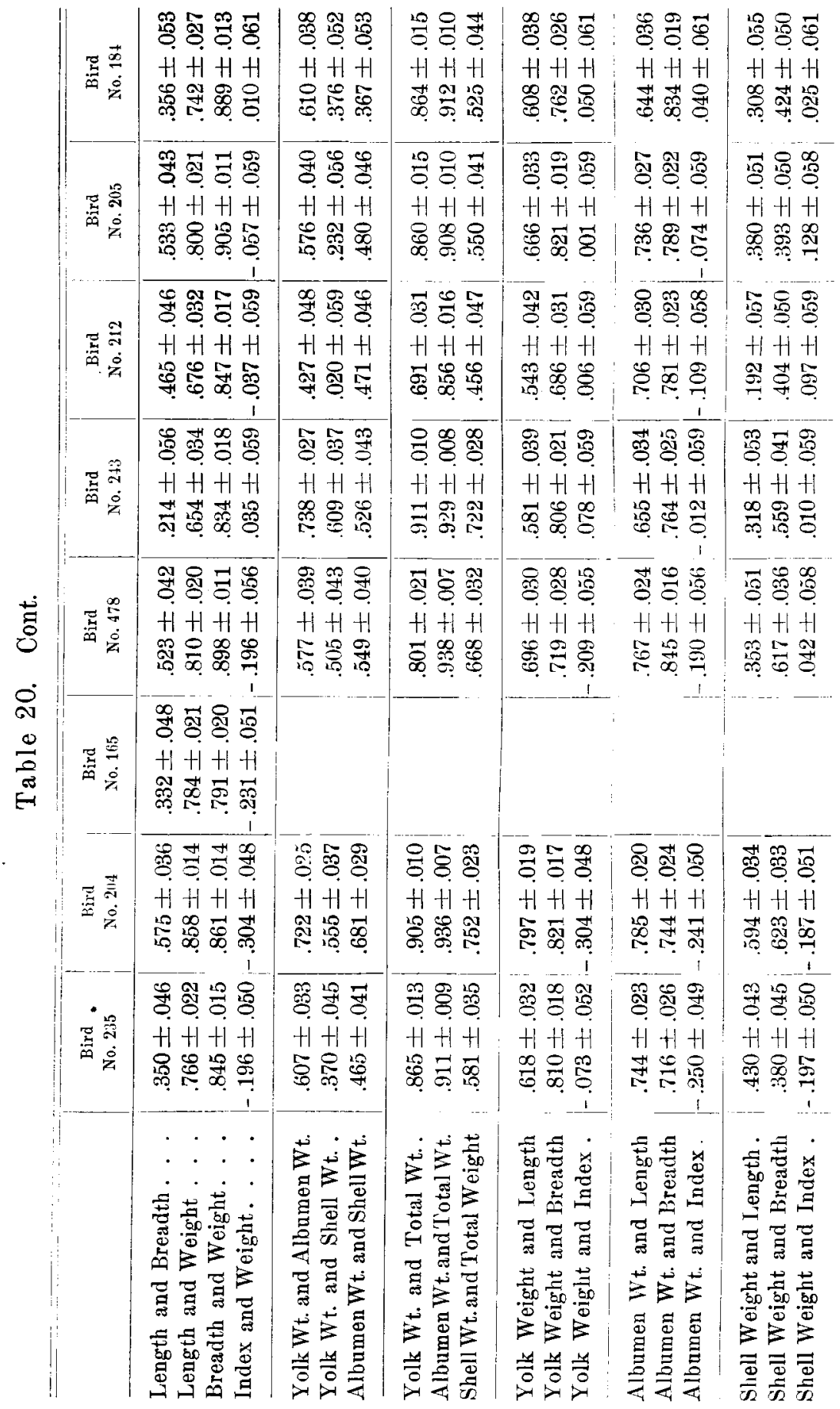


A Biometrical Study of Egg Production in the Domestic Fowl. IV. 259

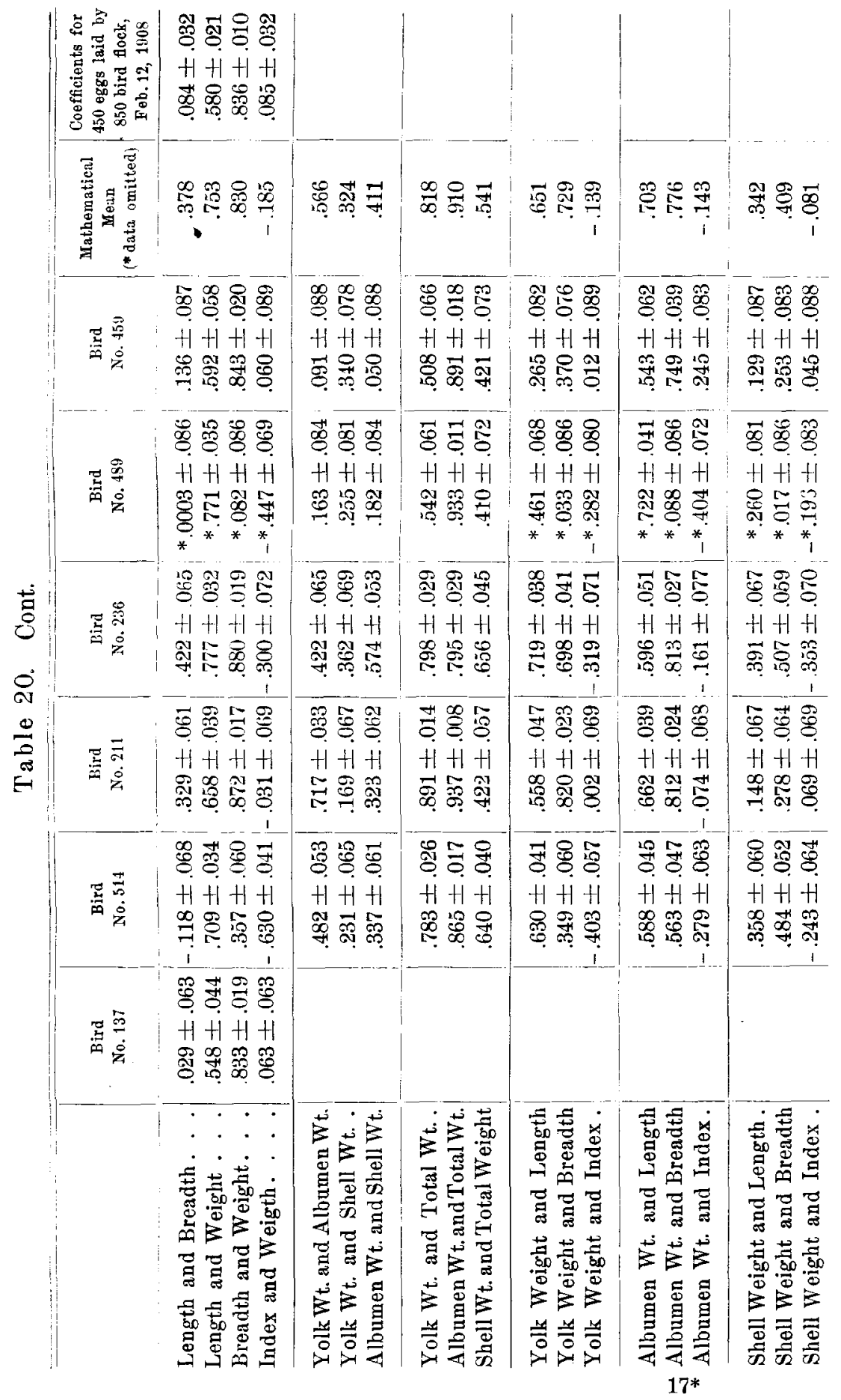


treme difference in the individuals studied the coefficient for any individual can be shown to differ significantly from the coefficients of from ten to twenty of the other individuals.

3) Breadth is positively correlated with weight. For twenty of the twenty-two individuals this correlation is very high, ranging from .934 \pm .007 (Bird No. 192) to $.761 \pm .020$ (Bird No. 446). The extreme difference in these twenty birds is $.173 \pm .004$. That is while different individuals show significantly different degrees of association between breadth and weight the difference is not high for the large part of the flock. The other two individuals show decidedly less correlation between these characters. The coefficient for bird No. 514 is $.357 \pm .060$ which while significant is very low compared to those for the greater part of the flock. In fact it differs more than twice as much from the next higher coefficient than any of the twenty high coefficients differ from each other. The coefficient $.082 \pm .086$ for bird No. 489 is not significant. Its low value however is due to the fact that of the sixty-one eggs laid by this bird six were of a very different shape from the others. They were large eggs which were long and narrow. This is the most pronounced case of dimorphism exhibited in the eggs of any of the birds studied and is worthy of special attention.

These six eggs were all laid between May 15 and June 7. The bird died on July 4. It is possible that some abnormal physiological condition may have modified the shape of these eggs. It should be said that during this same period the bird also laid thirteen eggs which conformed to the shape typical for this individual. The eggs which were abnormal in shape were laid in the following relation to the normal eggs.

1) May 15 - 2nd egg of a seven egg clutch.

2) May 24 - 1st egg of a three egg clutch.

3) May 26 - 3rd egg of a three egg clutch (same clutch as above).

4) May 29 - 1st egg of a five egg clutch.

5) June $4-1$ st egg of a nine egg clutch.

6) June $7-4$ th egg of a nine egg clutch (same clutch as above).

It would be quite impossible to say that there is any significance in the tendency for these abnormalities to occur at the ends of the clutches since the six eggs present two exceptions one of them nearly in the center of its clutch. 
A Biometrical Study of Egg Production in the Domestic Fowl. IV, 261

It is impossible now to determine what caused these modifications in the shape of the eggs but it was probably due to physiological disturbances, and is of great interest as it shows that the individuality of the eggs of a bird may be temporarily modified to a considerable extent.

The effect of such a dimorphism upon the correlation coefficients, especially when the total number of eggs is small is obvious. The length and negative index coefficients will be increased and the breadth coefficients decreased. The correlation table (Table 21) between the breadth and weight is given as an illustration.

Table 21. Showing the Correlation between Weight and Breadth in Eggs of Bird No. 489.

\begin{tabular}{|c|c|c|c|c|c|c|c|c|c|c|c|c|c|c|c|c|c|c|c|}
\hline \multirow[b]{2}{*}{$\begin{array}{l}\text { Egg breadth } \\
\text { iı } \downarrow \mathrm{mm} \text {. }\end{array}$} & \multicolumn{19}{|c|}{ Egg Weight in gms. } \\
\hline & $\begin{array}{l}8 \\
8 \\
0 \\
10 \\
1 \\
8 \\
0 \\
0\end{array}$ & 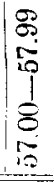 & $\begin{array}{l}\infty \\
\mathbb{8} \\
\infty \\
0 \\
1 \\
8 \\
8 \\
\infty \\
\infty\end{array}$ & $\mid \begin{array}{l}0 \\
1 \\
0 \\
0 \\
0 \\
0\end{array}$ & $\mid \begin{array}{l}\mathscr{8} \\
8 \\
0 \\
1 \\
8 \\
8 \\
8 \\
8\end{array}$ & 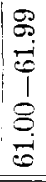 & 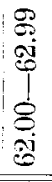 & $\mid$\begin{tabular}{l}
$\mathscr{g}$ \\
$\sigma$ \\
8 \\
8 \\
8 \\
8 \\
\hdashline \\
0
\end{tabular} & 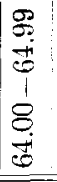 & $\begin{array}{l}98 \\
8 \\
8 \\
1 \\
8 \\
8 \\
8 \\
0\end{array}$ & 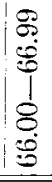 & 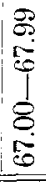 & $\mid \begin{array}{l}0 \\
\mathbb{g} \\
0 \\
0 \\
1 \\
1 \\
8 \\
0 \\
0 \\
0\end{array}$ & $\begin{array}{l}\mathscr{8} \\
8 \\
8 \\
0 \\
1 \\
8 \\
8 \\
8 \\
\end{array}$ & $\begin{array}{l}g \\
g \\
0 \\
0 \\
1 \\
8 \\
0 \\
0\end{array}$ & 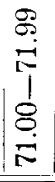 & $\begin{array}{l}g \\
g \\
i j \\
1 \\
1 \\
\delta \\
0 \\
i \\
i\end{array} \mid$ & $\mid \begin{array}{c}8 \\
8 \\
0 \\
1 \\
8 \\
8 \\
0\end{array}$ & $\stackrel{\frac{D}{7}}{\frac{\pi}{0}}$ \\
\hline & - & - & - & - & 一 & - & - & 1 & - & - & - & - & - & - & -1 & - & - & 1 & 1 \\
\hline $40.50-40.9$ & - & - & - & - & - & - & - & - & - & - & 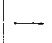 & - & - & 1 & - & 1 & - & - & 2 \\
\hline 41.00 & - & - & - & 一 & - & - & - & - & - & - & 1 & - & - & - & - & - & - & 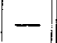 & \\
\hline $41.50-41.99$ & - & - & - & - & - & - & - & - & - & - & - & - & - & 1 & - & - & -1 & - & \\
\hline $2001-424$ & - & - & - & 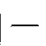 & - & & - & - & 一 & - & - & - & 一 & - & - & - & - & 1 & \\
\hline $42.50-42.99$ & - & - & -- & - & - & - & - & - & - & - & - & - & - & - & - & - & - & - & 0 \\
\hline 43 & 1 & 1 & - & - & - & - & - & - & 一 & $\cdots$ & - & - & - & - & - & - & - & - & 2 \\
\hline $43.50-43.9$ & - & - & - & 1 & 1 & 2 & 1 & $\rightarrow$ & - & - & - & - & - & - & - & - & - & - & 5 \\
\hline $44.00-44.4$ & - & - & - & - & 1 & & - & - & 3 & - & - & - & - & - & - & $i-$ & - & 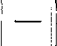 & \\
\hline 4 & - & - & - & 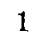 & - & 1 & 1 & 4 & 2 & 2 & - & - & - & - & - & - & 1 & - & 11 \\
\hline & - & - & - & - & - & - & 2 & 3 & - & 3 & 2 & 2 & -- & 1 & - & - & - & - & 13 \\
\hline $4 \grave{0}$ & - & - & - & - & - & - & 一 & 2 & 1 & 3 & 3 & - & 2 & 1 & - & - & - & - & 12 \\
\hline 46.0 & - & -- & - & - & - & - & - & 1 & 1 & 一 & S & - & - & - & - & 一 & - & - & 3 \\
\hline & - & - & - & - & - & - & - & - & - & - & - & - & - & - & - & - & - & - & c \\
\hline & - & - & - & & - & & - & - & - & - & - & - & 1 & - & 1 & - & - & - & 2 \\
\hline 47.50 & ii & - & 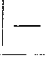 & & : & & & & $=$ & - & $-!$ & - & - & 1 & - & - & -1 & - & 1 \\
\hline 'l'otals & 1 & 1 & 0 & 2 & 2 & $\check{5}$ & 4 & 11 & 7 & 8 & 7 & 2 & 3 & 5 & 1 & 1 & 0 & 1 & 61 \\
\hline
\end{tabular}

A glance at this table shows that the breadth weight correlation for all the other eggs of the bird is high. The effect of the six peculiar eggs reduces the coefficient to insignificance. These six eggs may be considered abnormal as to shape and consequently the coefficients determined between the dimensions and the weight and between the dimensions and the weight of parts do not represent the typical relations between these characters in the normal eggs of the 
individual. For this reason all such coefficients for this bird are marked with an asterisk in Table 20 and are not used in calculating the mean individual coefficients given in that table nor will they be discussed further in the paper.

The normal eggs of this individual show a high positive correlation between breadth and weight.

4) The correlation between breadth and weight is in general higher than the correlation between length and weight; but the individual birds differ greatly in the relative degree of association between these characters. The following list gives for each individual of the flock the difference between the breadthweigth and length-weight correlation coefficients. It is arranged in the order of the magnitude of the difference.

\begin{tabular}{c|c}
\hline $\begin{array}{c}\text { Bird } \\
\text { No. }\end{array}$ & $\begin{array}{c}\text { Difference between length-weight } \\
\text { and breadth-weight correlation } \\
\text { coefficients }\end{array}$ \\
\hline 137 & $.285 \pm .048$ \\
459 & $.251 \pm .061$ \\
211 & $.214 \pm .043$ \\
243 & $.180 \pm .039$ \\
139 & $.148 \pm .026$ \\
184 & $.147 \pm .030$ \\
192 & $.116 \pm .018$ \\
205 & $.105 \pm .024$ \\
236 & $.103 \pm .037$ \\
478 & $.088 \pm .023$ \\
259 & $.083 \pm .024$ \\
235 & $.079 \pm .027$ \\
212 & $.072 \pm .036$ \\
516 & $.075 \pm .024$ \\
441 & $.063 \pm .020$ \\
218 & $.024 \pm .011$ \\
165 & $.077 \pm .029$ \\
204 & $.044 \pm .020$ \\
198 & $-.086 \pm .027$ \\
446 & $-.095 \pm .024$ \\
514 & $-.352 \pm .069$ \\
& \\
\hline &
\end{tabular}

From this list it is seen that the relationship between breadth and weight and length and weight in respect to correlations is also an individual matter. The differences between the coefficients for the several individuals are distributed over quite a long range reaching from $+.285 \pm .048$ to $-.352 \pm .069$. The differences are not evenly distributed over this range, but are significantly positive for about 
A Biometrical Study of Egg Production in the Domestic Fowl. IV. 263

one-half the individuals and significantly negative for one or two. For at least one third of the flock the differences are not significant.

Thus it is seen that as the eggs of an individual increase in weight they increase in both breadth and length. In about one-half the individuals breadth increases more rapidly than length. In one or two individuals length increases more rapidly than breadth. The two dimensions increase at a practically equal rate in about one-third of the flock.

5) The correlation between index and weight when significant is negative and is never very high. It is significant for about one-half of the individuals. The highest coefficient is - $-630 \pm .041$ (Bird No. 514). The next lower coefficient is $-.476 \pm .034$ (Bird No. 218). Bird No. 514 then has a much higher negative index correlation than any of the other birds. The coefficients for the rest of the flock decrease gradually from $-.476 \pm .034$ to insignificance. The several individuals show a great deal of variation in the value of the coefficient.

The same points in regard to the general interrelation of the dimensions and weight are shown by comparing the means given in Table 20. These show that length and breadth are significantly but not highly correlated; that both dimensions are highly correlated with weight, breadth being more highly correlated than length, and that index is slightly negatively correlated with weight.

\section{The Relation of Intra-individual to Intra-racial Correlation.}

The relationship of two egg characters within the eggs of the individual and the relationship between the same characters within the eggs of the race may be compared. PearL and SURface ${ }^{1}$ ) calculated the coefficients for the 450 eggs laid February 12, 1908, by the 850 bird flock of the same strain as the birds used in this investigation. Their results are given in the final column of Table 20. These coefficients show that weight is highly correlated with both length and breadth and that it is more highly correlated with breadth than with length. The correlations between length and breadth and between index and weight are not significant. Only one of the twenty-two individuals used in the present investigation shows a correlation coefficient between length and weight as low as the coefficient

1) Pearl, R., and Surface, F. M., loc. cit. 
for the flock. On the other hand the mean individual coefficient between breadth and weight is only slightly higher than the flock coefficient.

This comparison indicates that while the individuals show a great variation in the degree of association between egg dimensions and between each egg dimension and the egg size there is in general a closer relation between these characters within the eggs of an individual than within the eggs of the race. The relation between breadth and weight is, however, not significantly greater for the eggs of the individual than for the eggs of the race.

The Partial Correlation Between Dimensions and Weight.

It is evident that the dimensions and the weight of the eggs of an individual are interrelated characters. If the eggs increase or decrease in weight one or both of the dimensions must correspondingly increase or decrease. It is interesting to note the anount of correlation shown in the two dimensions in eggs of the same weight and between each of the dimensions and the weight when the other dimension is constant. This is made possible by calculating the partial correlation coefficients of the first order by the method developed by Pearson 1). The formula for the partial correlation coefficient between characters 1 and 2 when character 3 remains constant is

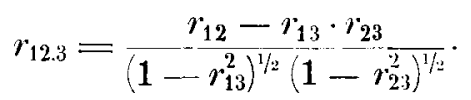

Table 22 gives the partial correlation coefficients for the ten birds laying the largest number of eggs.

The following relationships are shown by the first three lines of the table:

1) When the weight of the egg is constant, length and breadth are negatively correlated. The degree of correlation however varies considerably in the different birds.

2) When the breadth is constant length is highly correlated with weight. The birds show less individual variation than in the former case or in the case of the gross correlation between length and weight.

3) When the length is constant the breadth is highly

1) Peanson, K., Regression Heredity and Panmixia. Phil. 'Trans. Roy. Soc. Vol. 187 A. 1896. pp. 253-318. 
A Biometrical Study of Egg Production in the Domestic Fowl. IV. 265

Table 22. Showing the Correlation between two Characters when a Third Character is Constant.

The Sign for the Constant Character is Separated by a Period from the Sign for the Correlated Characters. $l=$ length, $b=$ breadth, $i=$ index, $w=$ weight, $a=$ albumen, $y=$ yolk, $s=$ shell.

\begin{tabular}{|c|c|c|c|c|c|}
\hline \multirow{2}{*}{$\begin{array}{l}\text { Characters } \\
\text { correlated }\end{array}$} & \multicolumn{5}{|c|}{ 13ird Numbers } \\
\hline & 218 & 446 & 139 & 516 & 441 \\
\hline$r_{l b} \cdot w$ & $-.754 \pm .019$ & $-.467 \pm .038$ & $-.906 \pm .009$ & $-.813 \pm .017$ & $-.780 \pm .020$ \\
\hline$v_{l u-b}$ & $.914 \pm .007$ & $.850 \pm .013$ & $.950 \pm .005$ & $.916 \pm .008$ & $.908 \pm .009$ \\
\hline$r_{b u \cdot l}$ & $.933 \pm .006$ & $.751 \pm .021$ & $.972 \pm .003$ & $.942 \pm .006$ & $.938 \pm .006$ \\
\hline$r_{t u} \cdot y$ & $.960 \pm .003$ & $.954 \pm .004$ & $.86 \tilde{ \pm} \pm .003$ & $.930 \pm .007$ & $.970 \pm .008$ \\
\hline$r_{y w \cdot a}$ & $.927 \pm .006$ & $.923 \pm .007$ & $.936 \pm .006$ & $.914 \pm .008$ & $.944 \pm .005$ \\
\hline$r_{a y \cdot u}$ & $-.812 \pm .01 \tilde{0}$ & $-.799 \pm .018$ & $-.858 \pm .013$ & $-.785 \pm .019$ & $-.864 \pm .012$ \\
\hline$r_{y s \cdot u}$ & $-.287 \pm .041$ & $-.259 \pm .045$ & $-.105 \pm .048$ & $-.602 \pm .019$ & $-.492 \pm .038$ \\
\hline$r_{a s \cdot w}$ & $-.146 \pm .043$ & $-.128 \pm .048$ & $-.556 \pm .034$ & $-.060 \pm .050$ & $-.032 \pm .050$ \\
\hline$r_{l a \cdot w}$ & $-.048 \pm .044$ & $-.009 \pm .049$ & $.038 \pm .049$ & $.079 \pm .049$ & $.093 \pm .050$ \\
\hline$r_{b a \cdot w}$ & $-.102 \pm .043$ & $.138 \pm .048$ & - .0õ \pm .049 & $-.241 \pm .047$ & $-.177 \pm .049$ \\
\hline$r_{i a} \cdot v$ & $-.038 \pm .044$ & $.142 \pm .048$ & $.258=046$ & $-.137 \pm .049$ & $-.125 \pm .049$ \\
\hline$r_{l y \cdot w}$ & $.017 \pm .044$ & $.23 \tilde{0} \pm .046$ & $-.071 \pm .049$ & $.164 \pm .048$ & $-.093 \pm .050$ \\
\hline$r_{b y \cdot v}$ & $.29 j \pm .041$ & $-.056 \pm .048$ & $.171 \pm .047$ & $.273 \pm .046$ & $.214 \pm .048$ \\
\hline$r_{i y} \cdot w$ & $.099 \pm .044$ & $-.146 \pm .048$ & $.296 \pm .045$ & $.035 \pm \pm .050$ & $.081 \pm .050$ \\
\hline$r_{l s} \cdot u$ & $-.059 \pm .044$ & $-.199 \pm .047$ & $.110 \pm .048$ & $-.294 \pm .04 \tilde{\jmath}$ & $-.141 \pm .049$ \\
\hline$r_{b s} \cdot u$ & $-.327 \pm .040$ & $-.144 \pm .048$ & $-.36 \check{ \pm} \pm .042$ & $-.148 \pm .048$ & $-.112 \pm .050$ \\
\hline$r_{\text {is }} \cdot$ & $-.412 \pm .037$ & $.0 \tilde{6} \pm \pm .048$ & $-.090 \pm .048$ & $.175 \pm .048$ & $.081 \pm .050$ \\
\hline
\end{tabular}

Table 22. Cont.

\begin{tabular}{|c|c|c|c|c|c|c|}
\hline \multirow{2}{*}{$\begin{array}{l}\text { Characters } \\
\text { correlated }\end{array}$} & \multicolumn{5}{|c|}{ Bird Numbers } & \multirow{2}{*}{ Me:ın } \\
\hline & 192 & 259 & $23 \tilde{~}$ & 204 & 478 & \\
\hline $\boldsymbol{r}_{l b} \cdot w$ & $-.544 \pm .036$ & $-.796 \pm .019$ & $-.848 \pm .015$ & $-.627 \pm .032$ & $\mid-.791 \pm .022$ & -.7326 \\
\hline$r_{l w} \cdot b$ & $.771 \pm .021$ & $.909 \pm .009$ & $.937 \pm .006$ & $.872 \pm .012$ & .907 上.010 & .8934 \\
\hline$v_{b w} \cdot l$ & $.918 \pm .008$ & $.943 \pm .006$ & $.957 \pm .004$ & $.875 \pm .012$ & $.949 \pm .006$ & .9178 \\
\hline$r_{a x \cdot y}$ & $.975 \pm .008$ & $.976 \pm .008$ & $.967 \pm .003$ & $.961 \pm .009$ & $.973 \pm .003$ & .9631 \\
\hline$r_{y z \cdot} \cdot t$ & $.972 \pm .008$ & $.930 \pm .007$ & $.951 \pm .00 \tilde{}$ & $.943 \pm .006$ & $.917 \pm .009$ & .9357 \\
\hline$r_{u y \cdot v}$ & $-.838 \pm .015$ & $-.85 \tilde{5}+.014$ & $-.873 \pm .012$ & $-.840 \pm .016$ & $-.839 \pm .017$ & -.8363 \\
\hline$r_{y s \cdot x}$ & $-.189 \pm .050$ & $-.159 \pm .051$ & $-.323 \pm .047$ & $-.448 \pm .042$ & $-.067 \pm .058$ & -.2931 \\
\hline$r_{a, s ;} \cdot r$ & $-.284 \pm .048$ & $-.339 \pm .046$ & $-.189 \pm .050$ & $-.095 \pm .053$ & $-.301 \pm .053$ & -.2130 \\
\hline$r_{l a}, w$ & $-.147 \pm .0551$ & $-.041 \pm .052$ & $.174 \pm .051$ & $-.099 \ddagger$ & $.036 \pm .058$ & .0076 \\
\hline$r_{b a} \cdot w$ & $.176 \pm .050$ & $.133 \pm .05 z 1$ & $-.243 \pm .049$ & $-.350 \pm .047$ & $.023 \pm .058$ & -.0698 \\
\hline$r_{i(t)} \cdot u$ & $.203 \pm .050$ & $.054 \pm .052$ & $-.176 \pm .051$ & $-.129 \pm .052$ & $-.020 \pm .058$ & .0032 \\
\hline$r_{l y} \cdot w$ & $.226 \pm .049$ & $.013 \pm .052$ & $-.137 \pm$ & $.094 \pm .053$ & $.134 \pm .057$ & .0582 \\
\hline$r_{b y \cdot w}$ & $-.4 \check{0} 0 \pm .037$ & $.073 \pm .0 \tilde{2} 2$ & $.296 \pm .048$ & $.190 \pm .051$ & $.001 \pm .058$ & .1007 \\
\hline$r_{i y \cdot z}$ & $-.197 \pm .050$ & $.028 \pm .052$ & $.195 \pm .050$ & $-.072 \pm .053$ & $-.089 \pm .057$ & .0230 \\
\hline$r_{l s} \cdot w$ & $-.104 \pm .051$ & $.156 \pm .051$ & $-.029 \pm .052$ & $-.150 \pm .052$ & $-.430 \pm .052$ & -.1140 \\
\hline $\boldsymbol{r}_{l s, u}$ & $-.201 \pm .050$ & $-.299 \pm .047$ & $-.253 \pm .051$ & $-.072 \pm .053$ & $.055 \pm .058$ & -.1866 \\
\hline$r_{i s} \cdot w$ & $-.002 \pm .051$ & $-.259 \pm .049$ & $-.104 \pm .052$ & $.066 \pm .0 \overline{0} 3$ & $.236 \pm .055$ & -.0253 \\
\hline
\end{tabular}


correlated with weight. As in the former case the different individuals show less variation than in the gross correlation coefficients.

4) The correlation between breadth and weight in eggs of a common length is higher than the correlation between length and weight in eggs of a common breadth. This difference is not large and is not significant for all the individuals. In fact bird No. 446 has a partial correlation coefficient for length and weight which is probably significantly higher than that for breadth and weight.

The Relation of Each Part of the Egg to the Whole Egg.

The egg is composed essentially of three parts, albumen, yolk and shell and its weight is the sum of the weights of these three parts. What is the correlation between the weight of each of these parts and the weight of the whole? A study of this point was made on nineteen birds. The correlation coefficients are given in lines eight to ten inclusive of Table 20 .

The correlation between the weight of each part of the egg and the weight of the whole is significant and positive for every individual. The several parts howevervary greatly both in the actual value of the coefficients and in the amount of variation shown in the coefficients for the different individuals.

Since the heaviest part of an egg is the albumen and the lightest is the shell, one would naturally expect the egg weight to be more highly correlated with albumen weight than with yolk weight and less highly correlated with shell weight than with either of the heavier parts. Inspection of the coefficients in the body of the table, or a comparison of the means at the end, shows that this is in general true. For every individual in the flock the correlation between egg weight and shell weight is significantly less than that between egg weight and either of the other parts. However, the difference between the coefficients for albumen weight and yolk weight is of sufficient magnitude to be certainly significant in only about one-half the individuals. When the difference is significant the albumen weight correlation is the higher.

The correlation between egg weight and albumen weight is high and the individual variation in respect to the degree of correlation is small. In the different individuals it varies only from .795 \pm .029 for bird No. 336 to $.949 \pm .004$ for bird No. 218. This difference is 
A Biometrical Study of Egg Production in the Domestic Fowl. IV. 267

equal to $.154 \pm .029$. For fifteen of the birds the maximum difference is only $.058 \pm .019$. This difference cannot be considered certainly significant.

The correlation between egg weight and yolk weight is also high but the individual variation in the degree of correlation is much greater than in the case of the correlation between egg weight and albumen weight. The range of the correlation coefficients between egg weight and yolk weight is from $.508 \pm .066$ for bird No. 459 to $.933 \pm .007$ for bird No. 193. This range of $.425 \pm .067$ is three times as great as that of the coefficients for egg weight and albumen weight. Inspection of the coefficients for the different individuals shows also that they are distributed more evenly over the range. That is the coefficient for any individual differs significantly from the coefficients for from twelve to eighteen of the other individuals.

The correlation between egg weight and shell weight is significant for all individuals. It is lower than the correlation between the weight of either of the other parts and the whole, and the variation in the degree of correlation between the different individuals is greater. The egg weight and shell weight correlations range from $.274 \pm .050$ for bird No. 516 to $.752 \pm .023$ for bird No. 204. This is a range of $.478 \pm .055$. Not only is this a wider range than is shown by the coefficients for either of the other parts but the individuals are distributed much more evenly over it.

Thus we see that the weight of each part of the egg is positively correlated to the weight of the whole egg. The weight of the heaviest part, i. e., the albumen, is invariably very closely correlated. The weight of the yolk is also closely correlated, but there is a greater individual difference in the degree of the relationship. The weight of the shell is much less closely correlated and there is even more individual difference in the amount of relationship shown.

Lines four and five of Table 22 give the partial coefficients for the correlation between the weight of the egg and the weight of one of the two heavy parts (albumen and yolk) while the other part remains constant. These coefficients show that in eggs with a constant yolk weight, albumen weight and egg weight are closely correlated. The coefficients for the several individuals do not differ significantly. The same is true for the relationship between yolk weight and egg weight in eggs with a constant albumen. The partial correlation for albumen 
weight and egg weight is slightly higher for every individual but the differences are too small for one to be sure of their significance.

\section{The Correlation of the Parts of the Egg.}

Lines five to seven inclusive of Table 20 give the coefficients for the interrelations of the parts of the egg. In most individuals the two heavier parts, albumen and yolk are more highly correlated with each other than is either of them with shell. In most individuals also the correlation between albumen and shell is higher than between yolk and shell. The range of correlation for each of these pairs of characters in the different individuals extends from insignificance to high positive correlation (.768 \pm .021 for albumen and yolk; .615 \pm .032 for yolk and shell and $.681 \pm .029$ for albumen and shell). A study of the coefficients given in the table shows great individual differences in the degree of correlation between any two parts, and also individual differences in regard to the relationship of the different pairs of parts. As an illustration of the latter point bird No. 459 shows a correlation between yolk and shell which is much higher than the correlations either between yolk and albumen or albumen and shell. Attention has already been called to the fact that for most individuals the correlation between yolk and shell is lower than that between albumen and shell and much lower than that between albumen and yolk. The table presents a number of individual exceptions to the above generalization. These exceptions emphasize the importance of considering relationships from an individual basis.

The partial correlation coefficients between each pair of parts in eggs of the same weight are given in lines six to eight inclusive of Table 22. These partial correlations are all negative. That is in eggs of the same weight any part is negatively related to the weight of both of the other parts. As one would expect this negative correlation is significantly higher for yolk and albumen than for either of these parts and shell. The individual differences between the yolk and albumen partial correlations are not high. The partial correlations between yolk and shell and between albumen and shell both vary greatly. Little more can be determined from these coefficients than the facts that most. of them are significantly negative, and that the variation hetween different individuals in respect to these relationships is great. 
A Biometrical Study of Egg Production in the Domestic Fowl. IV. 269

\section{The Relation Between the Dimensions and Shape of the Egg and the size of the Parts.}

A study of the correlation coefficients for egg weight with length, breadth and index respectively has shown a) that both breadth and length are highly positively correlated with egg weight; and b) that for most individuals breadth is more highly correlated than length. The correlation between index and weight when significant is negative and is never very high.

These same relations are true for the correlation of the weight of any part of the egg and length, breadth and index. The actual values of the coefficients and the number of individuals which show these relationships to a certainly significant degree depend upon the absolute size of the part, that is they are highest for albumen and lowest for shell.

The lower half of Table 20 gives the coefficients for length, breadth and index with each part (albumen, yolk and shell). These coefficients show that length and breadth are positively correlated with the weight of each part. In general breadth is more highly correlated than length. The coefficients for the different characters range as follows:

Breadth albumen

From .563 \pm .047 (Bird No. 514)

To $.901 \pm .010$ (Bird No. 192)

Breadth-yolk

From .349 \pm .060 (Bird No. 514)

To $.878 \pm .010$ (Bird No. 218)

Breadth-shell

From $.159 \pm .048$ (Bird No. 516)

To .623 上.033 (Bird No. 204)
Length-albumen

From .543 t. .062 (Bird No. 459)

To $.836 \pm .013$ (Bird No. 218)

Length-yolk

From .265 \pm .082 (Bird No.459)

To $.817 \pm .016$ (Bird No.446)

Length-shell

From $.040 \pm .050$ (Bird No. 516)

To $.557 \pm .036$ (Bird No. 259)

A comparison of these, or a study of all the coefficients given in the table, shows that both breadth and length are positively correlated with albumen, yolk and shell.

When the index correlation with any part is significant it is negative. In the case of each part it is significant for less than half the individnals and ranges from insignificance to $-.462 \pm .035$ (Bird No. 218) for albumen, -.47j \pm .038 (Bird No. 446) for yolk, and $-.397 \pm .037$ (Bird No. 218) for shell.

The albumen and breadth correlation is significantly higher than 
that for albumen and length for about one-half of the individuals. In none of the individuals is it significantly smaller. The yolkbreadth correlation is also significantly larger than the yolk-length correlation for about one-half of the flock. The reverse relation is, however, significant in one or two individuals. These are the same individuals, birds No. 514 and No. 446, whose length-weight correlations were significantly higher than their breadth-weight correlations. The difference between shell-breadth and shell-length correlation coefficients is certainly significant for only four or five individuals and in these eases it is positive. Length and breadth then are both positively correlated with the weight of any part. Breadth is significantly more highly correlated than length for some of the individuals of the flock. Index is significantly negatively correlated with the weight of the parts in some individuals. The index correlations are never positively significant and are never large.

The relative degrees of correlation of each dimension with the different parts of the egg are as follows:

1) Both length and breadth are much less highly correlated with weight of shell than with weight of yolk or albumen.

2) For fire individuals (Nos. 259, 459, 514, 478, and 192) the breadth-albumen coefficient is higher than the breadth-yolk coefficient to a degree which is certainly significant, that is the difference is more than three times the probable error. In one individual (No. 516) the breadth-yolk coefficient is possibly significantly higher.

3) Three individuals show a length-albumen coefficient which may be significantly higher than the length-yolk coefficient. None of the flock show the reverse relation to a significant degree.

4) The index correlations are significant for but few individuals and often then not in all three characters in the same individual. It is therefore impossible to determine any general relationship between these correlations for the different parts.

Length or breadth is more highly correlated both with albumen and yolk than with shell. The correlations with albumen are significantly higher than those with yolk in several individnals while the reverse is true in only one case. The parts arranged in the order of closest correlation with either dimension are albumen, yolk and shell. This is the order of the weight of the parts.

The last half of Table 22 gives for the ten highest laying birds the partial correlation coefficients for the dimensions and the weight 
A Biometrical Study of Egg Production in the Domestic Fowl. IV. 271

of the parts when the weight of the eggs are constant. A large number of these correlations are not significant and the different individuals show a great deal of variation in the interrelationships. The most general tendency exhibited in the relationship of the dimensions to weight of the parts in eggs of the same weight is for breadth to be positively correlated with yolk and negatively correlated with albumen and shell.

\section{Summary.}

1) Different pairs of egg characters show a decided difference in the degree of correlation.

2) There is a general tendency for a given pair of characters to be similarly related in the eggs of the several individuals.

3) Individuals, however, show significantly different degrees of correlation in any pair of characters. The range of the individual variation is wider and the number of individuals which differ significantly from each other is larger for some pairs of characters than for others.

4) Length and breadth are positively but not highly correlated.

5) Both length and breadth are highly positively correlated with weight.

6) Breadth-weight correlation is as a rule higher than lengthweight correlation but an individual may show the reverse relation.

7) Index and weight correlation when significant is negative and low.

8) The relation between length and breadth, length and weight, and index and weight is much closer within the eggs of an individual than within the eggs of the strain, but breadth and weight are as closely related within the eggs of the strain as within the eggs of an individual.

9) In eggs of the same weight the two dimensions are negatively correlated but the degree of correlation varies greatly in the different individuals.

10) Either dimension is highly correlated with weight when the other dimension is constant. The correlation between breadth and weight is higher than the correlation between length and weight. The individual variations are less than in the gross correlations or in the correlations between length and breadth in eggs of the same weight.

11) The weight of each of the three parts of the egg (albumen, 
yolk and shell) is positively correlated with egg weight. The heaviest part, albumen, is invariably very closely correlated. Yolk is also closely correlated but there is a greater individual variation in the value of the coefficients. Shell, the lightest part, is much less closely correlated and the individual differences are much greater than in the case of the two heavier parts.

12) The correlation between either of the two large parts and the whole egg when the other part remains constant is high and shows insignificant individual differences. The albumen-weight correlation is slightly ${ }^{1}$ ) higher than the yolk-weight correlation.

13) The correlation between albumen and yolk is higher than the correlation between either of these and shell. In general the albumen shell correlation is higher than that for yolk and shell. 'The range of correlation for any of these pairs of characters, however, varies in different birds from insignificance to high correlation.

14) In eggs of the same weight any two parts are negatively correlated. The yolk-albumen correlation is highly negative and the different individuals show little variation in the value of the coefficient. The yolk-shell and albumen-shell correlations are significantly negative for most individuals but the value of the coefficients for the different indiyiduals varies greatly.

15) Length and breadth are positively correlated with the weight of each part of the egg. When there is a significant difference between the correlation of length and any part and the correlation of breadth and the same part the breadth correlation is higher ${ }^{2}$ ). There is, however, a great deal of individual variation in the degree of these relationships.

16) Albumen and yolk correlations with either dimension are higher than the shell correlation. Albumen correlations are significantly higher than yolk correlations for several individuals. The reverse is true in only one case.

17) In eggs of the same weight the correlation of either dimension with any part is often not significant. The different birds show a great deal of variation in these coefficients. The most usual relationship is for breadth to be positively correlated with yolk and negatively correlated with albumen and shell.

1) This difference may not be significant.

2) There are two exceptions to this statement. See p. 270 . 


\section{Part III.}

\section{An Analysis of the Variation Among the Eggs of the Same Bird.}

It has been shown in Part I that while the eggs of an individual resemble each other more closely than do eggs forming a random sample from other birds of the same strain, there is nevertheless a high degree of variation among them. This variation is appreciable in every egg character but the several characters show it in decidedly different degrees. The means of the individual coeffcients of variation given in Table 13 are repeated here.

\section{Table 23. Showing the Mean of the Individual Coefficients} of Variation for Each Egg Character.

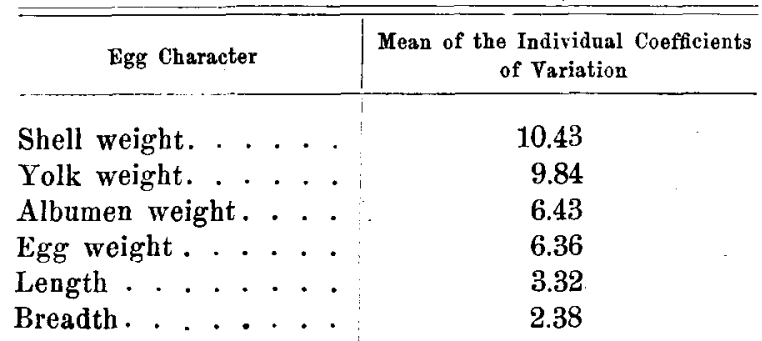

The purpose of the present part of the paper is to investigate further this variation among the eggs of the individual.

The fact that the first eggs of young pullets are smaller than those laid later has long been known. In Part I it was shown that the birds which did not lay throughout the year laid quite uniform eggs, although when the birds were laying throughout the year the degree of variation was not significantly related to the number of eggs laid. Attention was then called to the fact that there was a seasonal variation in the eggs.

The data collected in the present investigation offer material for the study of the following phases of the variation in the eggs of the individual. First the variation due to the age or maturity of the bird, second that due to the seasonal distribution of the laying, third that due to the general physiological condition, i. e., health of the bird, fourth variation due to the tendency of the birds to lay in litters and fifth that related to the tendency to lay in smaller groups or clutehes. 


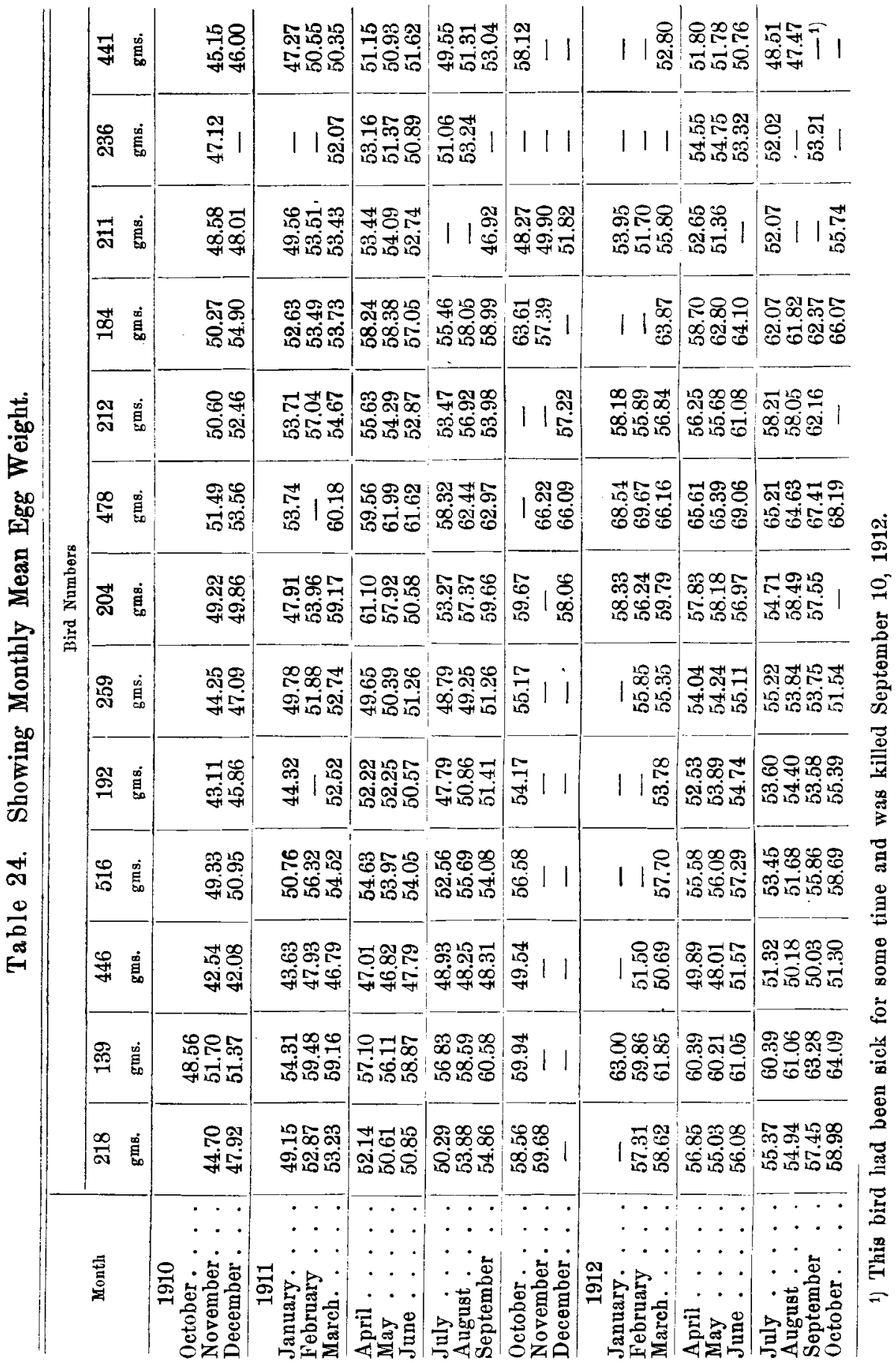




\section{The Variation Related to the Age or Maturity of the Bird.}

The data used in this study are the measurements taken on all the eggs laid by each of the twelve birds which lived and continned to lay throngh two years. To illustrate certain points it is possible to supplement this with the data on the eggs of other birds which did not complete their second year.

The progressive change in egg weight associated with the maturity of the bird is shown by the monthly mean egg weight. Table 24 gives for each individual the mean weight of the eggs laid during each month of the two years. In order to show the number of eggs upon which each mean in based Table 25 showing the monthly egg production of each bird is also inserted here.

Table 25. Showing the Monthly Egg Production.

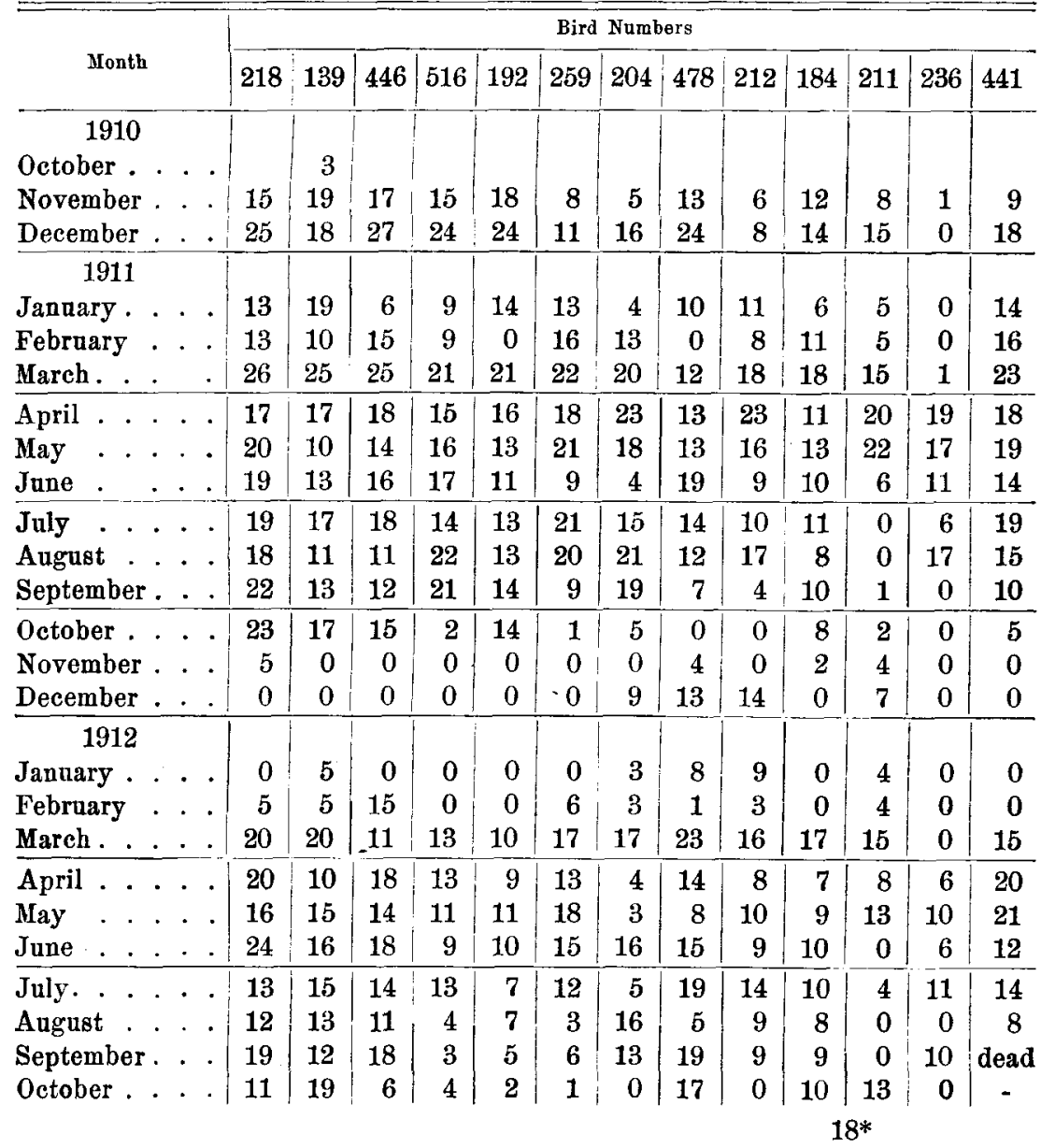


Inspection of Table 24 shows that in the case of each individual the egg weight at the end of the second year is decidedly greater than at the beginning of the first year. It also shows that with very few exceptions the egg weight for a given month in the second year is higher than that for the same month during the first year. The general tendency of the change in weight is best understood by representing graphically the monthly mean egg weight. These graphs were made for each of the twelve birds. They show slight differences in detail but in general are very similar. For the sake of economy of space only two (those for the two highest laying birds No. 218 and No. 139) are reproduced here. Similar diagrams can be made for any bird from the data given in the table.

These diagrams also show the monthly egg production plotted from the data given in Table 25 .

These diagrams show that from the beginning of laying until the beginning of the first breeding season the eggs increase rapidly in size. From this time on the weight of the egg is subject to quite perceptible seasonal fluctuations which will be discussed later; but the eggs of the second year are decidedly larger than the eggs of the corresponding months of the first year. That is the eggs of a bird continue to increase in weight with the increased maturity of the bird at least up to the end of the second laying year. After the beginning of the first breeding season the increase in weight is much slower than during the few months which precede.

This fact that the age of the female is related to the size of the egg she produced is in agreement- with results obtained by HALBAN ${ }^{1}$ ) for frogs, fishes, salamanders and turtles. This author also found that the increased egg weight was associated with an increase in the size of the young which developed from them. He suggests that a progressive growth of the ovarian eggs with the advance in age of a female may also account for the increase in birth weight of man ${ }^{2}$ ) and other mammals ${ }^{3}$ ) associated with an advance in the age of the mother.

1) Halban, Josef, Die Größenzunahme der Eier und Neugeborenen mit dem fortschreitenden Alter der Mütter. Arch. f. Entw.-Mech. Bd. 29. 1910. S. $439-455$.

2) Hecker, Monatsschr. f. Geburtskunde. Bd. 26. S. 348.

Hecker und BuHL, Klinik d. Geburtskunde. Leipzig 1861.

Dunchan, Edinburgh, Med. Journal. 1864. p. 497.

3) Wernich, Beitr. z. Geburtsh. u. Gyn. 1872. 
A Biometrical Study of Egg Production in the Domestic Fowl. IV. 277

Fig. 1.

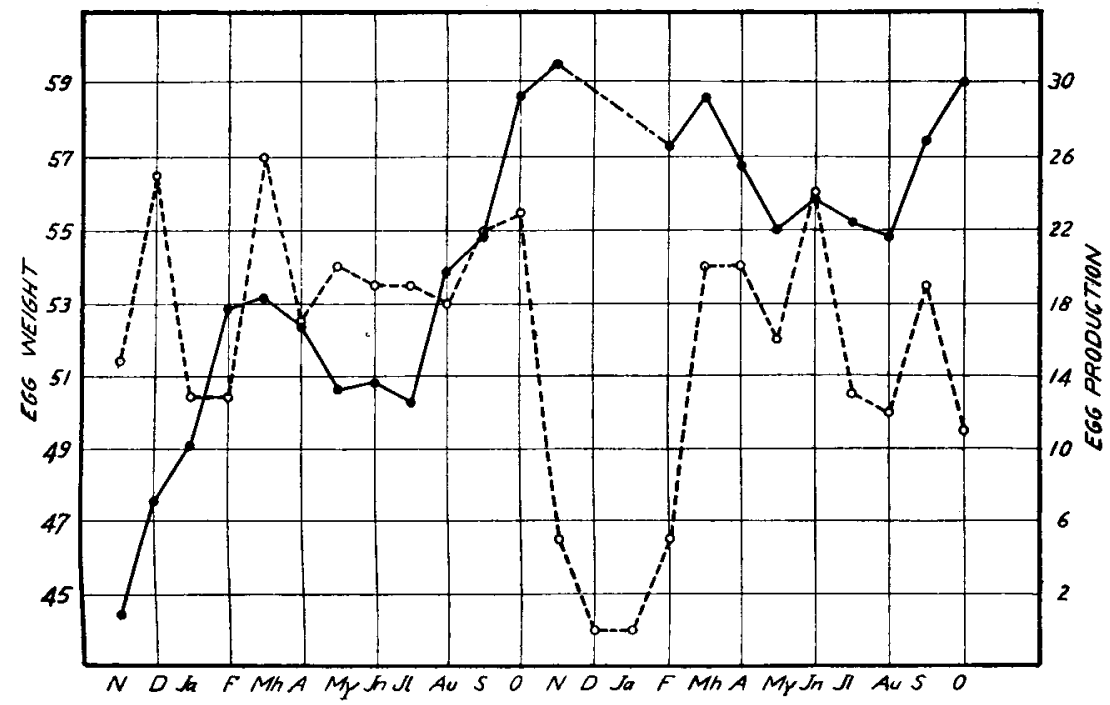

Diagram showing for bird No. 218 the mean egg weight and the number of eggs laid for each month from the beginning of the pullet laying year until the end of Oetober of the second year. The solid line represents the monthly mean egg weight and the dotted line the monthly production.

Fig. 2.

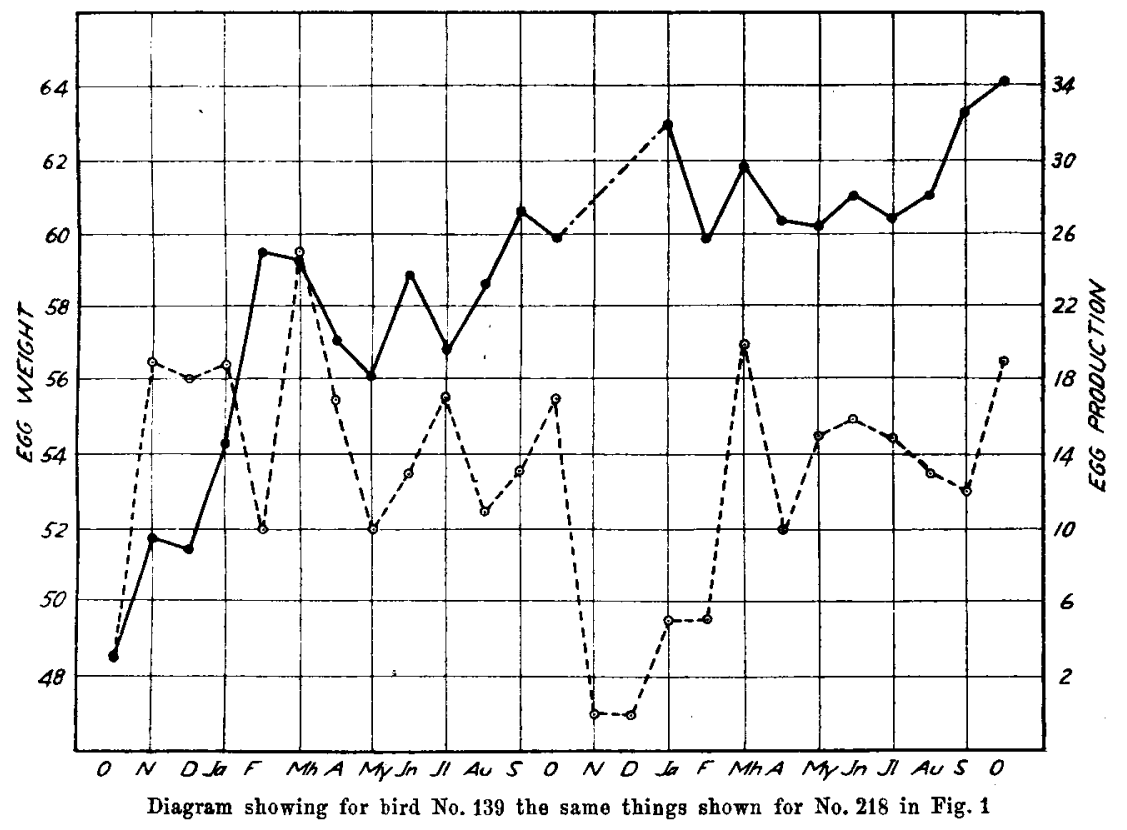


Figures 1 and 2 do not demonstrate a relationship between the number of eggs laid during the month and the mean weight. It must be kept clearly in mind that this does not preclude a relationship between the rate of fecundity and the weight of the egg, for the number of eggs laid during the month is often not an accurate measure of the rate of fecundity during the time in which the eggs were produced. For example bird No. 218 did not lay from January 2 until February 12. That is the thirteen eggs laid in February were laid during the last seventeen days. Bird No. 139 did not lay from January 31 to February 16. All ten February eggs were laid in thirteen days. In both these cases the rate of fecundity measured by the number of eggs laid during the calendar month is much below the true rate of fecundity which obtained during the production of the eggs. A more accurate measure of the rate of fecundity must be used in a study of the relation between this and egg size. The monthly production curves given here are chiefly useful in showing the number of eggs upon which the mean weight is calculated.

The weight of the egg is made up of the weight of the three parts albumen, yolk and shell. Each of these parts are also variable in weight. In fact, each is more variable than the weight of the whole egg.

A study of the progressive change in each of these parts can be made in a manner similar to the above study of egg weight. Table 26 gives the monthly mean yolk weights for each individual.

These monthly means show even more uniformly than the weight of the whole egg that the weight increases rapidly to the beginning of the first breeding season and from that time on more slowly. The yolk weight shows the seasonal fluctuations shown by the egg weight; but their magnitude is smaller.

Figures 3 and 4 show the monthly mean yolk weights for bird No. 218 and bird No. 139.

These diagrams resemble to some extent the diagrams for egg weight for the same birds (Figures 1 and 2). Since the yolk weight is about one-third the weight of the egg this resemblance would be expected. The fluctuations are in general smaller. There are two or three exceptions to this, the most evident of which is the yolk weight for December 1910 of bird No. 139. This mean is a just representation of the facts for this bird and month; the low mean is not due to a few abnormally small yolks. During the month this bird laid eighteen eggs and these eggs had yolks which ran smaller 
A Biometrical Study of Egg Production in the Domestic Fowl. IV. 279

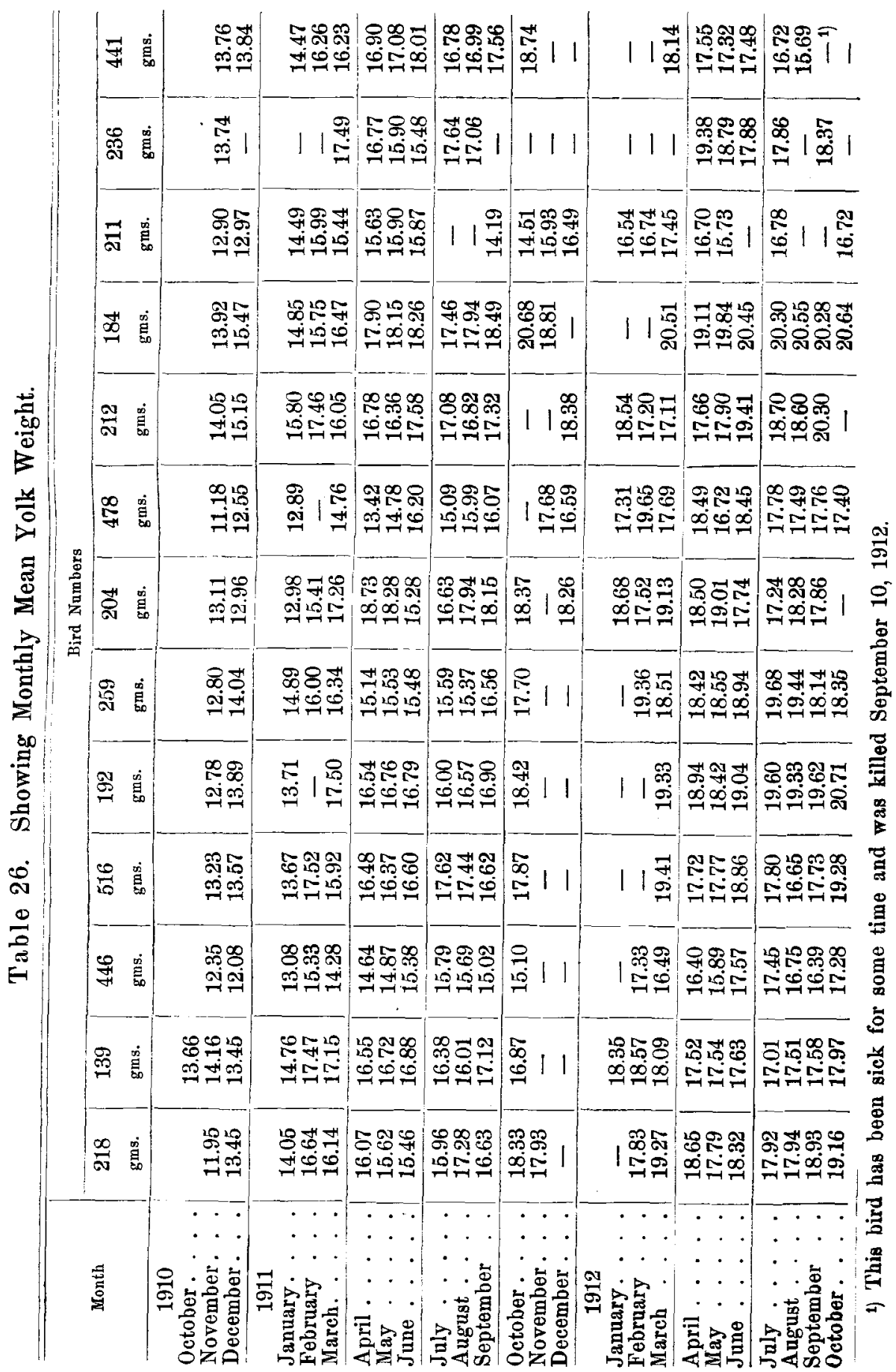


than those of the preceding or following months. On the other hand the albumen weight increased in nearly the normal manner. Therefore, the egg weight decreased proportionately less than the yolk

Fig. 3.

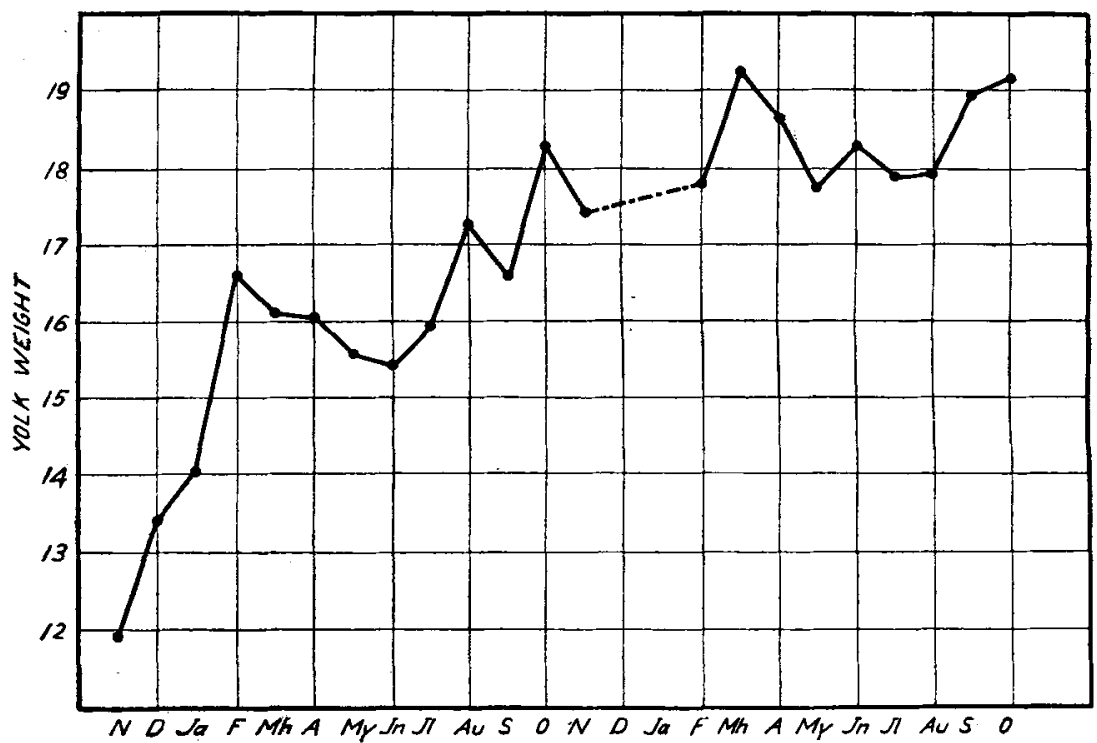

Diagram showing the monthly mean yolk weight for bird No. 218.

Fig. 4.

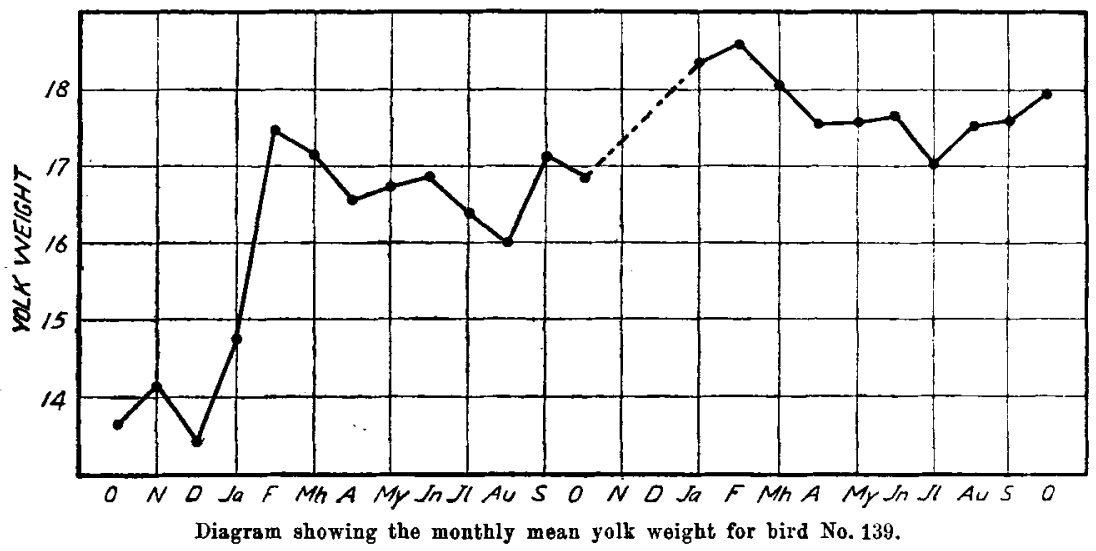

weight. With our present lack of knowledge of the factors which determine the quantitative limits of yolk deposition and albumen secretion we can only suggest that this irregularity is due to some 
A Biometrical Study of Egg Production in the Domestic Fowl. IV. 281

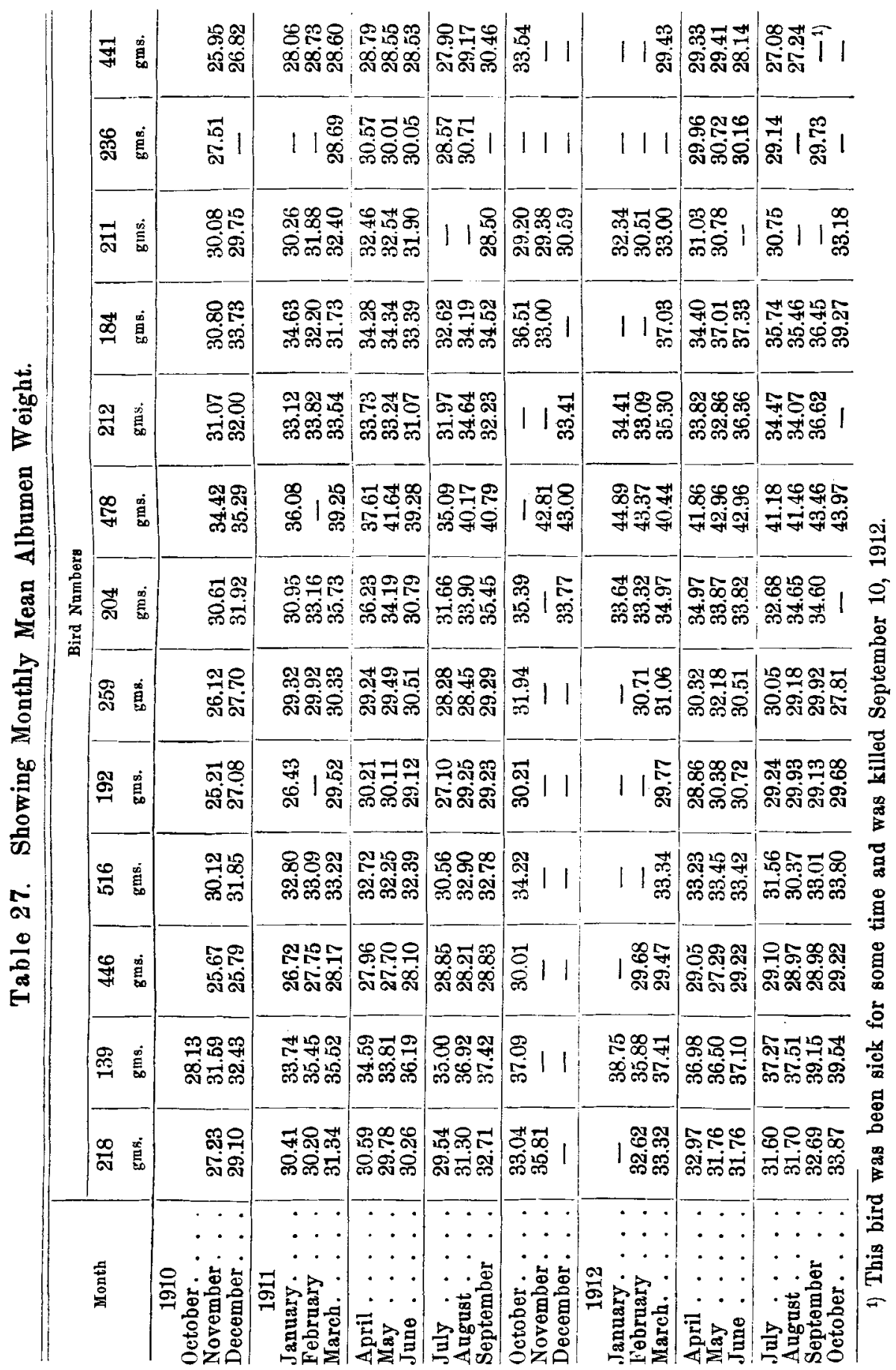


Fig. 5.

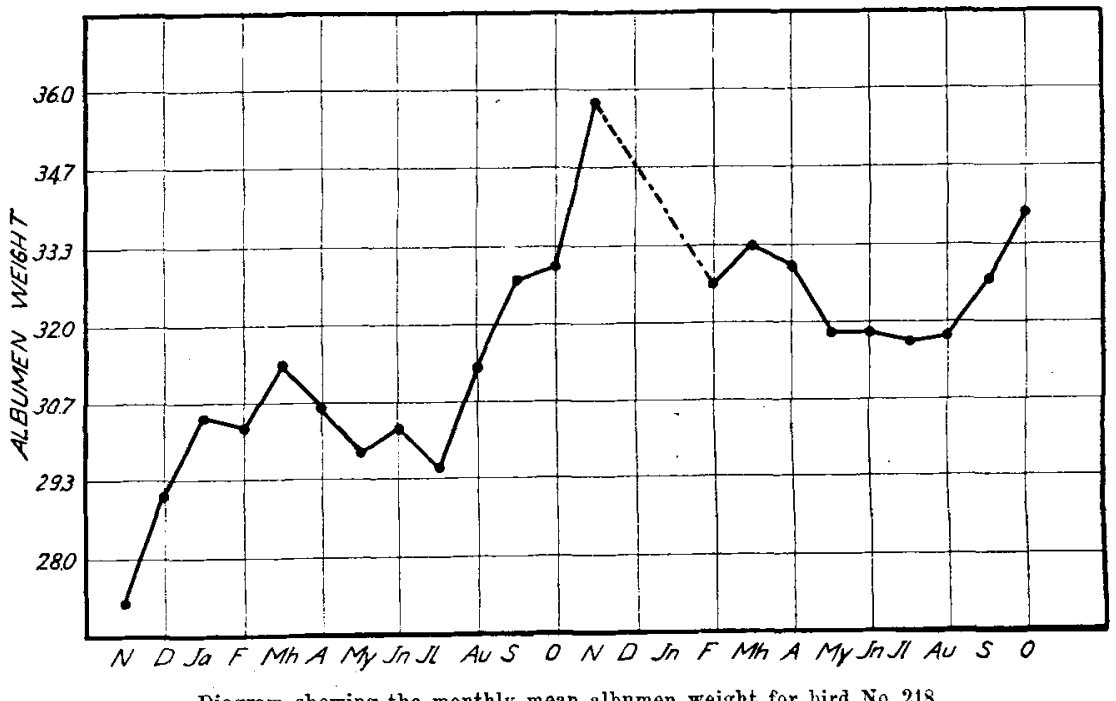

Diagram showing the monthly mean albumen weight for bird No. 218.

Fig. 6.

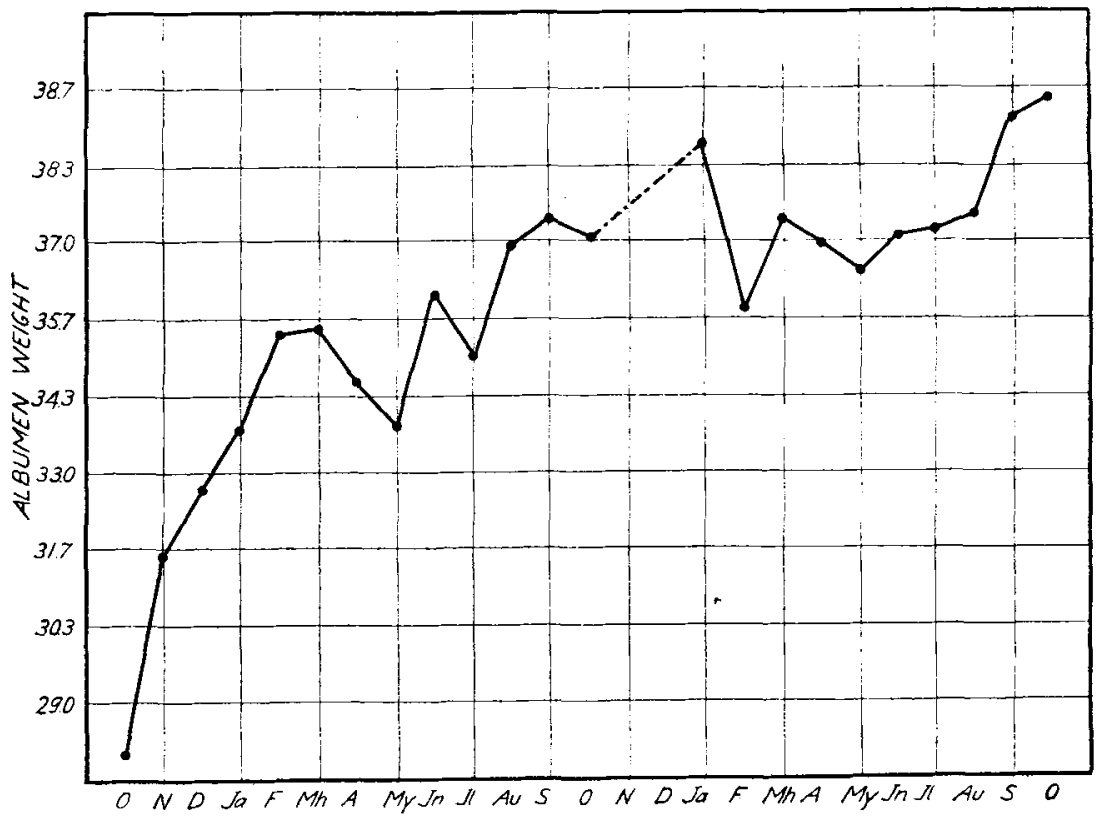

Diagram shoring the monthly mean albumen weight for bird No. 139 . 
A Biometrical Study of Egg Production in the Domestic Fowl. IV. 283

local disturbance of the physiological processes involved in yolk formation.

The monthly mean albumen weight for each individual is given in Table 27.

These means show a less abrupt rise during the first three months and greater seasonal fluctuations than the monthly mean egg weights or yolk weights. In general howerer they show an increase in albumen weight with an increase in the age of the bird.

Figures 5 and 6 show the monthly mean albumen weight for the two birds No. 218 and No. 139.

These diagrams resemble those showing the monthly mean egg weight for the same individuals (Figures 1 and 2) more closely than do those of yolk weight. This is due to the fact that the albumen weight is about 60 percent of the egg weight. The seasonal fluctuations of albumen weight and yolk weight show some decided differences which will be discussed later.

The monthly mean shell weight for each individual is given in Table 28.

These means are larger for the second than for the first year but they show a variation large in proportion to their actual size. This variation is usually related to the variation shown by the other parts but may be independent and in the opposite direction. For example during the first three months laying all but one of the birds show a decrease in shell weight which is as decided as the increase in the weight of the other two parts.

Figures 7 and 8 show the monthly mean shell weight for the birds No. 218 and 139.

In order to generalize the study of the increase in the weight of egg and of each of its parts as the bird grows older it is desirable to bring together the results of the study on the individual birds.

The birds used in this investigation form a more homogeneous group than is often available for statistical work. They were "purebred $\alpha$ in the fancier's sense and line-bred, and were within a few weeks of the same age. They had lived under the same environmental conditions since hatching and they began to lay at very nearly the same time. As stated above there are only slight differences between the diagrams of the same weight character for the several birds. 
The material has been brought together by calculating directly for each weight character the monthly means of all the eggs laid by the twelve birds.

Fig. 7.

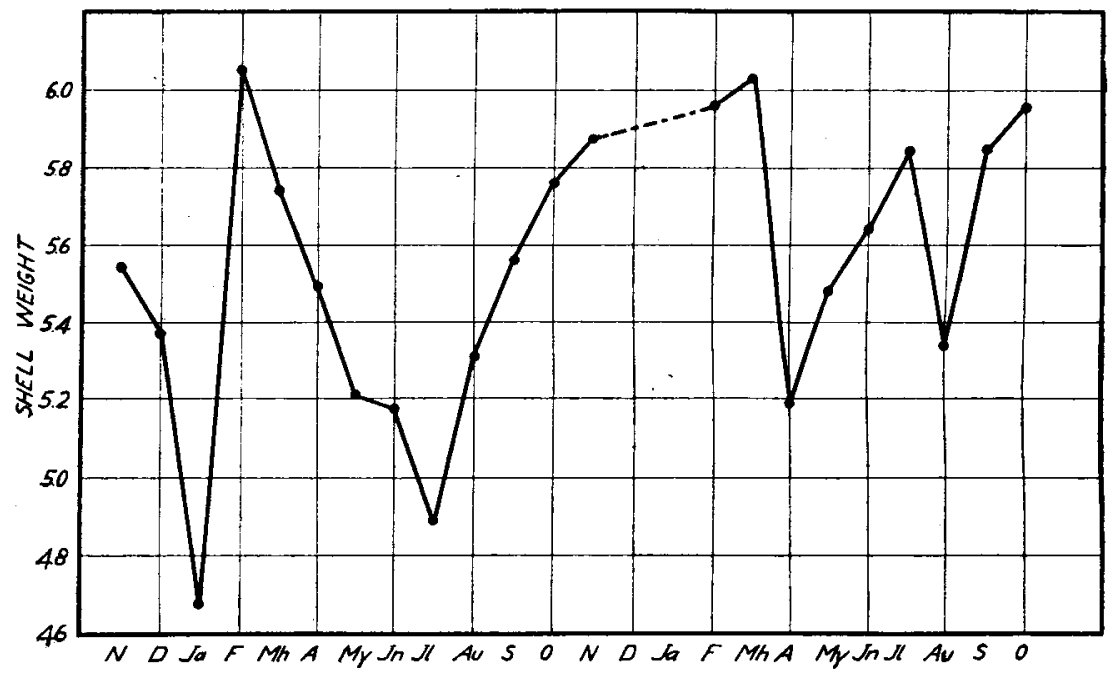

Diagram showing the monthly mean shell weight for bird No. 218.

Fig. 8.

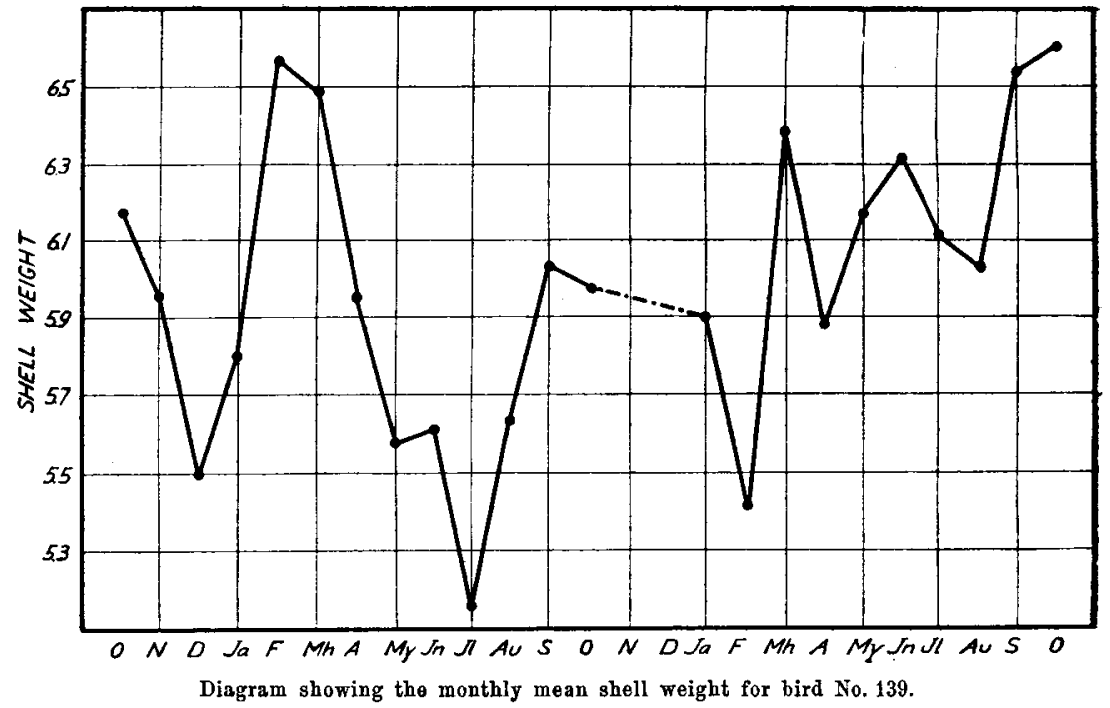

The means are given in Table 29.

The flock means given in this table show the same points brought out in the discussion of the means for the individuals, but the gaps 
A Biometrical Study of Egg Production in the Domestic Fowl. IV. 285

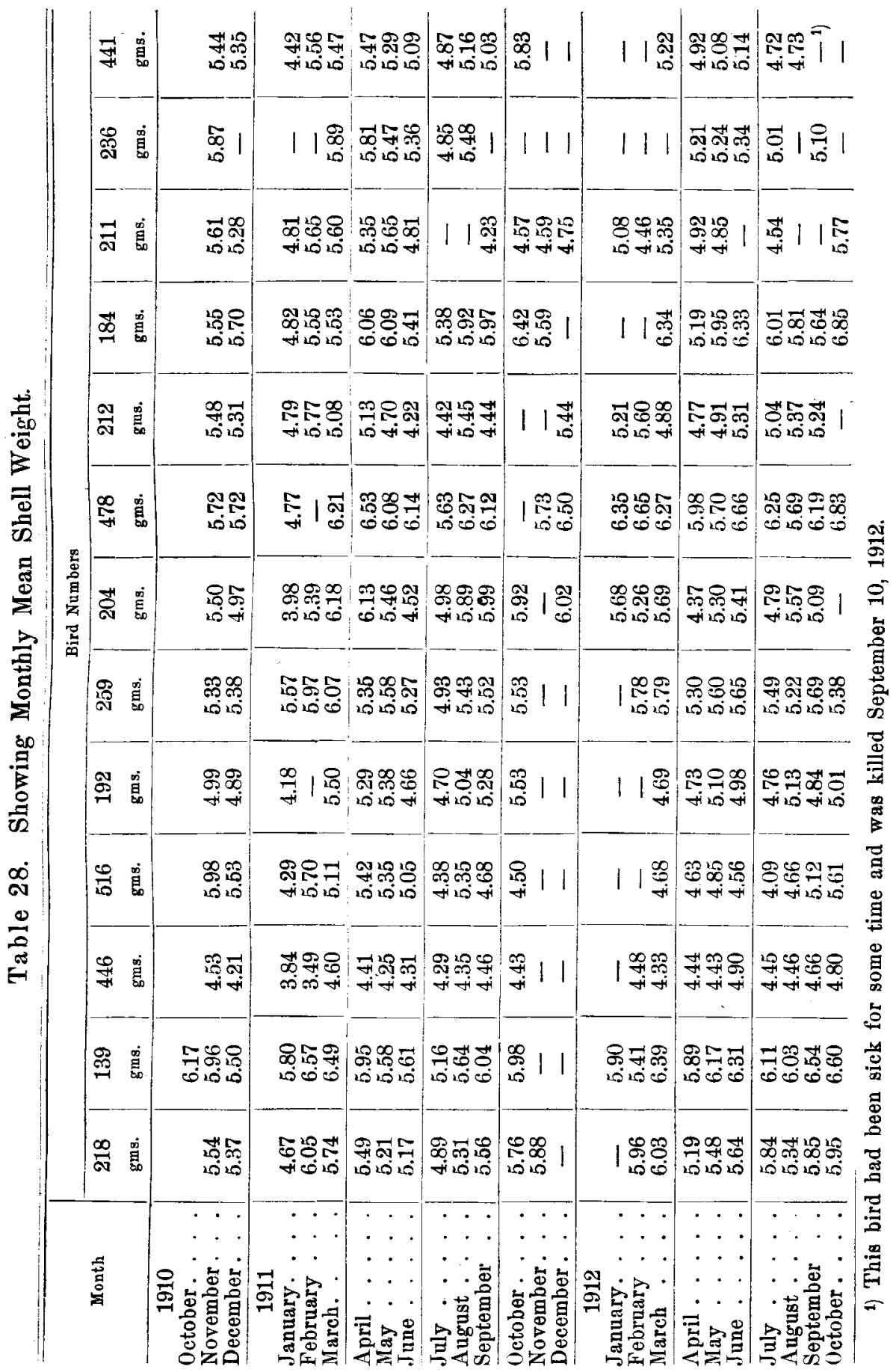


Table 29. Showing for Each Month the Number of Birds Laying, the Number of Eggs Laid and the Mean Egg Weight, Yolk Weight, Albumen Weight and Shell Weight for the Twelve Birds which Completed Their Second Year.

\begin{tabular}{|c|c|c|c|c|c|c|c|}
\hline Month & $\begin{array}{c}\text { No. } \\
\text { birds } \\
\text { laying }\end{array}$ & $\begin{array}{l}\text { No. } \\
\text { eggs } \\
\text { laia }\end{array}$ & $\begin{array}{c}\text { IIean egg } \\
\text { weight } \\
\text { gms. }\end{array}$ & $\begin{array}{c}\text { Mean yolk } \\
\text { weight } \\
\text { gms. }\end{array}$ & $\begin{array}{c}\text { Mean } \\
\text { albumen } \\
\text { weight } \\
\text { gms. }\end{array}$ & $\begin{array}{c}\text { Mean shell } \\
\text { weight } \\
\text { gms. }\end{array}$ & $\begin{array}{c}\text { Mean } \\
\text { temperature } \\
\text { in degrees } F\end{array}$ \\
\hline \begin{tabular}{l}
\multicolumn{1}{c}{1910} \\
October. . . \\
November . \\
December. .
\end{tabular} & $\begin{array}{r}1 \\
12 \\
11\end{array}$ & $\begin{array}{r}3 \\
137 \\
206\end{array}$ & $\begin{array}{l}48.56 \\
47.48 \\
48.99\end{array}$ & $\begin{array}{l}13.66 \\
12.87 \\
13.39\end{array}$ & $\begin{array}{l}28.13 \\
29.11 \\
30.38\end{array}$ & $\begin{array}{l}6.17 \\
5.46 \\
5.22\end{array}$ & $\begin{array}{l}48.40 \\
34.95 \\
19.55\end{array}$ \\
\hline \begin{tabular}{l}
\multicolumn{1}{c}{1911} \\
January . . \\
February . . \\
March . . .
\end{tabular} & $\begin{array}{l}12 \\
10 \\
12\end{array}$ & $\begin{array}{l}110 \\
100 \\
224\end{array}$ & $\begin{array}{l}50.37 \\
53.53 \\
54.25\end{array}$ & $\begin{array}{l}14.24 \\
16.27 \\
16.18\end{array}$ & $\begin{array}{l}30.88 \\
30.94 \\
32.46\end{array}$ & $\begin{array}{l}4.84 \\
5.37 \\
5.63\end{array}$ & $\begin{array}{l}18.15 \\
14.56 \\
25.20\end{array}$ \\
\hline $\begin{array}{l}\text { April. . . . } \\
\text { May . . . } \\
\text { June . . . . }\end{array}$ & $\begin{array}{l}12 \\
12 \\
12\end{array}$ & $\begin{array}{l}210 \\
193 \\
144\end{array}$ & $\begin{array}{l}54.42 \\
53.73 \\
53.66\end{array}$ & $\begin{array}{l}16.43 \\
16.23 \\
16.25\end{array}$ & $\begin{array}{l}32.48 \\
32.12 \\
32.23\end{array}$ & $\begin{array}{l}5.54 \\
5.39 \\
5.13\end{array}$ & $\begin{array}{l}40.90 \\
59.25 \\
62.30\end{array}$ \\
\hline $\begin{array}{l}\text { July . . . } \\
\text { August. . } \\
\text { September . }\end{array}$ & $\begin{array}{l}11 \\
11 \\
11\end{array}$ & $\begin{array}{l}158 \\
170 \\
132\end{array}$ & $\begin{array}{l}52.22 \\
54.75 \\
55.44\end{array}$ & $\begin{array}{l}16.31 \\
16.72 \\
16.88\end{array}$ & $\begin{array}{l}30.83 \\
32.53 \\
33.13\end{array}$ & $\begin{array}{l}4.87 \\
5.46 \\
5.41\end{array}$ & $\begin{array}{l}71.20 \\
66.20 \\
57.20\end{array}$ \\
\hline $\begin{array}{l}\text { October. } \\
\text { November } \\
\text { December }\end{array}$ & $\begin{array}{l}9 \\
4 \\
4\end{array}$ & $\begin{array}{l}86 \\
15 \\
43\end{array}$ & $\begin{array}{l}56.68 \\
58.51 \\
59.20\end{array}$ & $\begin{array}{l}17.61 \\
17.41 \\
17.50\end{array}$ & $\begin{array}{l}33.23 \\
35.57 \\
35.93\end{array}$ & $\begin{array}{l}5.55 \\
5.43 \\
5.77\end{array}$ & $\begin{array}{l}46.10 \\
34.40 \\
28.00\end{array}$ \\
\hline \begin{tabular}{l}
\multicolumn{1}{c}{1912} \\
January . . \\
February . . \\
March . . .
\end{tabular} & $\begin{array}{r}5 \\
8 \\
11\end{array}$ & $\begin{array}{r}29 \\
39 \\
179\end{array}$ & $\begin{array}{l}61.30 \\
54.73 \\
59.03\end{array}$ & $\begin{array}{l}17.90 \\
17.85 \\
18.46\end{array}$ & $\begin{array}{l}37.72 \\
31.88 \\
34.71\end{array}$ & $\begin{array}{l}5.67 \\
5.08 \\
5.68\end{array}$ & $\begin{array}{l}10.90 \\
17.70 \\
27.00\end{array}$ \\
\hline $\begin{array}{l}\text { April. . . } \\
\text { May . . . } \\
\text { Jnne . . . }\end{array}$ & $\begin{array}{l}12 \\
12 \\
11\end{array}$ & $\begin{array}{l}130 \\
138 \\
148\end{array}$ & $\begin{array}{l}56.12 \\
55.63 \\
58.10\end{array}$ & $\begin{array}{l}17.47 \\
17.71 \\
18.45\end{array}$ & $\begin{array}{l}33.10 \\
33.47 \\
34.30\end{array}$ & $\begin{array}{l}5.08 \\
5.31 \\
5.62\end{array}$ & $\begin{array}{l}43.50 \\
57.10 \\
63.80\end{array}$ \\
\hline $\begin{array}{l}\text { July . . . } \\
\text { August . . } \\
\text { September . } \\
\text { October. . . }\end{array}$ & $\begin{array}{r}12 \\
10 \\
11 \\
9\end{array}$ & $\begin{array}{r}137 \\
88 \\
123 \\
83\end{array}$ & $\begin{array}{l}56.97 \\
57.16 \\
58.46 \\
61.64\end{array}$ & $\begin{array}{l}18.31 \\
18.16 \\
18.19 \\
18.19\end{array}$ & $\begin{array}{l}33.46 \\
33.61 \\
34.69 \\
37.20\end{array}$ & $\begin{array}{l}5.32 \\
5.39 \\
5.53 \\
6.23\end{array}$ & $\begin{array}{l}67.20 \\
62.50 \\
57.50 \\
49.80\end{array}$ \\
\hline
\end{tabular}

are filled in and the irregularities are reduced, so that the lines plotted from the flock data show more clearly the relationship between the weight of the egg or its parts and the age of the bird. 
A Biometrical Study of Egg Production in the Domestic Fowl. IV. 287

From this table it is seen that in the case of the tlock, as in the case of individual birds, the yolk weight increases more constantly than the weight of the other two parts or of the whole egg. That is it shows smaller irregular fluctuations. The change of the flock monthly mean yolk weight in the successive months of life is shown by the irregular curve in Figure 9 .

This observation curve rises rapidly at the start, turns sharply and then continues to rise gradually. This suggests that the increase in yolk weight is following a logarithmic curre of the form

Fig. 9.

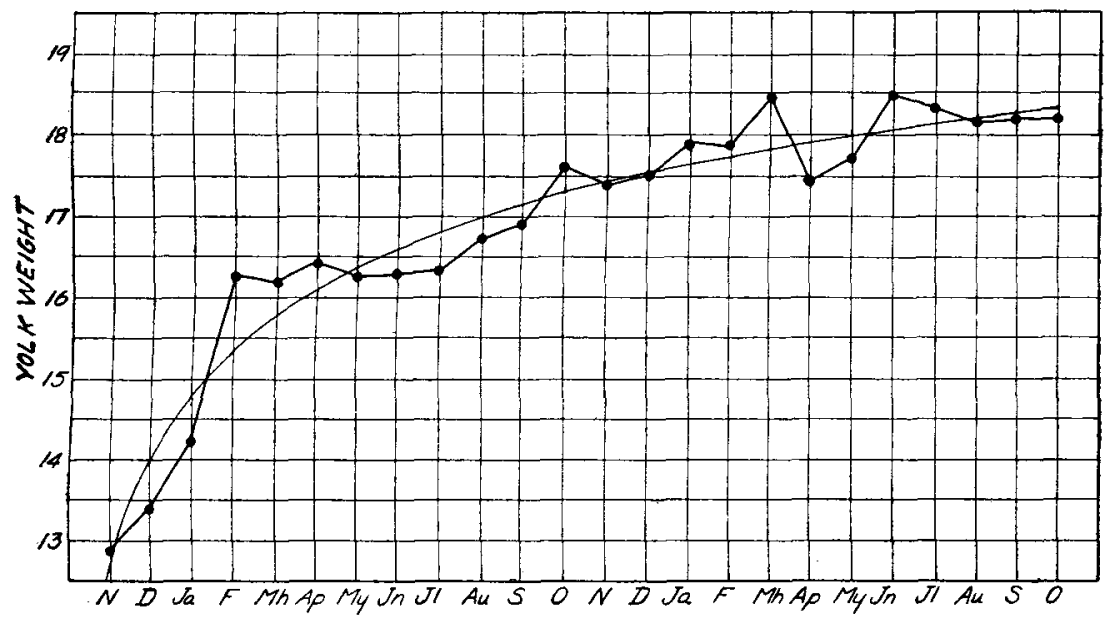

Diagram showing the observed monthly mean yolk weight for twelve Barred Plymouth Rock birds from the beginning of laying to the end of the second year, and the smooth curve of the type $y=A+B x+C$ $\log x$ fitted to the observations by the method of least squares. Irregular line gives the observations, and the smooth line the theoretical curve.

$y=A+B x+C \log x$ where $y=$ yolk weight, $x=$ time, and $A$, $B$ and $C$ are constants. This type of curve was fitted as a first trial.

In determining the constants for this equation by the method of least squares a great amount of labor was saved by the use of ELDERTONs 1) tables of the sums of powers of natural numbers, and of Pearl and McPherers ${ }^{2}$ ) tables of the sums of the logarithms and logarithmic functions of natural numbers.

1) Eldoerton, W. P., Tables of Powers of Natural Numbers and of the Sums of Powers of Natural Nambers from 1-100. Biometrika. Vol. 2. 1903. pp. $474-480$.

2) Pearl, R., and McPheters, L. A., A Note on Certain Biometrical Computations. The American Naturalist. Vol. 45. 1911. pp. 756-760. 
The resulting curve is

$$
y=12.6728-.0261 x+4.5669 \log x .
$$

The ordinates of this curve were calculated and plotted. This resulted in the smooth curve shown in Figure 9. The excellence with which this fits the data indicates that the increase in weight of the egg yolk in these birds is in fact expressed analytically by this logarithmic curve. In other words this shows that the mean yolk weight increases with each successive month from the beginning of laying at least to the end of the second year but the rate of increase diminishes with the successive months.

The data on which these calculations were based were taken from the eggs of birds which began to lay at an age of from five and one-half to six and three-fourths months. It is interesting to know the size of the egg yolks at the beginning of laying and the direction and rate of change in yolk weight when a bird is older or younger than this at the time she begins to lay. For this reason three birds that began to lay February 23 were added to the individuals under investigation. These birds were eight and threefourths to nine months old, i. e., they were from two to three and one-half months older than those pullets just discussed. It is not so easy to investigate pullets which begin to lay younger, as the Barred Plymouth Rocks, at least under the methods of hatching and handling employed at this Station, rarely lay before they are five months old. However data can be given on the first ten eggs of one pullet which began to lay when she was exactly three months old.

This pullet was a pure-bred Barred Plymouth Rock of a fancy strain belonging to Mr. Walter Gerald of Unity, Maine. She was hatched February 25, 1912. On May $25 \mathrm{Mr}$. Gerald found her laying and gave her a nest. She laid also on the 26 th. On the 27 th Mr. Gerald offered to present her to the Maine Agricultural Experiment Station, in order that records and data might be preserved. It was impracticable at that time to accept his offer. We are pleased to express our gratitude to Mr. GERALD for this courteous offer, and also for forwarding to us the records and the eggs laid by this bird up to June 9.

Mr. GERALD's letter of May 27 states that the pullet weighed three pounds and had not yet moulted her chicken feathers. On June 13 nine of the first ten eggs laid by this bird were received from Mr. Geralu. The other egg was soft shelled and could not 
A Biometrical Study of Egg Production in the Domestic Fowl. IV. 289 be sent. Plate VIII is a photograph of these eggs. The data are given in Table 30 .

Table 30. Table Showing the Data Taken June 13, 1912, on Eggs Laid by a Three Months Old Pulled Owned by Mr. Walter Gerald, Unity, Maine.

\begin{tabular}{|c|c|c|c|c|c|c|c|}
\hline $\begin{array}{l}\text { Egg } \\
\text { No. }\end{array}$ & Date 1912 & $\begin{array}{l}\text { Length } \\
\mathrm{mm} \text {. }\end{array}$ & $\begin{array}{c}\text { Breadth } \\
\mathrm{mm} .\end{array}$ & $\begin{array}{l}\text { Weight } \\
\text { of Egg } \\
\text { gms. }\end{array}$ & $\begin{array}{l}\text { Weight of } \\
\text { Albumen } \\
\text { gms. }\end{array}$ & $\begin{array}{l}\text { Weight } \\
\text { Yolk } \\
\text { gms. }\end{array}$ & $\begin{array}{c}\text { Weight } \\
\text { Shell } \\
\text { gms. }\end{array}$ \\
\hline 11) & May $2 \tilde{5}$ & $\check{5} 4.09$ & $3 \check{.} .27$ & 36.05 & 19.77 & $6.21 \times 2$ & 3.86 \\
\hline 2 & May 26 & 55.18 & 36.96 & 41.79 & \multicolumn{2}{|c|}{$\begin{array}{c}\text { Spoiled. Could not } \\
\text { tell whether there had } \\
\text { been } 1 \text { or } 2 \text { yolks }\end{array}$} & 4.54 \\
\hline 3 & May 28 & \multicolumn{2}{|c|}{ A soft shelled egg } & & & & \\
\hline 4 & May 30 & 46.04 & 31.50 & 23.08 & 13.24 & 6.79 & 3.05 \\
\hline 5 & June 1 & 60.26 & 37.28 & 47.72 & 28.45 & $\left\{\begin{array}{l}7.21 \\
7.26\end{array}\right\}$ & 4.80 \\
\hline 6 & June 2 & 57.87 & 37,67 & 46.86 & 27.31 & $\left\{\begin{array}{l}7.36 \\
7.45\end{array}\right\}$ & 4.74 \\
\hline 7 & June 3 & 48.83 & 34.20 & 32.45 & 21.00 & 7.86 & 3.59 \\
\hline 8 & June 6 & 47.90 & 34.40 & 32.50 & 21.16 & $7.6 \tilde{0}$ & 3.69 \\
\hline 9 & June 7 & 46.50 & 34.00 & 30.63 & 19.62 & 7.42 & 3.59 \\
\hline 10 & June 9 & 48.12 & 34.42 & 32.53 & 21.68 & 7.22 & 3.63 \\
\hline
\end{tabular}

These eggs were very small and the yolks were especially small. Another peculiarity seen from the table is that three at least and probably four of them were double yolked.

The bird continued to develop normally. On June $17 \mathrm{Mr}$. Gerald wrote that she then weighed three and one-half pounds and her second feathers were coming. She had laid several eggs but our absence from Orono prevented the acceptance of Mr. GERALD's offer to forward them.

A study of the yolk weights given in the table shows that the weight of yolks for the first eggs of this three months old pullet is but little more than half the weight of the yolks of the first eggs of the five to six months old pullets considered above. Also the yolk weight increased considerably during the fifteen days observations. The decrease at the end of the period is no doubt due to the approaching end of the litter. In spite of this falling off the last yolk was one gram heavier than the one fifteen days earlier.

1) This egg contained two yolks of apparently equal size, one of which was broken in attempting to separate it. 
The case of this precocious pullet adds evidence to the view suggested by the data from the flock investigated, namely that the egg yolks increase in weight as the bird matures and that this increase is more rapid at early than at later stages of development. There is further evidence of this fact from the data on the birds which began to lay in February. Table 31 gives the age in months at the laying of the first egg for the twelve birds used in the computations and of the three birds added to the flock in February.

Table 31. 'Table Showing Age in Months at the Beginning of Laying.

\begin{tabular}{|c|c|c|c|c|c|c|c|c|c|c|c|c|c|c|c|c|}
\hline & \multicolumn{16}{|c|}{ Bird No. } \\
\hline & 218 & 139 & 446 & 516 & 192 & 259 & 204 & 478 & 212 & 184 & 211 & 236 & 441 & ō14 & 459 & 489 \\
\hline $\begin{array}{c}\text { Age in } \\
\text { months at } \\
\text { laying of } \\
\text { 1st egg }\end{array}$ & $5^{1 / 2}$ & $63 / 4$ & 6 & $\tilde{\mathbf{b}}^{3 / 4}$ & $6^{1 / 4}$ & $6^{1 / 4}$ & $6^{1 / 2}$ & $\tilde{5}^{3} / 4$ & $61 / 4$ & 6 & $6^{3} / 4$ & $5^{3 / 4}$ & 6 & 9 & $83 / 4$ & $83 / 4$ \\
\hline
\end{tabular}

From this table it is seen that the last three birds were from eight and three-fourths to nine months old when they began to lay. Bird No. 236 laid one egg in November but did not lay again until March 31. She may therefore be considered as a bird without laying experience until she was practically nine and three-fourths months old. The one egg in November however indicates the size of eggs she would have laid at that period. The egg data for these four birds are given in Table 32 .

The data given in this table show that in these cases the yolk weight does not begin small and increase very rapidly, as in the case of the birds which begin to lay in the fall. In fact the yolk weight for three of the birds even shows a steady slight decrease for the first few months. This is evidently a seasonal decrease and is shown by several of the birds that began to lay in November (see Table 26). Unfortunately none of these birds except No. 236 laid through the second year but up to within a month of death these birds showed monthly means very similar to the means for others of the flock during the same months. The monthly mean yolk weights for Bird No. 236 and Bird No. 514 are plotted in Fig. 10.

A comparison of these curves with the yolk weight curves for bird No. 218 and bird No. 139 (Figures 3 and 4 ) show that in the case of these birds there was an increase in yolk weight similar to the increase in yolk weight during the same period which is slown by 
A Biometrical Study of Egg Production in the Domestic Fowl. IV. 291

Table 32. Showing monthly mean egg weight and yolk weight for the birds which began to lay in February.

\begin{tabular}{|c|c|c|c|c|c|c|c|c|c|}
\hline \multirow{3}{*}{\multicolumn{2}{|c|}{ Month }} & \multicolumn{8}{|c|}{ Bird numbers } \\
\hline & & \multicolumn{2}{|c|}{$4 \check{0} 9$} & \multicolumn{2}{|c|}{489} & \multicolumn{2}{|c|}{514} & \multicolumn{2}{|c|}{236} \\
\hline & & $\begin{array}{c}\text { Egg } \\
\text { weight }\end{array}$ & $\begin{array}{c}\text { Yolk } \\
\text { weight }\end{array}$ & $\begin{array}{c}\mathbf{E g g} \\
\text { weight }\end{array}$ & $\begin{array}{c}\text { Yolk } \\
\text { reight }\end{array}$ & $\begin{array}{c}\text { Egg } \\
\text { weight }\end{array}$ & $\begin{array}{c}\text { Yolk } \\
\text { weight }\end{array}$ & $\begin{array}{c}\text { Egg } \\
\text { weight }\end{array}$ & \begin{tabular}{|c|c|} 
Yolk \\
Teight
\end{tabular} \\
\hline 1910 & & & & & & & & & \\
\hline October. . & $\cdots$ & & & & & & & & \\
\hline November. . & . . & & & & & & & 47.12 & 13.74 \\
\hline December. . & . . & & & & & & & - & - \\
\hline 1911 & & & & & & & & & \\
\hline January. . & . . & & & & & & & - & - \\
\hline February . & . . & 51.87 & 14.15 & 63.82 & 17.28 & 53.61 & 15.75 & $\ldots$ & 一 \\
\hline March . . & . . & 53.76 & 14.29 & 64.98 & 16.16 & 51.93 & 14.59 & 52.07 & 17.49 \\
\hline April . . . & . . & 55.10 & 14.84 & 64.13 & 15.50 & 52.60 & 14.84 & ธิ3.16 & 16.77 \\
\hline May . . . & . . & 55.05 & 15..0̃1 & 65.31 & 16.90 & 53.08 & 15.05 & 51.37 & 15.90 \\
\hline June . . . & . . & 56.17 & 14.61 & 65.12 & 15.77 & 53.74 & 16.04 & 50.89 & 15.48 \\
\hline July . . . . & . . & 54.94 & 14.56 & 61.791 & $12.72^{\prime}$ & 53.64 & 16.04 & 51.06 & 17.64 \\
\hline Angust . . . & . . & 57.44 & 15.98 & & & 52.70 & 15.49 & 53.24 & 17.06 \\
\hline September. & . . & -- & - & & & 54.84 & 16.38 & - & - \\
\hline October. . & . . & - & - & & & 一 & - & - & - \\
\hline November. . & . . & - & - & & & - & - & - & - \\
\hline December. . & . . & - & - & & & - & - & - & - \\
\hline 1912 & & & & & & & & & \\
\hline January . & . . & - & - & & & - & -- & - & - \\
\hline February . & . . & - & - & & & 56.34 & 17.67 & - & - \\
\hline March . . & . . & - & - & & & อ5.272) & $16.952)$ & - & - \\
\hline April . . . & . . & - & - & & & & & 54.50 & 19.38 \\
\hline May $\cdot \cdot$ & . . & - & - & & & & & 54.75 & 18.79 \\
\hline Jane ... & . . & - & - & & & & & 53.32 & 17.88 \\
\hline July . . . & . . & - & - & & & & : & $\tilde{0} 2.02$ & 17.86 \\
\hline August . . & . . & - & - & & & & & - & - \\
\hline September. & . . & - & - & & & & & 53.21 & 18.37 \\
\hline October. & 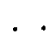 & - & - & & & & & - & - \\
\hline
\end{tabular}

the birds which began laying in Norember. That is, the first egg's laid by birds which do not lay until they are nine months old have yolks as large as the yolks of eggs laid at the same time by birds of practically the same age which began to lay some months earlier. The rate of change in yolk weight also is similar to that shown during the same time by the birds which had laid younger. The one observation in November for bird No. 236 is also in accord with the observations for the other birds at that time.

1) Bird died July 4, 1911. (Only one egg in July which was laid on day before death.)

2) Bird died Narch 27, 1912. 
It is also interesting to note from both Tables 26 and 32 and Figures 3,4 and 10 that the yolk weight shown by any bird at any month are dependent upon the size typical for the individual and upon the time of year. It is apparently independent of whether the bird has been laying during the previous months, or, in fact, of whether or not she has ever laid before. That is the increase in yolk weight does not seem to be due to a perfection of the morphegenetic activity due to physiological practice but seems rather to be due to the stage of development or differentiation of the individual.

Fig. 10 .

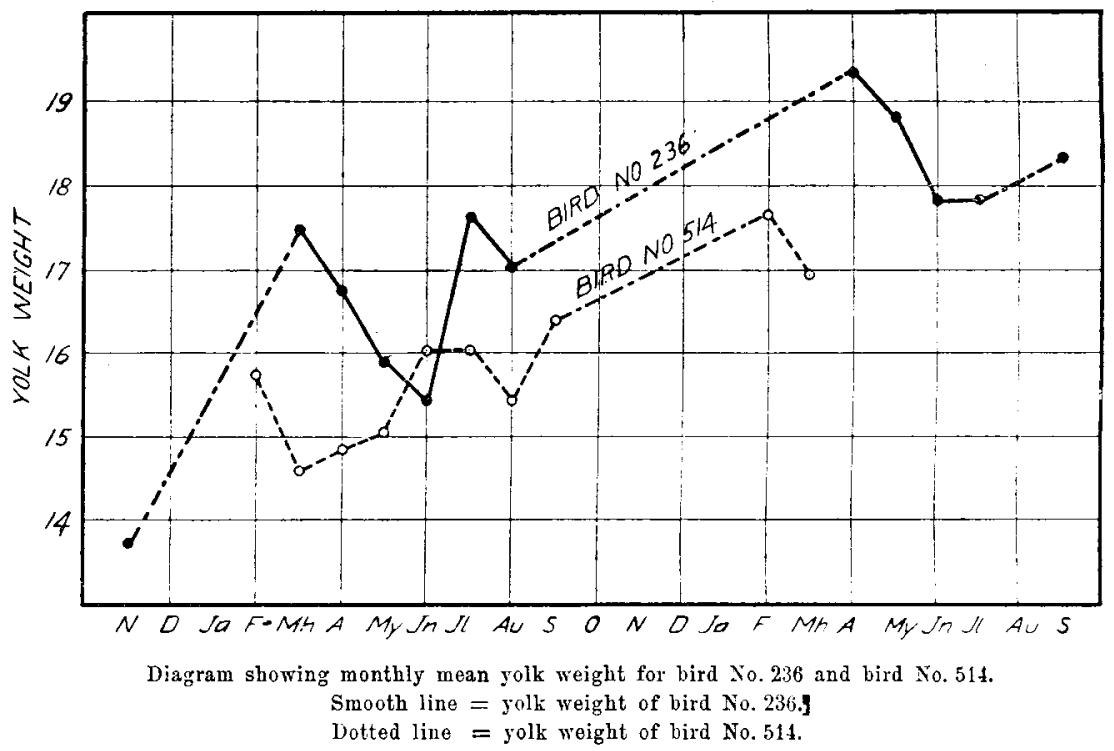

Since the birds used in this investigation were very nearly the same age it is not possible to separate absolutely the effects of the age of the bird and of the season of the year. Certain undoubted seasonal variations will be discussed later. It seems however that the general tendency for a continued increase in yolk weight at a constantly diminishing rate through all seasonal conditions must be due to the general stage of maturity of the bird. The fact of small but rapidly increasing yolks in the precocious pullet also supports this view. This gradually diminishing increase in yolk weight is represented by the logarithmic curve shown in Fig. 9. The equation for this curve was given on page 288 . This curve which represents 
A Biometrical Study of Egg Production in the Domestic Fowl. IV. 293

analytically the law of the increase in yolk weight with the age of the bird is of the same type as the curves which bave been found to fit various kinds of growth data in both animals and plants. They were first used in this connection by PEARSON ${ }^{1}$ ) to fit observations on the growth of the human head but he does not discuss their significance. PEARL, PEPPER and HAGLE' ${ }^{2}$ showed that for Ceratoployllam the first law of growth as expressed by the regression of leaf number on position is logarithmic. That is $*$ The form of any particular whorl of a Cercatopleyllum plant is a function (in a mathematical sense) of the number of whorls which have been produced before it on the same axis". This law holds good for all the axial divisions of the plant (main stem, primary, secondary and tertiary branches) and for plants in different environments, although the absolute size of the elements is modified by environmental differences.

Donaloson ${ }^{3}$ ) has shown that the growth of the body and the growth of the nervous system in mammals proceed with diminishing. rapidity, and are graphically represented by logarithmic curves.

The application of these mathematical methods in the interpretation of growth phenomenon originated with the above workers but the essential fact, namely that the rate of growth of an organism is a function of the degree of development already attained is also clearly shown by Minot ${ }^{4}$ ). His extensive studies of growth and differentiation in guinea pig, rabit, chick and man show that these processes go on together from the germ to death. The rate of each is exceedingly rapid during the early prenatal existence and continues to decrease steadily as the organism develops. The rate of this loss of growth power also diminishes. "The loss occurs with great rapidity in the young - less rapidly the older we become. \&

1: Pearsox, KarL, On the Inheritance of Mental and Moral Characters in Man and Its Comparison with the Inheritance of the Physical Characters. Biometrika. Vol. 3. 1904. pp. $131-190$.

2) Peari, R., Pepper, O. M., and Hagle, F. H., Variation and Differentiation in Ceratophyllum. Carnegie Institution Publ. No. 58. 1907.

3) Donaldson, H. H., A Comparison of the Albino Rat with Man in Respect to Growth of the Brain and of the Spinal Cord. Jonrn. Comp. Neurol. and Psych. Vol. 18. 1908. pp. 345-392.

- On the Relation of the Body Length to the Body Weight and to the Weight of the Brain and the Spinal Cord in the Albino Rat. Ibid. Vol. 19. 1909. pp. $155-167$.

4) Mroot, S. C., Age, Growth and Death. G. P. Patnam's Sons, New York and London, 1908. 
He believes that the growth and differentiation of the protoplasm are the cause of the loss of the power of growth.

Richard HERTwig ${ }^{1}$ ) also calls attention to the enormous diminution in cell production which must be assumed to account for the fact that the human germ cell increases in bulk a billion times between fertilization and birth while in twenty years the new born child increases its bulk but sixteen times.

It is then well established that organic growth takes place by the addition of increments per time unit which decrease in size very rapidly at first but at a rate which becomes constantly slower until the increments become negligible and even counterbalanced by processes of deterioration.

It is in fact now recognized that curves of individual growth are logarithmic. $\mathrm{HATAI}^{2}$ ) has recently offered a dynamical interpretation of this fact based on the simple assumption that the law of De Maupertius, or the principle of least action, is applicable to the growth of an organism. That is he assumes that during growth, energy is most economically utilized.

Every organism presumably has a limit beyond which it cannot be induced to grow. The limit varies with the species and must be due to fundamental differences in the constitution of the germ cells. "This fundamental difference in composition may be interpreted as the ,inherited character. This would mean then that a different amount of potential growth energy is already stored within the fertilized ovum according to the different species before any growth has actually taken place... This energy must be stored within the respective germ cells potentially since the external agencies fall to modify this relation." "It is true that this energy diminishes gradually but at a fixed rate as growth proceeds and at the end this energy is either zero or negligibly small. Meantime inversely as the growth energy diminishes an individual gains an increment of weight. In other words the growth energy is used in order to convert various forms of matter into the mass which composes the body. Thus the mass so formed is an index of the amount of growth energy transformed.... We wish to determine what law, if there is any, governs in any individual the rate of transforming growth energy into work."

1) Hertwig, R, Über die Lrsache des Todes. Reprinted from Allgemeine Zeitung, Dec. 12, 1906.

2) HataI, Shinkishi, An Interpretation of Growth Curves from a Dynamical Standpoint. The Anatomical Record. Vol. 5. 1911. pp. 373-382. 
A Biometrical Study of Egg Production in the Domestic Fowl. IV. 295

He then shows by methods of integral calculus that the logarithmic equations, the curves of which have been shown empirically to represent the rate of growth in organisms, are one group of equations which satisfy MaUPenTIUs law which is expressed mathematically in the following form:

$$
\text { Action }=\int m v d s
$$

sor action is a space integral of the momentum, with the definition that subject to the condition that total energy is assigned the mode in which a conservative system passes from one configuration to another is such that the action is a minimum «. In consequence of these facts he offers the provisional definition of growth:

"An organism during growth tends to form the greatest amount of mass with the least loss of growing capacity.

BANCROFT ${ }^{1}$ ) considers this law of least action as universally applicable to changing systems whether they be chemical, physical or biological.

It has been shown above that the weight of the yolk of the successive eggs increases as the bird matures but the absolute increment of weight diminishes and this change in the weight of the yolk is parallel to the change in size characters of an organism during growth. The change in rate of increase in yolk weight is similar also to the change in rate of differentiation in an organism. The first interpretation that suggests itself is that this increase in the size of the yolk is a direct effect of the analogons increase in the size of the individual. That the body weight as well as yolk weight normally continues to increase at least to the end of the second year can be seen by comparing the three body weights given in Table 18 . However, the curve showing the increase in yolk weight is not parallel to a curve which shows the increase in body weight at the same period. In fact at the beginning of laying the body weights of these birds had already reached the point where the increments were very small. During November and December of 1911 and January 1912 weekly body weights were taken. The gain in weight during this period was impossible to determine since the weights fluctuated irregularly. This fluctuation was no doubt due largely to the fluctuation in the weight of the contents of the alimentary tract. During

1) Bancroft, Wilder D., A Universal Law. Science, N. S. Vol. 33.1911. pp. $159-179$. 
this period of most rapid increase in yolk weight the increase in body weight was too small to be certainly distinguished from the fluctuations due to temporary variations in the amount of food and waste present in the body. This indicates that the stage of $\mathrm{de}$ velopment or differentiation which determines the size of yolk is not accurately measured by the body weight. It is of course well known that the different organ systems of the body show different growth stages at the same time and that the reproductive system shows most rapid growth not long before the beginning of its functional activity.

Fig. 11.

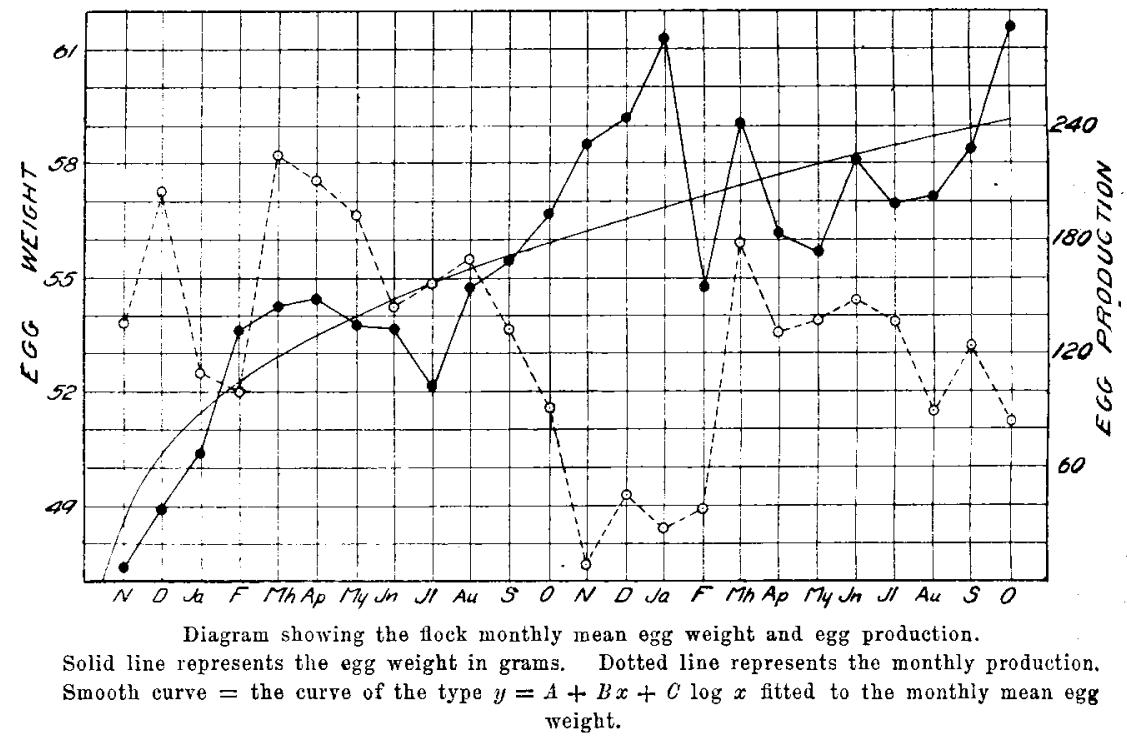

In yolk weight we find a logarithmic approach of successively formed structures to a type. Pearl ('07)1) found this true of leaf number per whorl in Ceratophyllum and later $\left({ }^{\prime} 09,2\right)$ of egg shape in a domestic fowl. In the case of yolk weight, however, it is certain that this is not due to the continued production of the like parts but to the conditions of the individual at the time the part is produced.

1) Pearl, R., loc. cit.

2) Pearl, Raymond, Studies in the Physiology of Reproduction of the Domestic Fowl. I. Regulation in the Morphogenetic Activity of the Oviduct. Journ. Exp. Zool. Vol. 6. 1909. pp. 339-35̃8. 
A Biometrical Study of Egg Production in the Domestic Fowl. IV. 297

The change in yolk weight due to the age or maturity of the bird has been discussed at length because the weight of this part of the egg seems to be most closely related to the age of the bird and least affected by the other natural causes of variation in egg size. The weight of albumen and shell also both increase with the age of the bird but the fluctuations are much greater than in the case of yolk weight. Since the weight of each of the parts increase with the age of the bird the weight of the egg must show this relation also. The three following figures show for the flock the monthly

Fig. 12.

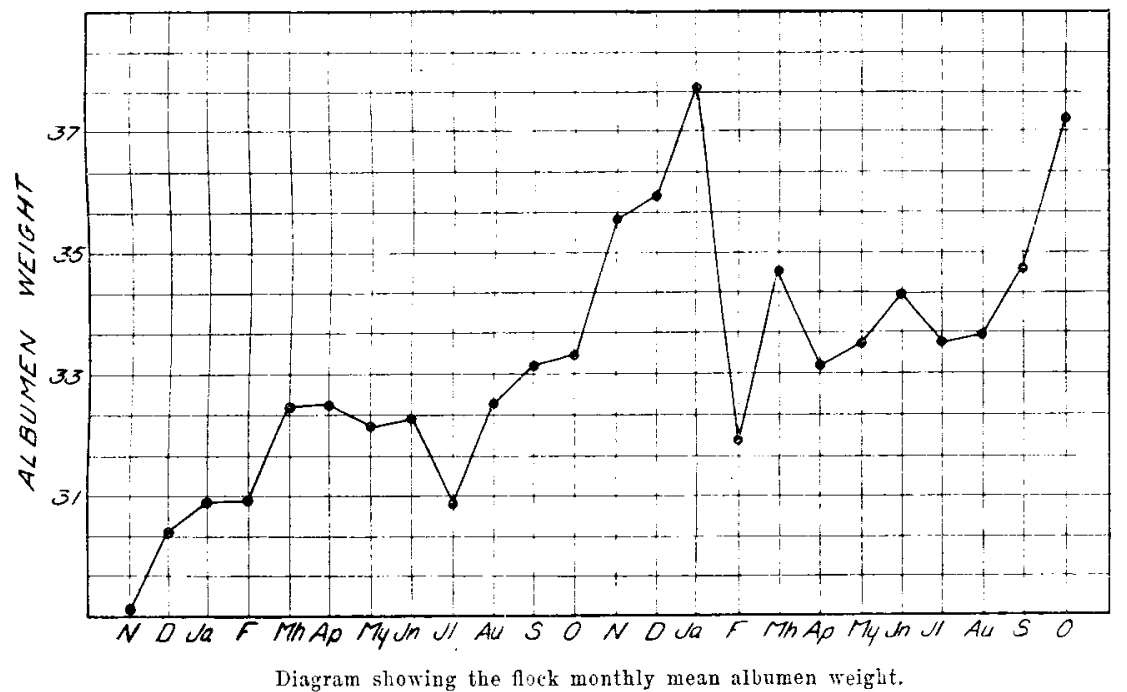

mean egg weight and egg production the monthly mean albumen weight and the monthly mean shell weight.

The solid irregalar line in Figure 11 shows the observation curre for the monthly mean egg weight. The general resemblance of this curve to the curve for the monthly mean yolk weight (Figure 9) is apparent but the fluctuations are greater. That the increase in the size of the whole egg is in general logarithmic in character looked probable. A curve of the type $y=A+B x+C \log x$ was also fitted to this data. The resulting equation $y=48.4768+.1376$ $x+5.3644 \log x$.

This is the equation of the smooth curve shown in Figure 11. It is a reasonably good fit to the data but there are much larger deviations of the observations from the smooth curve than in the case 
of yolk weight. These deviations must be caused by the effect of the weights of the albumen and shell.

Figure 12 shows the observation curve for the flock monthly mean albumen weight.

The logarithmic character of this curve is less pronounced and it is evident that the deviation of the observations from it would be very great. It is in fact apparent that while there is a tendency for albumen weight to increase logarithmicly there are other factors which modify this tendency. The fluctuations will be discussed below.

Fig. 13.

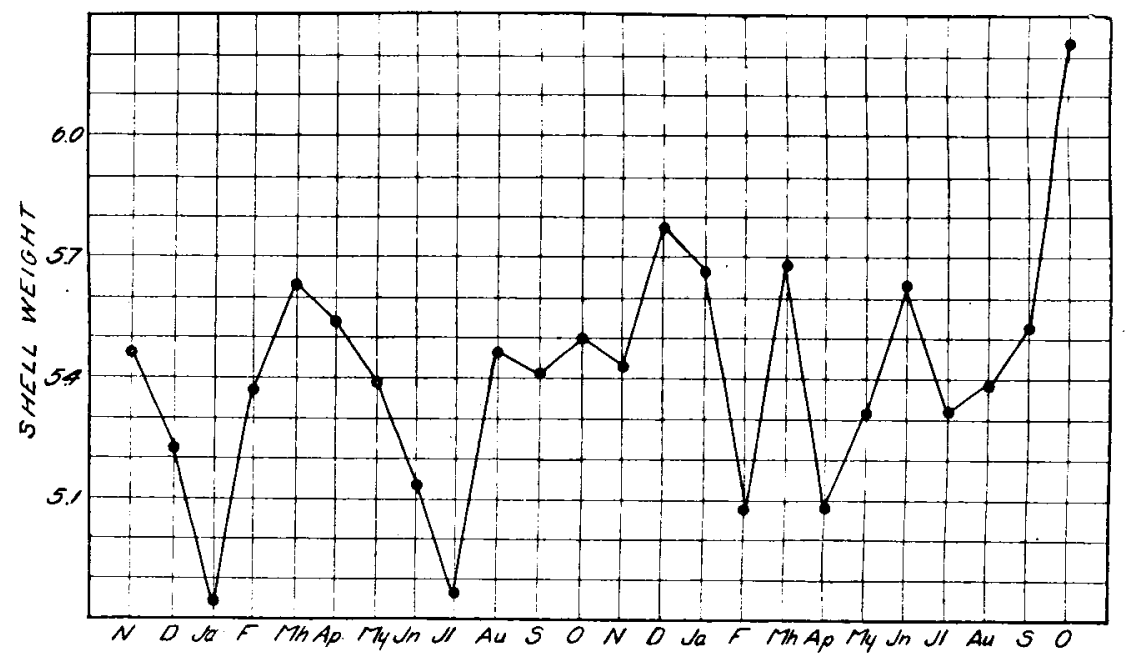

Diagram showing the flock monthly mean shell weight.

Figure 13 shows the flock monthly mean shell weight. This curve shows a slight general tendency to increase with the age of the bird but there is no suggestion of a logarithmic rate of increase and the fluctuations are very great.

We have seen that in general the weight of each part of the egg increases with the age of the bird. In the case of the yolk weight the rate of increase is quite precisely logarithmic. The fluctuations from this type are small. Albumen weight shows a tendency to this type of increase but certain fluctuations are very great. The increase in shell weight is not logarithmic. In the preceding parts of the paper it has been shown that although there is a significant correlation between the weights of the several parts there is nevertheless a tendeney to independent variation. 
A Biometrical Study of Egg Production in the Domestic Fowl. IV. 299

The different nature of the physiological processes involved in the formation of the parts of the egg affords ample basis for an independent variation. The weight of the yolk is determined by the amount of yolk deposited while it is within the ovarian follicle. The albumen weight depends upon the amount of secretion of the albumen glands of the entire oviduct, while the weight of shell depends only upon the secretions of the shell forming glands of the uterus. It is conceivable that a disturbance in the processes involved in the formation of one part of the egg may have little or no effect on the processes involved in the formation of the other parts. The results given above indicate that the factors which determine the size of the yolk are less disturbed by the temporary conditions than are those which determine the amount of albumen and shell secretion.

\section{Variation Related to the Season of the Year.}

Yolk weight and albumen weight show in general similar seasonal variations but the difference in the degree of this variation is very great. For convenience of comparison the observation curves shown in Figures 9 and 12 are plotted together in Figure 14.

The comparison between these curves shows a general relationship between the fluctuations in yolk weight and albumen weight. The weight of each of these parts increases rapidly from the beginning of laying to the beginning of the first breeding season. In January the yolk weight however shows a larger proportionate increase than the albumen weight. All these birds stopped laying for from two to four weeks during the last half of January and the first half of February. At the beginning of the first breeding season in February the yolk weight increased very decidedly while the albumen weight was about the same as at the end of the winter laying in January. In March the yolk weight remained practically the same as in February but the albumen weight made a good deal of increase. It did not, however, increase proportionately to the increase in yolk weight which had occurred in February. From the beginning of the breeding season until the end of July the yolk weight remained nearly constant. Several of the individual birds show a slight decrease in weight during this period and a few a slight increase. The albumen weight tends to fall off during this period especially toward the end. In August both yolk and albumen increase and continue to increase up to the beginning of the second breeding season. At this season the increase in albumen weight is much greater than the increase in 
yolk weight, so much so in fact that it alters considerably the proportion of the two parts. At the beginning of the second breeding season in February the yolk weight remains practically the same as in January but the albumen weight is very much smaller. In March both increase, but the albumen weight does not regain its February loss. The fluctuations through the second summer are similar in the two parts. Those in albumen weight being of greater magnitude. In the second antumn the decidedly rapid increase in albumen weight seen in the previous autumn again takes place. The increase in yolk weight at this time is not significant.

Fig. 14.

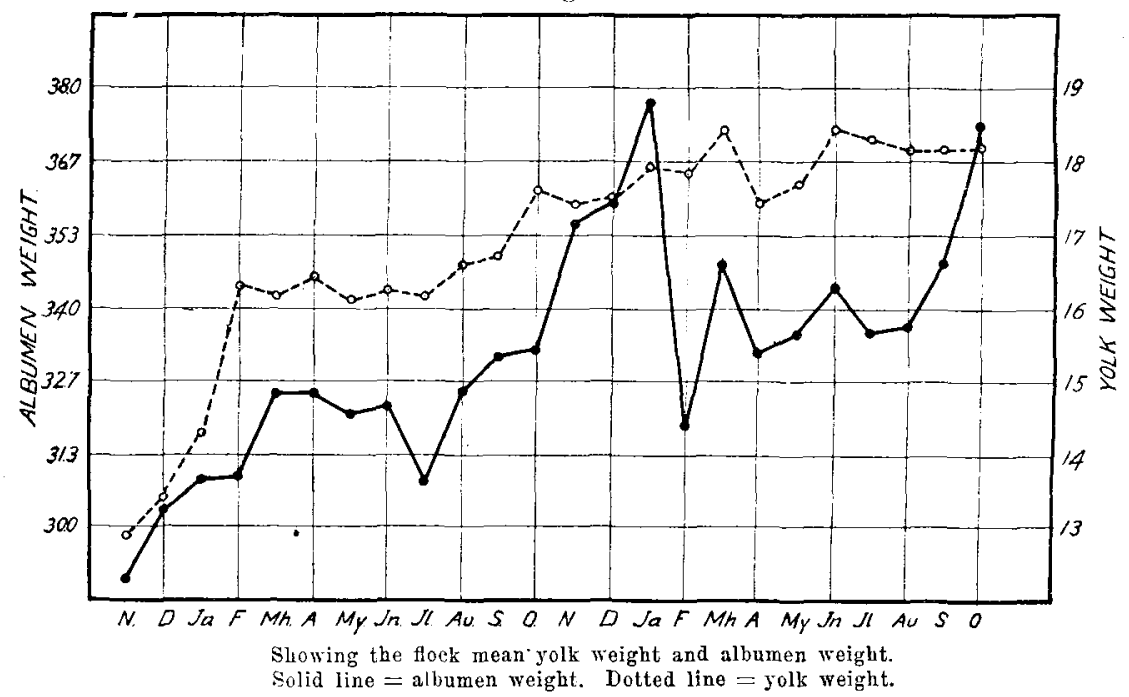

The difference in the rate of increase in the two parts at the various seasons results in a decided difference in the proportion of the parts as is readily seen from the changing relation of the curves in Figure 14. The proportion of albumen in the eggs during November, December and January of both years is conspicuously greater that an other seasons.

The curre in Figure 13 shows the monthly mean shell weight for the eggs of the flock. If this curve is compared point by point with the curve of the monthly mean albumen wejght many of the same fluctuations will be noted. There is one decided exception. During the first three months shell weight is decreasing proportionately more rapidly than the albumen weight is increasing. The fluctuations shown at other seasons are proportionately much greater in shell weight than in albumen weight. 
The variation in weight which is associated with the change in season is to a certain extent similar in the case of each part of the egg. The parts, however, vary greatly in the proportional magnitude of the seasonal variations. The difference is so great that the proportion of the parts is altered in different seasons. Yolk weight is apparently least affected by these seasonal factors. Albumen weight shows very large fluctuations which have a decided tendency to repeat themselves in successive years and therefore appear to be undoubted seasonal fluctuations. The fluctuations in shell weight are proportionately greater than in either of the other parts, but do not show the same tendency to repeat themselves in the successive years. It therefore seems possible that some of the large fluctuations in shell weight may be due to some other circumstances than the normal change in season.

Showing that certain changes in yolk weight and albumen weight are correlated with change in season does not indicate the fundamental cause of these changes. The solution of this problem must be by controlled experiments. Two interpretations suggesst themselves. 1) The fluctuations may be due to the direct effect of seasonal changes in environment. 2) They may be due to the general changes in metabolic processes which also find expression in the differentiation of a breeding season and a fall molt, and which are probably due in part to environment and in part to heredity.

In the lower vertebrates or cold blooded animals, whose body temperature coincides more or less closely with the temperature of the medium in which they live the rapidity of growth and of other physiological processes is dependent upon the temperature of the medium. The higher vertebrates on the other hand regulate, within limits, their own body temperature. Simpsox 1 ) has shown by observations on the rectal temperatures of fowls that $\gg$ the body temperature curve in a general way rises and falls with the temperature of the air but the relationship is not a close one, unless when the temperature is very high or very low. « His curves for body temperature and temperature of the air show a very striking resemblance especially during the very warm and very cold months. Since the body temperature changes as the external temperature changes it

1) Sinpson, S., An Investigation into the Effects of Seasonal Changes on Body Temperatures. Proc. Roy. Soc. of Edinburgh. Vol. 32. Part I. 1911-12. pp. 110-135. 
seems quite possible that the amount of yolk deposited or of albumen or shell secreted may thus be indirectly related to the external temperature.

The amount of material available for egg production must be one of the important factors in determining egg weight. This available material must depend, first, upon the amount of food digested and absorbed above what is neccssary for the maintenance of the other physiological processes of the bird, and, second, upon the amount available from the foods stored in the body. RICE 1 ) found a close relation between the amount of food consumed and the number of eggs produced. He continued his stndy from August 11, 1906, to November 8, 1907. He found that "periods of large egg production always appear to be periods of increased food consumption and vice versa... That the increase in the amount of food consumed precedes by a few weeks the increase in production... and that the body weight of the bird is greater preceding heaviest egg production*. He also shows that the flocks which produce the largest number of eggs at a given period also consume the most food. It is not, of course, fair to compare his food consumption curves with the egg weight curves obtained from the birds in the present investigation except in the most general way. There is, however, a very striking similarity between these curves except for the months of September and October. That is the seasonal fluctuation in amount of food consumed appears to be related to the seasonal fluctuations in egg weight. In September and October the birds begin to molt. Egg production ceases entirely or is confined to an occasional egg. The large size of these occasional eggs and especially the large amount of albumen they contain has already been discussed. The disturbed conditions of metabolism which initiate and accompany the molt are no doubt in some way related to the large eggs with disproportionately large percentages of albumen which are characteristic of the period of the molt.

It thus seems probable that while the seasonal fluctuations in egg weight may be to some extent the direct effect of environmental conditions, yet to a much greater extent they are the indirect effect of such conditions, that is they are due to general physiological changes in the individual.

1) RICE, J. E., The Molting of Fowls. Cornell Univ. Agr. Expt. Sta. Bulletin 258. 1908. pp. 1-68. 
A Biometrical Study of Egg Production in the Domestic Fowl. IV. 303

\section{Variation Related to the State of Health.}

One of the birds (No. 441) used in this investigation offers an opportunity to study the effect of the state of health upon the weight of the egg. This bird laid 179 eggs during her pnllet year. These eggs increased in size exactly in accordance with the general rule for the flock. Her body weight increased from $2003 \mathrm{gms}$. in November and December 1910 to $2325 \mathrm{gms}$. in September 1911. That is up to the first fall month she was a normal bird. She stopped laying for the molt October 17, 1911, and did not lay again until March 4, 1912. From this time until August 17 she laid quite well for a second year Barred Plymouth Rock, producing $90 \mathrm{eggs}$ in this time. These eggs were smaller than the eggs of the previous year. Nothing abnormal was seen in the appearance of the bird until during the summer when she began to appear somewhat sick. She did not seem to have symptoms of any of the best known communicable diseases and was left with the flock. She continued to lay until August 17. After this she became more dumpish. In September it was apparent that she would not recover and lay before the close of the investigation in November. She was, therefore, killed and autopsied September 10, 1912.

At autopsy her body weight was 2190 gms. a slight decrease from the weight a year before. The following lesions were recorded. 1) The liver was congested and friable. 2) The lungs were congested and showed yellowish lesions. 3) There was some peritoneal disturbance which had caused a greenish deposit on the intestinal mesentery. That is the bird at antopsy showed evidence of disturbances which were probably of some time standing.

The monthly mean egg weight, the monthly production and monthly mean weight for each of the parts of the egg are given in the final columns of Tables 25 to 28 inclusive. These weights are plotted in Figures 15 to 18 inclusive.

A comparison of these diagrams with the corresponding diagrams for the other birds (see Figures 1 to 8 inclusive) shows that during the first year each egg part increased in weight in the normal manner. The bird was then no doubt in good physical condition. The bird did not lay from October 1911 to March 1912. Throughout the second year the weight of each egg part decreased. This decrease was most rapid after the bird was observed to be sick but had been going on for three months before this. Evidently the physiological 
Fig. 15.

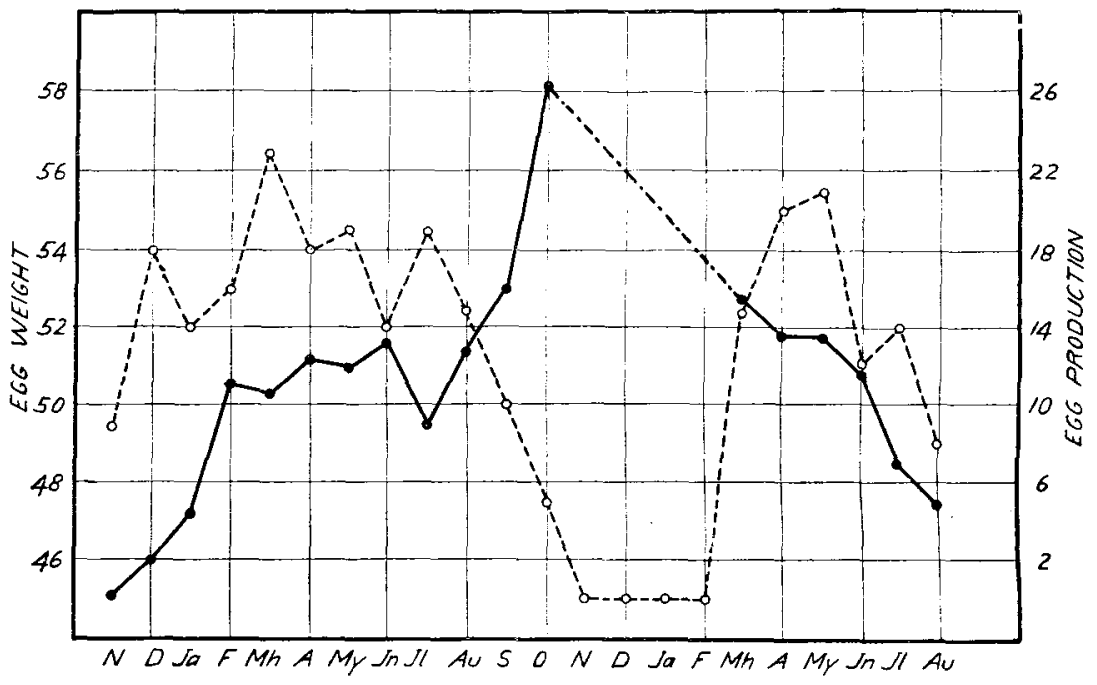

Diagram showing monthly mean egg weight and monthly production of bird Yo. 441 .

Continuous line represents egg weight.

Broken line represents monthly production.

Fig. 16.

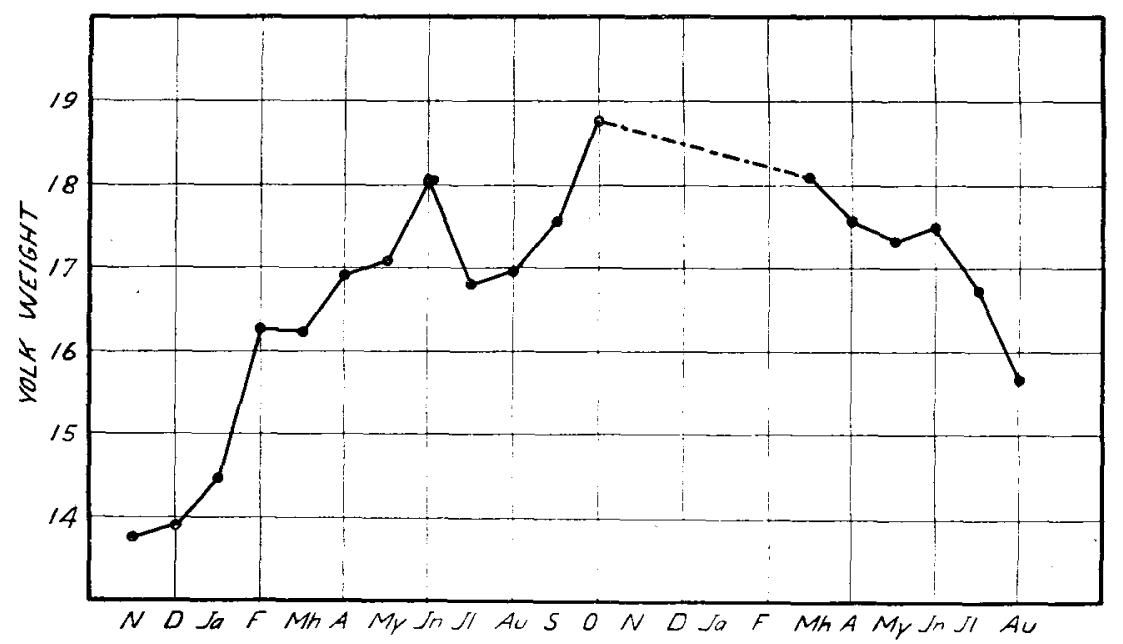

Diagram showing monthly mean jolk weight for bird No. 441. 
A Biometrical Study of Egg Production in the Domestic Fowl. IV. 305

Fig. 17.

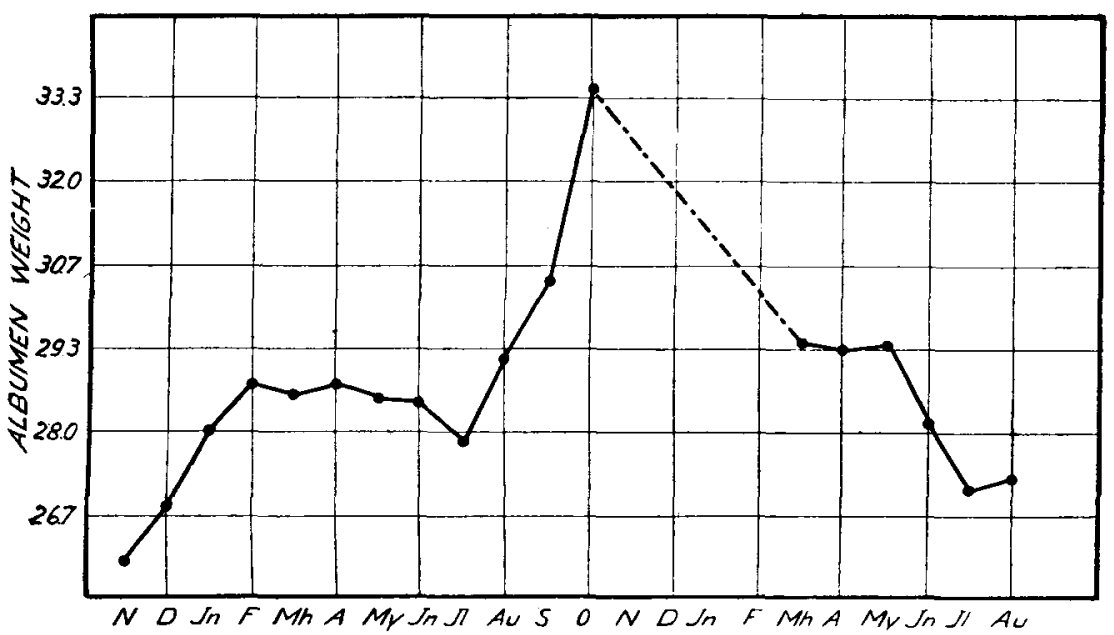

Diagram showing monthly mean albumen weight for bird No. 441.

Fig. 18.

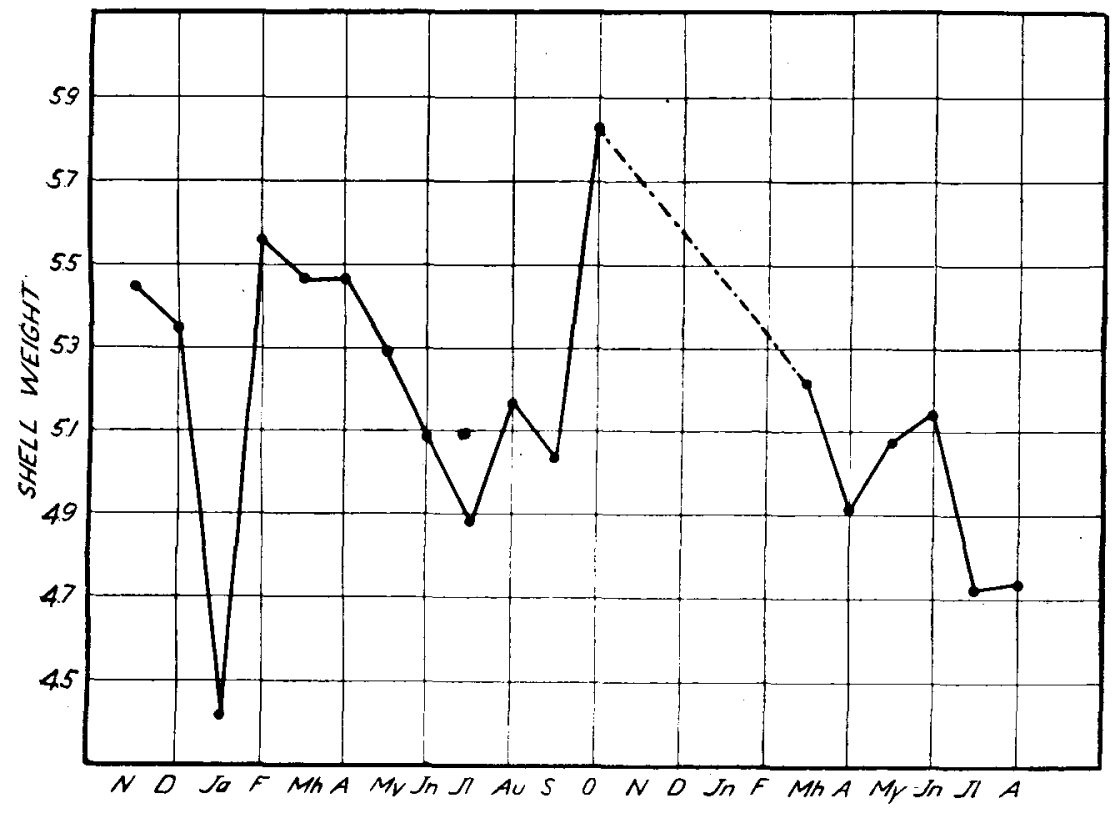

Diagram showing monthly mean shell weight for bird No. 441. 
disturbances had affected the size of the egg before it affected the behavior of the bird.

Five other birds died or were killed during the investigation. None of these were affected by long standing diseases and their evidence on the effect of the state of health is not as significant as in the case just presented. Each case is given below.

Bird No. 459 died July 4, 1911, from the effect of a heat prostration on July 3. The day of the prostration she laid a smail egg (see Table 32). The yolk of this egg was the smallest yolk this bird had ever produced.

Bird No. 243 died of peritonitis April 29, 1911. She had not laid for a month. The last four eggs laid were somewhat smaller than those which preceded but this difference may not have been significant.

Bird No. 514 developed a roup tumor on her head and was killed March 27, 1912, to prevent the spread of the disease in the flock. Aside from the tumor the bird appeared at autopsy to be in normal condition. Table 32 shows that the monthly mean egg weight and yolk weight for the month of death was smaller than for the preceding month. These differences may not be significant since they are no greater than those shown by three of the normal birds of the flock.

Bird No. 205 died July 8, 1911. At autopsy her lungs and ovary were found congested. Otherwise she was in good normal condition. There was a normally large egg in the shell gland. The disturbance which caused death could not have been of a nature to cause a decrease in the size of the egg.

Bird No. 235 was accidentally killed Sept. 19, 1911. Autopsy showed that she was suffering from a bronchial cold which also affected her air sacs. She had not laid for a week previous to this time. The last eggs laid were of normal size.

It is clear that a diseased condition of a bird may cause a decrease in the weight of each part of the egg without causing a cessation of laying. It is also clear that other disturbances sufficient to cause death may not affect the size of the egg produced on the day of death.

FÉRÉ 1 ) studied the effect of morphine intoxication on the weight

1) FŕRÉ, M. Cr., Note sur la puissance toxiane et la puissance tératogène de la morphine sur le poulet. Bull. et mém. de la Soc. méd. des hop. de Paris. Vol. 14. Séries 3. 1897. pp. 608-617. 
A Biometrical Study of Egg Production in the Domestic Fowl. IV. 307

of the egg. He found that a dose of $0.681 \mathrm{gr}$. to $.749 \mathrm{gr}$. per kilogramme of body weight stupified the bird for from twelve to twentyfour hours. $0.808 \mathrm{gr}$. was a fatal dose. The stupefying dose caused a diminution in the weight of the egg which was laid on the day of the intoxication and which must bave been nearly formed at the time of the injection of the morphine.

The effect of the morphine interrupted the laying for four days and when it was resumed the first two or three eggs were smaller than before the intoxication. This shows that an experimentally altered physiological condition may cause a diminution in the weight of the egg.

It has been shown that, in general, the monthly mean egg weight increases with the age of the bird, fluctuates with the season of the year and is affected by the state of health. The fact now to be considered is that during any month the eggrs of each bird show a very considerable variation in egg weight and in the weight of each of the egg parts.

In order to make a study of this variation in the successive eggs the weight of each egg and of each of its parts was plotted as ordinate and the date of laying as abscissa, Plate $X$ shows one of these diagrams. It is the one for the lighest laying bird (No. 218) and it is in all important respects typical for the flock.

Before considering the variation in the weight of the egg and of the egg parts it is important to notice the following points in regard to the rate of production of the bird.

1) Periods of production alternate with periods of non-production. That is the bird lays in litters.

2) The length of the periods of production and the number of eggs laid in one litter vary at different seasons of the year.

3) Throughout the warm months (April to September) the period of non-production is typically a period of broodiness. That is the instinct of the bird is to lay a litter of eggs and then incubate them. While thirteen of the birds show this instinct so typically illustrated by bird No. 218 (see letters $B$ on diagram Plate $\mathrm{X}$ ) nine were never broody. It is also interesting that broodiness or non-broodiness is typical of the individual, for when a bird was broody the first year she was also broody the second year and if she was not broody the first year she did not show this instinct the second year. There was only on exception to this. Bird No. 259 was broody just once during the first year and was not broody at all during the second year. An 
examination of the facts indicates that the birds are separated into two classes, first those which possess the broody instinct and, second, those which do not. But the degree to which the instinct is manifested varies. The number of times a bird was broody during the first year varied from zero to seven. The frequency distribution is given in Table 33.

Table 33. Showing the frequency distribution of the number of times an individual was broody during her pullet year.

\begin{tabular}{c|c}
\hline \hline Number of times brody & Number of birds \\
\hline 0 & 9 \\
1 & 1 \\
2 & 1 \\
3 & 3 \\
4 & 2 \\
5 & 4 \\
6 & 1 \\
7 & 1 \\
\hline Total. & 22
\end{tabular}

This table shows that typically a bird which was broody at all was broody four or five times but that the number of times varied with the individual. From an examination of the daily egg records or the charts similar to Plate $\mathrm{X}$ for the nine birds which were never broody it was seen that they show all degrees of a tendency to lay in litters from the extreme case of No. 165 which laid from February to the end of the year at a nearly uniform rate, i. e., in clutches of 1 to 3 usually two eggs separated by one or two days on which no egg was laid, to the opposite extreme of No. 137 which laid in. litters. She had exactly the same definite periods of non-production as bird No. 218 but she lacked the instinct to incubate the eggs.

4) Within a litter the laying is broken up into elutches. The eggs of a clutch are laid on successive days. The clutches are separated by one or two (occasionally more) days on which no eggs are produced.

5) The number of eggs in a clutch and the number of days between clutches vary in the different birds in the same season and in the same bird at different seasons. At the beginning of laying the clutches are usually small (two or three eggs)... The number of eggs laid on successive days increases slightly in December and decreases in January at the end of the winter laying. When the lay- 
ing begins again in February the number of eggs in a clutch is small at first but soon shows a marked tendency to increase. During February, March and April single eggs and two egg clutches are rare ${ }^{1}$, while clutches of three, four, five, and six eggs are common. After the first broody period in April the size of the elutch again increases, five to seven eggs being the rule but there are occasionally one and two egg clutehes. After the second broody period in May the individuals show a great deal of variation in the size of the clutch. Bird No. 218 (see Plate X) begins the litter with her largest clutch (18 eggs), while the size of the first clutch of the other birds varies from one to nine. As a rule, however, the first elutch is small and the number in the successive clutches at first increases and then decreases toward the end of the litter. There is also a great deal of variation in different individuals in the size of the clutches after the June broodiness. Most of the birds including No. 218 start the litter with small clutches. The size of the successive clutches first increases and then decreases, but there is an exception to this rule. No. 441 starts the litter with a four egg clutch and then lays only single eggs until the middle of July when the size of the clutch increases to 4 and 5 . It decreases again at the end of the litter in August. The next broody period comes typically somewhere in July or early August. In the case of several birds the litter which follows this broody period starts with small clutches which increase in size and then decrease but five heavy laying birds start this litter with a large clutch (8 to $14 \mathrm{eggs}$ ) and then produce smaller clutches. No. 218 is one of these five birds. Through September and October the laying is in one to four egg clutches. The few egg produced during November, December, January and February are single eggs or in a few individuals single eggs with occasionally two and three egg clutches.

These facts indicate that during the part of the year when the bird is not laying in litters succeeded by broody periods the size of the clutches is small. The birds which lay continuously (i. e., do not lay in litters) lay in small clutches throughout the season. During the part of the year when periods of production alternate with periods of broodiness the litters show a decided tendency to start and end with small clutehes while the number of eggs in the intermediate

1) Some of the birds which did not show the broody instinct laid small clutches throughout the season. 
clutches is larger. An individual may nevertheless start or end a litter with large clutches.

These facts, in general, accord with the hypothesis of PearL and Surface 1). The actual visible egg production in each individual bird tends to occur in definite cycles or periods of varying lengths, alternating with non-productive periods.

* The rate of fecundity (amount of egg production per unit of time conceived in the sense of the differential calculus) is in any bird a minimum at the beginning of the cycle of production increases to a maximum at what may be termed the height of the cycle and decreases to a minimum as the end of the cycle is approached."

The diagrans given in Plate $\mathrm{X}$ show the weight of the egg and each egg part for each day on which an egg was laid. The line I represents egg weight; the line II, albumen weight; the line III, yolk weight and the line IV, shell weight. When eggs were laid on successive days the points are connected with a solid line when two or more days elapse between successive eggs the points are connected with a dotted line. Therefore the number of successive points connected by solid lines represent the number of eggs in a clutch. The basal units between successive points connected by dotted lines represent the number of days between the clutches. A letter $B$ on the egg weight curve indicates the day on which the bird became broody.

The relation of the egg weight to the age of the bird and the season of the year has already been investigated by the use of monthly means. The conclusions brought out from that study (pp. 298 and 301) are illustrated in this diagram. The chief interest of the diagram, however, is that it shows the relation of the weight of the egg and of each egg part to its position within the clutch and litter.

\section{Relation of the Weight of the Egg to its Position in the Litter.}

In a short note on the variation in the weight of the eggs of the domestic fowl Féré ${ }^{2}$ makes the following statement.

1) Pearl, R., and Surface, F. M., A Study of Egg Production in the Domestic Fowl. II. Seasonal Distribution of Egg Production. U. S. Dept. of Agl. Bur. An. Ind. Bull. 110. Part II. 1911.

2. Fúré, M. Ch., Note sur le poids de l'œuf de poule et sur ses variations dans les pontes sncessives. Joumal de l'Aiatomie et de la Physiologie. Tom. 34. 1898. pp. 123-127. 
A Biometrical Study of Egg Production in the Domestic Fowl. IV. 311

»Les variations les plus faciles à constater sont celles qui sont en rapport avec la période de la ponte et la succession des pontes. En général le premier ouf de la ponte est moins lourd que les suivants et a la fin de la ponte on observe un abaissement du poids de l'cuf. Mais cet abaissement final n'est pas constant. *

By the variation related to the succession of the litters FÉRÉ refers to the increase in mean egg weight as the bird becomes older. By his variation related to the period of the $>$ ponte he refers to the size of the egg due to its position within the litter. His statement that, in general, the eggs at either end of the litter are smaller than the intermediate ones but that this relation is not absolute is verified by the observations on the birds used in the present investigation. Bird No. 218 (Plate $\mathrm{X}$ ) for example shows this relation for several litters. In fact the weight of the egg in relation to the position within the litter approximates a curve of the type of the hypothetical * rate of fecundity* curve proposed by PEARL and SurFACE ${ }^{1}$ ) (1911). It thus seems possible that the same conditions which cause fluctuations in the rate of production may also be responsible for the cyclic fluctuation in the egg weight. It is certain, however, that the weight of the egg is also related to the position of the egg in the clutch and that the position of the egg in the clutch and in the litter may have opposite effects on the size.

\section{Relation of the Weight of the Fgg to its Position in the clutch.}

From Plate $X$ it is seen that when an egg was produced on each day for a number of successive days, as a rule, the eggs decreased in weight from the first egg to the end of the series. The first egg after a day on which no egg was laid was larger than the egg at the end of the preceding series. That is the eggs of the clutch decrease in size from the first egg. The first egg of a new clutch is larger than the last egg of the preceding clutch. This is shown in all the clutches of the first period of production. Later there were some exceptions to this especially where a litter begins with a long clutch as in February, May and August of 1911 and July of 1912.

WILLARD and SHAw ${ }^{2}$ ) made chemical analyses of all the eggs laid between July 18 and August 1, 1905, by twenty-three birds of

1) Pearl and Surface, loc. cit.

2) Willard, J. F., and Shaw, R. H., Analyses of Eggs. Kans. Agr. College. Bull. 159. 1909. pp. 143-177. 
four different breeds. Their tables also show the weights of the successive eggs of each of these birds and they make the following statement in regard to egg weight.

-In respect to the weights of the eggs, study of the tables shows that a bird may be credited with an egg each day for several days and then a day is skipped, or perhaps more than one day. In many instances it may be seen that during the time that the eggs are laid daily the weight becomes constantly smaller, then after a day or two of rest the eggs produced are again larger... It will be seen that there are here several striking series of the kind indicated, in which a day with no egg followed a continued diminution in the size and preceded a series beginning with an increased weight. On the other hand, there are several exceptions to the regularity of change... On the whole, however, a tendency in this direction must be conceded.*

This agrees entirely with the observations made on the birds used in this investigation. In most cases the eggs of a clutch tend to decrease in size, while the first egg of a succeeding clutch is considerably larger than the last egg of the clutch which preceded. This decrease may be seen by comparing the successive eggs of a bird as shown in Plates VI, VII and VIII. In these plates the eggs of a clutch are placed side by side. (Note in Plate VI that the 24th egg of bird No. 205 should be placed next to the 25 th since they were laid on successive days.) From these plates it is easily seen that in most cases where two or more eggs were laid in succession the eggs decreased in size. For example the 35th, 36th and 37th eggs of bird No. 446 (Plate VII) and the 36th and 37th of bird No. 139 (Plate VI). Two very apparent exceptions are also shown. Of the three eggs laid December 21, 22 and 23 by bird No. 478 (Plate VIII) the middle egg is the smallest and the last egg the largest, and of the three eggs laid by 205 (Plate VI) on the same days the middle egg is largest and the first egg smallest.

The fact that in general the eggs laid on successive days decrease in size while after a day or two on which no egg is produced the egg size increases seems to indicate that there is either an exhaustion of material available to elaborate into the various egg parts or that there is a fatigue of the reproductive organs which causes a decrease in the amount of material elaborated. A variation in the supply of available materials or a variation in the physiological tone of the organs would account for the cases of unusual size relations between successive eggs. 
It has now been shown that the variation in egg weight is related to the age of the bird, the season of the year, the state of health and the rate of egg production.

The correlation between the weight of the several parts discussed in Part II is shown graphically in Plate X by the tendency toward simultaneous fluctuations in the same direction in all the parts, while the possibility of independent variation of the parts discussed in Part I is illustrated by certain exceptions to this tendency for all the parts to fluctuate in the same direction at the same time.

The weight of all the egg and egg parts for the individual birds for two years furnish material to test PEARL's ${ }^{1}$ ) ('07) » second law of growth i. e., that the variability of successively produced like parts decreases with the number of such parts produced. If this law was operating during the production of successive eggs the magnitude of the fluctuations in egg weight would decrease with the number of eggs laid. Plate $\mathrm{X}$ and similar diagrams for each of the other birds show that the fluctuations in egg weight and weight of each of the egg parts are as large at the end of the second as at the beginning of the first year. It is evident then that this law does not hold for the variation in weight of successive eggs. PearL ${ }^{2}$ ) ('09) found no evidence that this law was acting in regard to the shape of the eggs of a fowl on which he studied regulation in shape.

\section{Summary to Part III.}

1) There is an increase in the weight of the whole egg and of each of its parts from the beginning of laying to the end of the second year. That is the weight of each part increases with the age of the bird.

2) The monthly mean yolk weight increases with the increasing age of the bird according to the equation

$$
y=A+B x+C \log x
$$

where $y$ denotes monthly mean yolk weight, $x$ denotes age of the bird and $A, B$ and $C$ are constants. That is the yolk weight increases with the successive months from the beginning of laying to the end of the second year but the rate of increase diminishes with the successive months.

\footnotetext{
1) Peart, R, loc. cit.

2) Pearl, R., loc. cit.
} 
3) The change in rate of increase in yolk weight is similar to the change in rate of growth and differentiation in an organism.

4) The increase in albumen weight with the age of the bird is in general similar to the change in yolk weight, but the fluctuations are greater.

5) The increase in shell weight with the age of the bird is not logarithmic.

6) There is a seasonal fluctuation in the weight of each of the parts of the egg. This is greater in albumen weight than in the weight of the other parts.

7) This seasonal fluctuation is no doubt due, in part, to the indirect effect of environmental conditions, i. e., to such conditions as cause physiological changes in the individual.

8) Diseased conditions may cause a decrease in the weight of each of the parts of the egg: but sudden physiological disturbances may cause death without decreasing the weight of any part of the egg formed on the day of death.

9) Egg production in an individual occurs in periods which alternate with periods of nonproduction. Throughout the warm months the periods of nonproduction are typically periods of broodiness. That is the bird typically lays a litter of eggs, then incubates them.

10) The litter is composed of elutches of varying length. That is the bird lays an egg on each day for from two to eighteen days and then skips one or more days.

11) In general the observations made in this investigation confirm the hypothesis of Pearl and Surface (1911) that sthe rate of fecundity (amount of egg production per unit of time conceived in the sense of the differential calculus) is in any bird a minimum at the beginning of the cycle of production increases to a maximum at what may be termed the height of the cycle and decreases to a minimum as the end of the cycle is approached «.

12) In general the weight of the egg and of each egg part increased from the beginning of a cycle until it reached a maximum for the cycle then decreased toward the end of the cycle.

13) The eggs of a clutch on the other hand normally decrease in size from the first egg.

14) The weight of any bird's egg depends, first, upon the hereditary constitution of the bird, second, her physical constitution or state of health, third, her stage of development, fourth, the season of the year, and fifth, the position of the egg in its clutch and litter. 
A Biometrical Study of Egg Production in the Domestic Fowl. IV. 315

15) The degree of variation in the weight of the egg or of any of its parts does not decrease with the number of eggs produced. That is the variation in successive eggs is as great at the end of the second as at the beginning of the first year's laying.

\section{Discussion of Results.}

Only a beginning of the analysis of the factors which produce variation in the eggs of the domestic fowl is possible from the results of this investigation.

Since the individual variation in egg characters is less than race variation, and since the association of various pairs of egg characters is greater within the egg of an individual than within the eggs of the race, it is concluded that an individual inberits or, at least, possesses at sexual maturity, the tendency to lay eggs of a certain particular and individual shape, size and physical constitution.

The seasonal and cyclic fluctuations in the eggs of the individual on the other hand show that this predisposition toward eggs of a particular type and size may be influenced by physiological and possibly also environmental conditions.

That the individuality in egg characters is related to individuality in other characters seems certain. The fact that the large varieties of hens lay larger eggs than bantams indicates that within broad limits the size of the egg is related to body size. The insignificance of the correlation coefficient between egg size and body size for the egg of the individuals studied however shows that this relation does not necessarily obtain within narrow limits. It is not possible to decide the limits of the relation of body size to egg size from so small a number of individuals. The point is open to further investigation.

In the study of egg characters it must be kept in mind that eggs are quite different material than is usually employed in biological studies of variation. They are not organs or parts of organs that owe their size and shape to growth, i. e., the proliferation of the cells of which they are made up. Each egg is one modified cell and represents the accumulated results of the activity of a great many other cells. The different parts of the egg arise from different organs or parts of organs (the ovary and the parts of the oviduct) and by quite distinct physiological processes (yolk deposition and albumen, membrane, and shell secretion). 
The egg then represents not a normal organic part of the individual but a discrete unit of production of certain correlated organs. The size and form of such units are to a certain extent dependent upon the size and form of these organs. But the size, form and frequency are necessarily also dependent upon the physiological tone of the organs and of the entire organism.

It is not strange that the same individual at different seasons and different individuals throughout the year may show variations in egg size and in the number of eggs produced which are out of proportion to the variation in body size. It is quite possible that egg production like milk production ${ }^{1}$ ) is related to the amount of food consumed above maintenance. That is the bird which lays large eggs and many of them is one which in addition to the organic potentiality to lay eggs of this size possesses also both the physiological capabilities of digesting a large amount of food above the amount required for the maintenance of the body and of using this absorbed food for the production of yolk, albumen, etc. The fact that the same individual lays larger eggs and more of them at certain seasons than at others may be due to the fact that she is capable of digesting and utilizing for egg production more food at those seasons. It has in fact been shown by RICE ${ }^{2}$ ) that the number of eggs produced by a flock is positively correlated with the amount of food consumed, and the fluctuations which he found characteristic for the amount of food consumed are very similar to the seasonal fluctuations in egg weight. The work of RIDDLE ${ }^{3}$ ) on yolk formation also supports this view. He gives the following ${ }^{4}$ ) outline of the processes involved.

* Yolk formation as it is indicated by the facts presented in this paper may be connectedly outlined as follows: Yolk will be formed 1) when conditions are such in the egg, follicle cell, food-supply, or organism that excess of food may enter the egg; but 2) in those regions only where some excess of food fat (and protein) can exist without undergoing oxidation; 3) the maintenance of such excess of food is dependent upon the amount of food, or upon marked fluctuations in

1) Eckles, C. H., and Reed, O. E., A Study of the Cause of Wide Variation in Milk Production in Dairy Cows. Mo. Agr. Expt. Sta. Research. Bull. No. 2. 1910.

2) RICE, J. E., loc. cit.

3) RIDdLe, Oscar (1911), On the Formation Significance and Chemistry of White and Yellow Yolk of Ova. Journ. of Morphol. Vol. 22. pp. 4ō6-484.

4) loc. eit. p. 481. 
the amount of food outside the egg, and 4) upon the distribution coefficient of the elements of yolk in the substance inside and immediately outside of the egg, and doubtless by other undetermined conditions within the egg; 5) the actual and active processes of yolk increase or decrease are essentially identified with the partially known synthetic and analytic, - i. e., reversible-action of the enzymes which act upon the constituents of yolk; 6 ) in the first stages of the growth of a (white yolk) yolk spherule the proportion of fats and phosphatids in its composition is small; 7) in later and more complete (yellow yolk) stages the proportion of these constituents is large..

That is the laying down of yolk occurs only when there is in the blood an excess of fatty acid, $i$. e., when the bird is assimilating more of this kind of food than is needed for immediate use, or is utilizing for this purpose reserve fat. Since the quantity of reserve fat is comparatively limited, absorbed food must be the most important source of supply.

In general the conditions which favor the production of a large number of eggs also favor the production of large eggs (i. e., large for the particular individual). Yet there are limits to this relationship. When a number of eggs are produced in succession each successive egg is smaller than its predecessor. There is probably either an over-demand on the amount of available material or there is a fatigue of the reproductive apparatus which hinders the formation of the egg parts. A study of the interrelation of the different parts of the egg is a study of the correlation of the activities of the different organs and parts of organs by which they are formed. The fact that the oviduct of a bird approaching a period of laying enlarges as the yolks enlarge has been long recognized. The observations on the domestic fowl at this laboratory agree in general with those of BaRTELMEZ $^{1}$ ) on pigeons. There are nevertheless some specific differences between fowls and pigeons. In a bird in the non-laying condition the oviduct is a small straight tube and there are no oocytes on the ovary which contain a perceptible amount of yolk. About the time a group of oocytes enter upon the final growth period (when they begin to enlarge above $6 \mathrm{~mm}$.) the oviduct begins to enlarge. The stimulus which initiates these activities in fowls is not known. There is no evidence that it is connected with mating as has been

1) Bartelmez, George W., The Bilaterality of the Pigeon's Egg. Journ. of Morph. Vol. 23. 1912. pp. 270-310. 
shown for the pigeon 1). The presence of the male is certainly not necessary and no behavior on the part of a fowl has been observed to indicate that she is physically mated with another female or with anything else. Whatever the stimulus that starts the reproductive mechanism going, it is true that while the first yolk is forming the oviduct enlarges to functional size.

This correlation between the ovary and oviduct is now commonly attributed to the action of the internal secretion of the ovary. BARTELMEZ ${ }^{2}$ ) states that interstitial cells of the ovary show much greater signs of activity in functioning ovaries than do those in ovaries of birds that had not laid for a long times. That the enlargement of the oviduct is due to the internal secretion of the ovary has not been completely demonstrated by any means. Certain observations made in connection with other researches make the conclusion somewhat doubtful. They certainly show that enlargement of the oviduct is not necessarily connected with yolk formation although this is the normal relation.

The observations referred to are:

1) The oviduet of the hermaphrodite fowl described by PeARL and CuRTIS ${ }^{3}$ ) was at autopsy in essentially the same condition as that of a normal hen that bad recently completed or was soon to begin an egg laying period. Yet this bird had never laid and the histological examination of the ovary failed to demonstrate the presence of oocytes in any stage of development. The ovary of this hen was about the size of a functioning ovary after the large yolks have been removed. It was composed of a highly cellular stroma like tissue penetrated from the stalk by a very vascular connective tissue and covered externally by a layer of peritoneum. The presence of interstitial cells could not be demonstrated, but this may have been due to poor fixation 4 .

1) HARPER, E. H., The Fertilization and Early Development of the Pigeon's Egg. Am. Journ. Anat. Vol. 3. 1904. pp. 344-381.

CraIG, W., Oviposition Induced by the Male in Pigeons. Journ. of Morph. Vol. 22. 1911. pp. 299-305.

2) Bartelmez, G. W., loc. cit.

3) Pearl, R., and Curtis, M. R., Studies in the Physiology of Reproduction of the Domestic Fowl. A Case of Incomplete Hermaphroditism. Biol. Bull. Vol. 17. 1909. pp. 271-286.

4) The whole reproductive apparatus and the dorsal part of the body was preserved in formalin and dissected for anatomical study. 'The histological sections of this formalin tissue showed rather poor fixation. 
A Biometrical Study of Egrg Production in the Domestic Fowl. IV. 319

2) In the routine autopsy work in this laboratory there have been noted several cases of birds which had not laid for a long time and which bad no oocytes with any yolk but which possessed nearly functional sized oviducts. There were in these cases ovarian tumors which seemed here to be associated with the enlarged oviducts. None of these ovaries were examined for interstitial cells which may or may not have been present.

That the mere increase in weight of the ovary may stimulate the enlargement of the oviduct is not altogether impossible. These pathological ovaries may however have furnished the normal internal secretion in quantities sufficient to cause the enlargement of the oviduct. It is nevertheless certain that whatever the stimulus may be it is not absolutely dependent upon the deposition of yolk. The teleological view that the oviduct enlarges in order to be ready to lay the first egg is not tenable. Normally the oviduct enlarges while the yolks enlarge and reaches functional efficiency by the time the first yolk is mature.

The stimuli which initiate the peristaltic action of the oviduct and attract the funnel to the mature follicle are among the unsolved problems of physiology. The yolk is already oriented in the follicle before the funnel encloses it. In pigeons ${ }^{1}$ ) both chalazal and polar axes are determined in the primordial follicle; the first by the long axis of the oocyte and the second by the eccentric germinal vesicle. The polar orientation of the egg in the follicle is due to the action of gravity after the yolk becomes movable in the follicle (at the time of the formation of the zona radiata. The vegetative pole is heavier than the animal pole, hence the animal pole comes to lie beneath the stalk of the follicle.

Due to the pressure of the inclasing funnel and to increased internal pressure, the yolk ruptures the follicle and becomes free in the duct. At this time the secreting activity of the duct begins. Again the precise nature of the stimulus is not certainly known. It is normally connected with the presence of the yolk; but albumen secretion followed by normal membrane and shell formation have been induced in functioning oviducts by the insertion of artificial yolks. Results of this kind are reported by WEIDENFELD $^{2} j$ and TARCHANOFF ${ }^{3}$ ).

1) Bartelinez, G. W., loc. cit.

2) Weidexreld, Verh. d. Ornithol. Gesellsch. Bayern. 1905. S. 112.

3) Tarchaxofr, J. R., Über die Verschiedenheiten des Eiereiweißes bei befiedert geborenen (Nestflïchter) nnd bei nackt geborenen (Nesthocker) Vögeln 
Unpublished investigations at this laboratory have also shown that an egg may be formed around an artificial yolk or the artificial yolk may be fastened in the upper part of the oviduct and an egg may be formed which contains chalazae, both kinds of albumen, normal membrane and shell. This last result as well as the not infrequent occurrence of small yolkless eggs which contain all the other normal egg parts show that the secretory process may be started off by some adequate stimulus (possibly in the case of the yolkless eggs by the presence of a yolk in the oviduct which is later expelled into the body cavity) and may then continue to completion without the presence of the yolk. The results with artificial yolks indicate that the stimulns may be mechanical but the experiments of TARCHANOFF' ${ }^{1}$ and unpublished work done in this laboratory also show that an egg is not always formed around an artificial yolk introduced into an oviduct which is in functional condition. Until the other conditions necessary for the formation of eggs with artificial yolks are determined it cannot be certainly said that the only stimulus necessary is mechanical.

That the amount of albumen secretion of the oviduct is related to the degree of the stimulation by the yolk is shown by the significant correlation between the weight of the yolk and the weight of the albumen. Since the secretion of the duct does not begin until the yolk has completed its growth and severed its connection with its follicle this seems to be the only possible explanation of the correlation. To this evidence that the degree of stimulation influences the amount of secretion may be added that from abnormal eggs which contain unusually large or small quantities of yolk. On the one hand are the double and triple yolked eggs and on the other the pockeggs « or » witch-eggs « which contain little or no yolk. PearL $\left.{ }^{2}\right)$ ('10) showed that $\gg$ the relation of the observed size of the entire egg (measured here by the weight) to the number of yolks is very accurately described by a parabola $*$. He pointed out that this indicated that the amount of albumen secreted was related to the amount of the immediate mechanical stimulation due to the quantity of yolk present in the oviduct.

und über die Verhältnisse zwischen dem Dotter und dem Eiereiweiß. PflüGERs Areh. f. Physiol. Bd. 33. 1884.

1) Loc. cit.

2) Pearl, R., A Triple Yolked Egg. Zoologischer Anzeiger. Bd. 35. 1910. S. 418-423. 
The formation of the egg membrane is a discrete process. As an egg passes from the albumen portion into the isthmus as much of it as is within the isthmus is covered with membrane 1 ). The membrane becomes thicker during the passage through the isthmus ${ }^{2}$ ) probably by the addition of successive layers of secretion.

When the egg enters the uterus it is enclosed in a firm tough membrane and is often if not always already shaped. It contains the yolk with chalazae and 60 to 70 percent of its albumen ${ }^{3}$ ).

Within the uterús the egg receives the rest of its albumen (by osmosis) and its shell. The nature of the stimulus which sets up the shell secreting activity was investigated by PearL and Surface 4). The conclusions from their preliminary experiments were that the nature of the immediate stimulus which sets the shell secreting activity going in an oviduct in active functional condition is mechanical, and that shell formation is a local reflex not immediately dependent upon a specific activity of other portions of the reproductive apparatus.

That the weight of the shell is significantly correlated with the weight of each of the other parts indicates that the amount of secretion is influenced by the degree of stimualation. The larger the egg the greater the mechanical stimulation and hence the heavier the shell. The higher correlation between albumen and shell than between yolk and shell is probably due almost entirely to the fact that the albumen is heavier than the yolk. It may be partly due to the fact that 30 to 40 percent of the albumen is secreted in the uterus and that the periods of the albumen secretion and shell secretion overlap although the former is evidently complete before the latter has advanced very far ${ }^{5}$.

Abnormally-thin shelled eggs are as likely to be large as small and no doubt represent either a premature expulsion of the egg or an early arrest of the shell secreting activity. Paris 1874.

1) Coste, M., Histoire du développement des corps organisés. Tome I.

2) Pearl and Curtis, Studies in the Physiological Reproduction of the Domestic Fowl. V. Data Regarding the Physiology of the Ovidact. Journ. Exp. Zool. Vol. 12. 1912. pp. 99-124.

Membranes on eggs just completely past the cranial end of the isthmus weigh .24 to .28 grams. Those at the caudal end .53 to .58 grams.

3) Pearl and Curtis, loc. cit.

4) Pearl, R., and Surface, F. M., Science, N.S. Vol.29. 1909. pp. 428 - 429.

5) Pearl and Curtis, loc. cit. 
The shape of the egg is almost certainly due to the interaction of the two layers of muscle fibers in the oviduct walls 1 ). The inner layer of fibers is circular, that is they pass around the duct. The outher layer is longitudinal and somewhat spiral and extend into both the dorsal and ventral ligaments. Further work on the physiology of these muscles is necessary to determine the exact way in which they act. From their position and from observed activities of the duct it seems that the contraction of the circular fibers contract the duct and move the egg forward. The contraction of the longitudinal somewhat spiral fibers expand the duct, diminishing the resistance to the passage and also give the egg the spiral motion. If the resistance is slight, i. e., if the contractions are so timed that the duct ahead of the egg is expanded at the time of the contraction of the circular fibers behind, the egg will be long, narrow and pointed. On the other hand, if the resistance is great the egg will be short and broad.

The individuality of the eggs of a bird in respect to shape must be due to an individuality in the coordination of these two sets of muscle fibers and similarily the variation must be due to a variation under different conditions in the degree of coordination.

Breadth is more closely correlated with weight of the whole egg or with the weight of any of the parts than is length. This may be explained by the assumption that the larger the egg (beginning with the yolk) the greater the resistance to its passage and hence the broader it will be in proportion to the actual weight. This may be simply the mechanical effect of a larger body passing through the elastic tube or it may be due to an unequal increase in the effective stimulation of the two sets of muscle fibers.

\section{General Summary.}

This paper is a contribution to the analysis of the normal variation in the size, shape, and physical constitution of the eggs of the domestic fowl. The data on which it is based are the measurements of all of the eggs laid by twenty-two Barred Plymouth Rock birds. For thirteen of these birds records were taken on every egg laid up to

1) Curtis, M. R., The Ligaments of the Oviduct of the Domestic Fowl. Ann. Rept. Me. Agr. Expt. Sta. 1910. pp. 1-20

Surface, F. M., The Histology of the Oviduct of the Domestic Hen. Ann. Rept. Me. Agr. Expt. Sta. 1912. pp. 395-430. 
A Biometrical Study of Egg Production in the Domestic Fowl. IV. 323

the end of the second laying year. For the remainder records were taken covering the eggs of the first laying year. The thirteen birds which were alive at the beginning of their second adult molt were killed at that time. The more important results of the investigation may be summarized as follows:

I. The Individuality of the Eggs of the Same Bird.

1) The individuality of a bird is expressed in each physical character of her eggs.

2) The variation between the eggs of the different individuals is greater in respect to size than shape and it is also greater in respect to weight of albumen and shell than weight of yolk.

.3) There is a tendency for the several egg characters to be related to each other in such a way that when the eggs of an individual are large they are both long and broad and each of the parts is large; but the birds which lay large eggs lay eggs with a smaller proportion of yolk than birds which lay small eggs. Also individuals may show a decided tendency to vary from the flock type in quite different degrees in different characters.

4) The eggs of an individual tend to be either uniform or variable in all the egg characters but certain individuals may be variable in certain egg characters and uniform in others.

5) An individual is in general less variable than the race in respect to egg characters; but certain individuals may show a variation in an egg character which is relatively as great as the variation in the race. Also certain egg characters (particularly yolk weight) show a decided tendency to approach the race variation in several individuals.

6) The factors which bring about the individuality in respect to egg characters are too complex for analysis from the data at hand, but such data as were collected on other characters of the birds are presented.

The detailed summary of the results of the investigation regarding the individuality of the eggs of the same bird is given at the end of Part I (see page 253).

\section{Correlation of Egg Characters.}

1) Each egg character is related to every other egg character, bat different pairs of characters show a decidedly different degree of 
correlation. There is a general tendency for a given pair of characters to be similarly related in the eggs of the several individuals, but different individuals may show significantly different degrees of correlation in any pair of characters.

2) Length and breadth are significantly but not highly correlated. Both length and breadth are significantly correlated with the weight of the whole egg and of each of the egg parts. Breadth is as a rule more highly correlated with these weight characters than is length. The shape of the egg as measured by the length-breadth index is negatively correlated with the weight of the egg and with the weight of each of the egg parts.

3) The weight of each part of the egg is positively correlated with the weight of both the other parts.

A more complete summary of the results regarding the interrelations of the egg characters is given at the end of Part II (see page 271 ).

\section{Intra-individual Variation.}

1) The variation among the eggs of the same bird is shown to be related to certain other changes in the bird.

2) The egg weight and the weight of the egg parts, especially the weight of the yolk, increases as the bird matures. The rate of this gain in weight decreases with the successive months.

3) Each part of the egg shows a seasonal fluctuation in weight which is apparently related to the general seasonal fluctuation in the physiological activities of the bird, expressed also in the curves for food consumption and egg production.

4) The state of health also affects the size of the egg.

5) The size of the egg is related to the rate of production as it expresses itself in the laying of litters. As a rule the first and last eggs of a litter are smaller than the intermediate ones.

6) When eggs are produced on successive days they tend to decrease in weight while the egg laid on a day after one on which no egg is produced is larger than the last egg of the preceding series.

Part III is an analysis of the variation among the eggs of the same bird and a full summary of the investigation on this point is given on page 323 . 
A Biometrical Study of Egg Production in the Domestic Fowl. IV. 325

\section{Zusammenfassung.}

Die vorstehende Arbeit ist ein Beitrag zur Analyse der normalen Variation der Eier unseres Hausgeflügels in bezug auf Größe, Gestalt und physische Beschaffenheit. Die ihr zugrunde liegenden Tatsachen bilden die Messungen an sämtlichen von 22 Vögeln der Barred Plymouth Rock-Rasse gelegten Eiern. Bei 13 von diesen Vögeln warden die Daten für jedes bis zum Ende des zweiten Legejahres gelegte Ei registriert. Bei den übrigen geschah dies nur im Bereich der Eier des ersten Legejahres. Die 13 Vögel, die beim Beginn ihrer zweiten Mauser in erwachsenem Zustande am Leben waren, wurden zu dieser Zeit getötet. Die wichtigeren Ergebnisse der Untersuchung lassen sich wie folgt zusammenfassen:

I. Die Individualität der Eier desselben Vogels:

1) Die Individualität eines Vogels findet in jeder physischen Eigenschaft seiner Eier ihre Ausprägung.

2) Die Veränderlichkeit der Eier verschiedener Individuen ist größer in bezug auf Größe als auf Gestalt, ebenso ist sie größer in bezug auf das Gewicht des Eiweißes und der Schale als in bezug auf das Dottergewicht.

3) Die verschiedenen Eieigenschaften zeigen eine Tendenz, sich derart miteinander in Beziehung zu setzen, daB, wenn die Eier eines Individuums groß sind, sie sowohl lang als breit sind und auch jeder ihrer Teile groß ist; aber die Vögel mit großen Eiern legen Eier mit einem verhältniemäßig kleineren Dotter als die Vögel, welche kleine Eier legen. Ebenso können einzelne Individuen eine ausgesprochene T'endenz zeigen, in ganz verschiedenem Grade für verschiedene Eigenschaften vom Herdentypus zu variieren.

4) Die Eier desselben Individuums zeigen eine Tendenz entweder zur Gleichförmigkeit oder zur Variabilität in allen Eicharakteren; gewisse Individuen können aber in gewissen Eicharakteren variabel, in andern uniform sein.

5) Im allgemeinen zeigt ein Individuum beziiglich der Eicharaktere geringere Variabilität als die Rasse; gewisse Individuen können aber Verschiedenheiten eines Eicharakters aufweisen, die verhältnismäßig ebenso groß sind als seine Variation bei der betreffenden Rasse. Ebenso zeigen gewisse Eicharaktere (speziell das Dottergewicht), bei manchen Individnen die ansgesprochene Tendenz, sich der Variationsbreite der Rasse anzunähern.

6) Die Faktoren, welche die Individualität bezüglich der Eicharaktere herstellen, sind für eine Analyse an der Hand der vorliegenden Tatsachen zu kompliziert, es werden aber die bezüglich anderer Eigenschaften der Vögel gesammelten Tatsachen gegeben.

Die detaillierte Zusammenfassung der Furchungsergebnisse beziiglich der Individualität der Eier eines und desselben Vogels findet sich am Ende des ersten Teiles (vgl. S. 253).

\section{Korrelation von Eicharakteren:}

1) Jeder Eicharakter steht in Beziehung zu jedem andern Eicharakter; aber verschiedene Paare von Eigenschaften zeigen einen ansgesprochen verschiedenen Korrelationsgrad. Für ein gegebenes Paar von Charakteren besteht eine allgemeine Tendenz, sich in den Eiern der einzelnen Individuen korrelativ ähnlieh 
zu verhalten, verschiedene Individuen können aber für jedes Charakterenpaar bezeichnend verschiedene Korrelationsgrade aufweisen.

2) Länge und Breite stehen deutlich, aber nicht hochgradig miteinander in Beziehung. Beide stehen dentlich mit dem Gewicht des ganzen Eies und dem eines jeden seiner Teile in Korrelation. Die Breite steht in der Regel mit diesen Gewichtscharakteren in innigerer Beziehung als die Länge. Die Eigestalt, gegemessen durch den Längen-Breiten-Index, steht mit dem Gewicht des Eies und dem seiner einzelnen Teile in negativer Beziehung.

3) Das Gewicht jedes Eiteiles steht in positiver Korrelation mit dem Ge* wicht der beiden andern Teile.

Eine vollständigere Zusammenfassnng der Ergebnisse in bezug auf die Korrelation der Eicharaktere unter sich findet sich am Ende des zweiten Teiles (vgl. S. 271).

III. Variation in ein und demselben Individuam:

1) Es wird gezeigt, daß die Variation der Eier desselben Vogels mit gewissen andern Veränderungen desselben in Beziehung steht.

2) Das Ganzgewicht und die Teilgewichte des Eies, speziell das Dottergewicht, vergrößern sich mit der zunehmenden Reife des Vogels. Der Betrag dieser Zunahme nimmt in aufeinanderfolgenden Monaten ab.

3) Jeder Eiteil zeigt saisonale Gewichtsschwankungen, welche mit den allgemeinen saisonalen Schwanknngen der physiologischen Aktivitäten des Vogels anscheinend in Beziehung stehen, die sich auch in den Futterverbranchsund Legekurven auseprechen.

4) Auch der Gesundheitszustand hat Einfluß auf die Eigröße.

5) Die Eigröße steht in Beziehung zu dem Produktionsaufwande, der sich in der Ablage der Gelege ausspricht: Gewöhnlich sind die ersten und letzten Eier eines Geleges kleiner als die dazwischen abgelegten.

6) An direkt anfeinanderfolgenden Tagen abgelegte Eier tendieren zur Gewichtsverminderung, während das nach einem legefreien Tage hervorgebrachte Ei größer ist als das letzte der vorhergehenden Serie.

Der dritte Teil ist eine Analyse der Variation der Eier desselben Vogels; eine erschöpfende Zusammenstellung der Untersuchungen über diesen Punkt findet sich auf S. 323 .

(Übersetzt von W. Gebhardt.)

\section{Explanation of Plates.}

\section{Plate VI.}

A photograph of series of eggs laid by birds No. 139 and No. 205. The label on each egg shows at the top of the bird number; in the center the series number (the eggs are numbered from the first egg laid); and at the bottom the date on which the egg was laid. $>1 / 2$.

\section{Plate VII.}

A photograph of series of eggs laid by birds No.446 and No.212. For the significance of the numbers on the labels see the explanation of Plate VI. $\times 1 / 2$. 


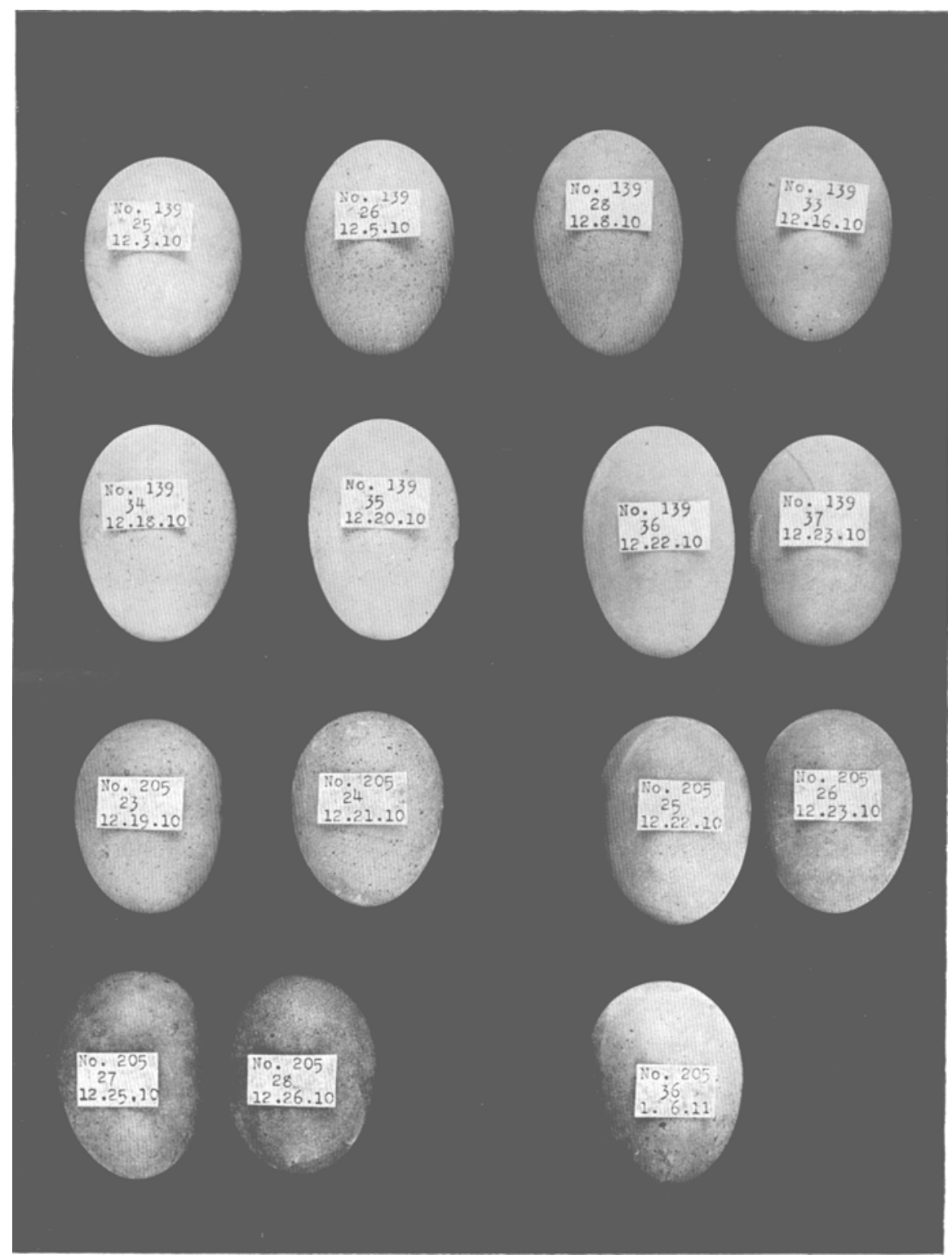

Curtis.

Verlag von Wilhelm Engelmann in Leipzig und Berlin. 


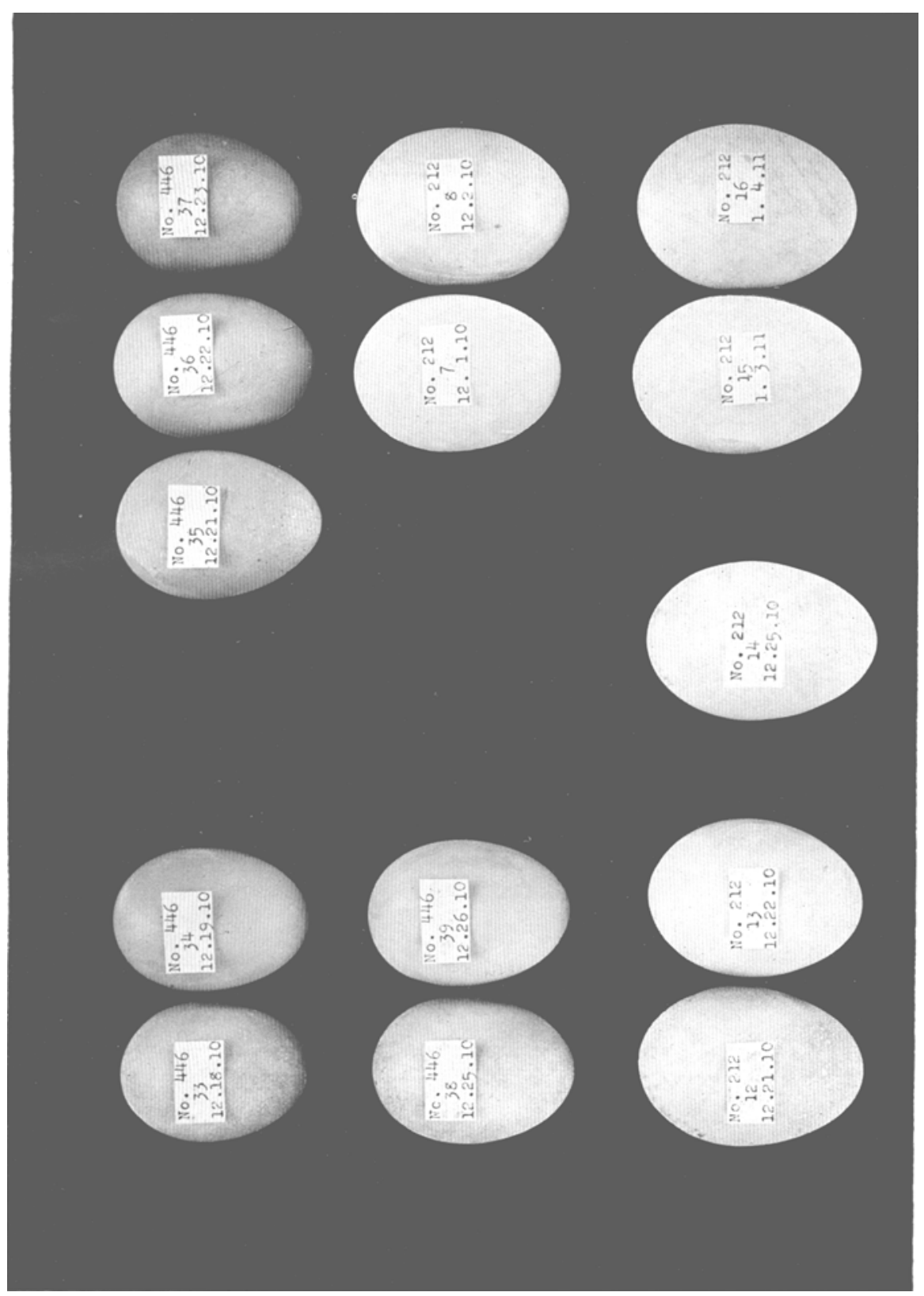

Curtis.

Vorlag von Wilhelm Engelniann in Leipzig und Berlin. 


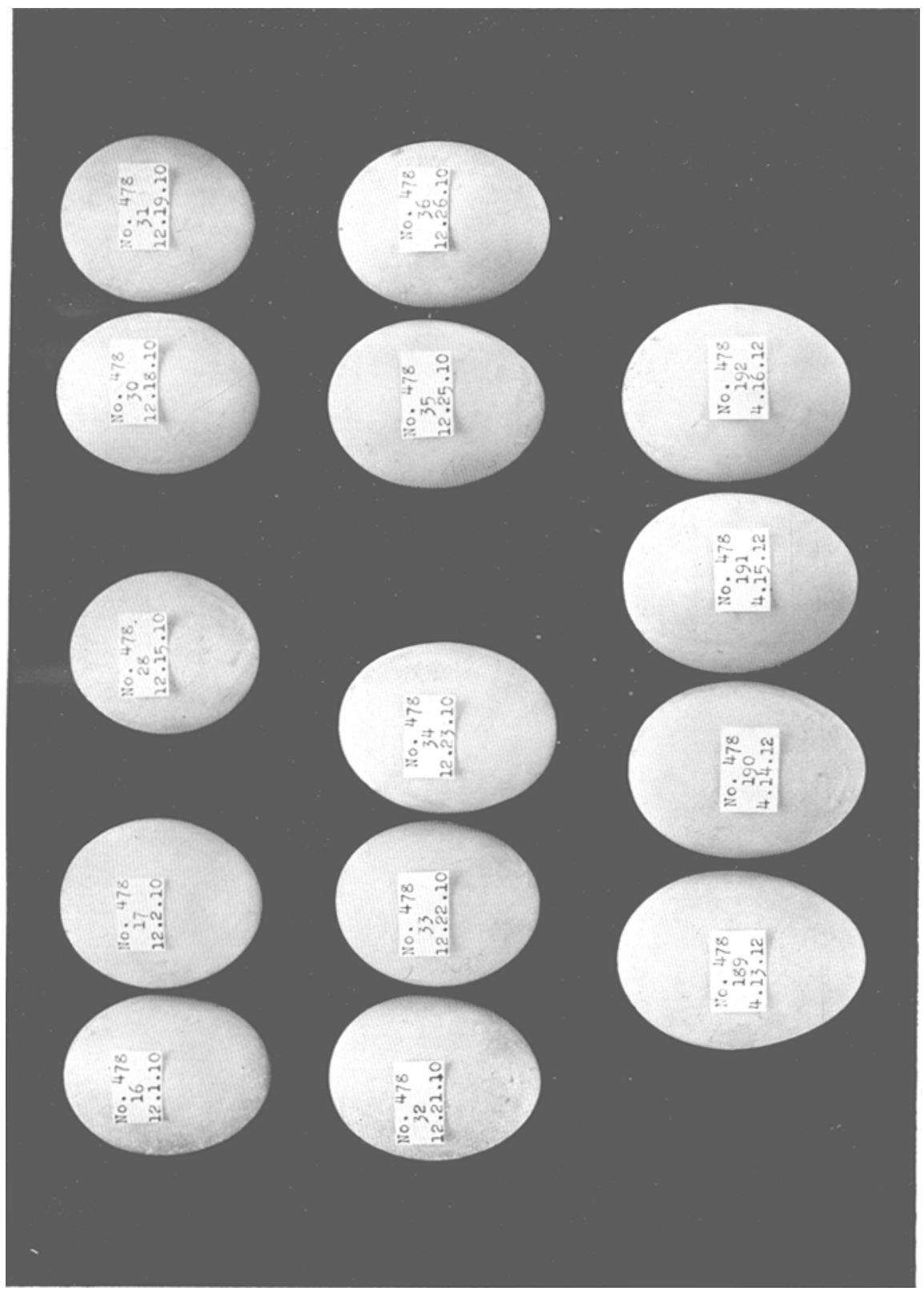

Curtis.

Verlag von Wilhelm Engelmann in Leipzig und Berlin. 


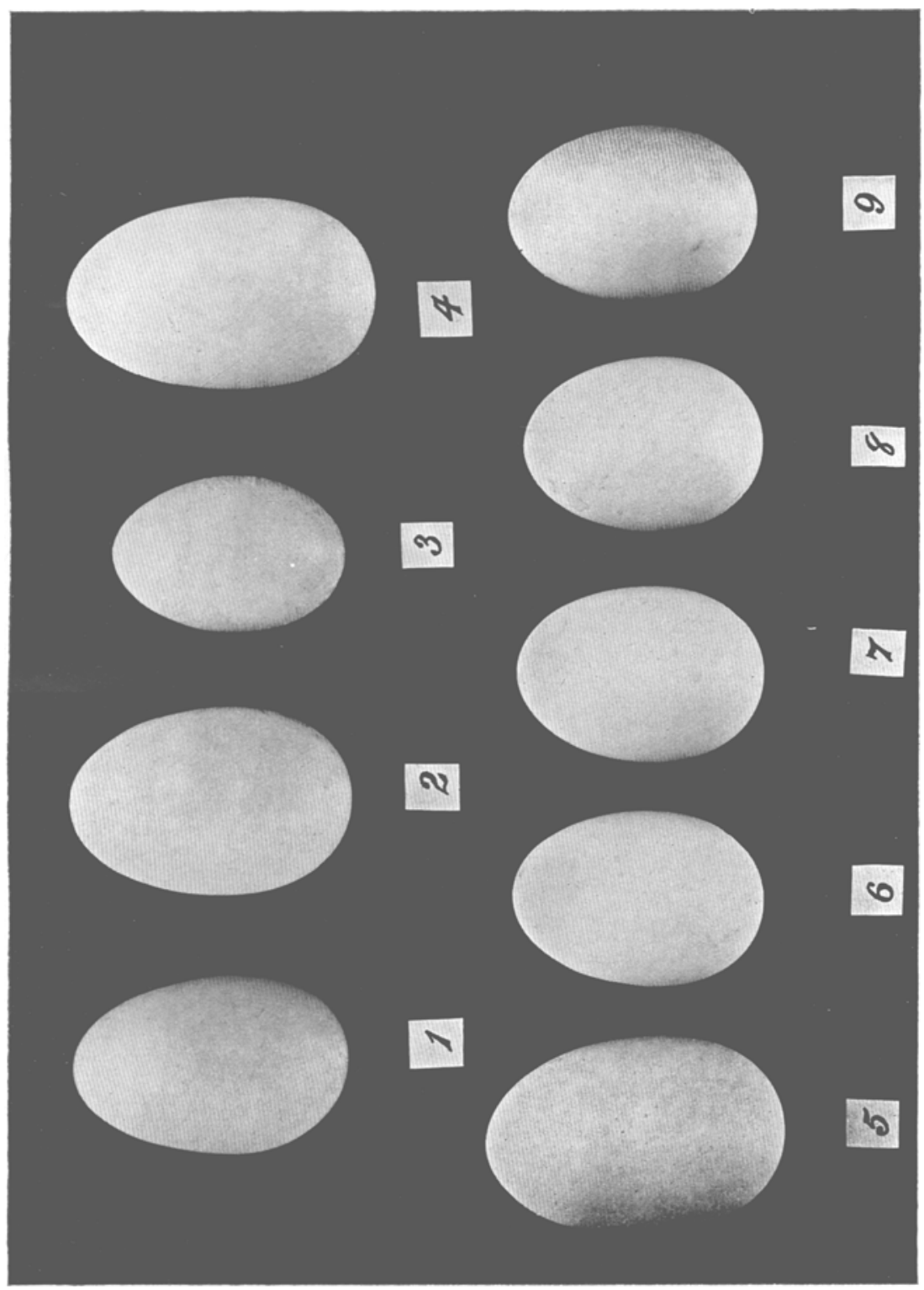

Curtis.

Verlag von Wilhelm Engelmann in Leipzig und Berlin. 


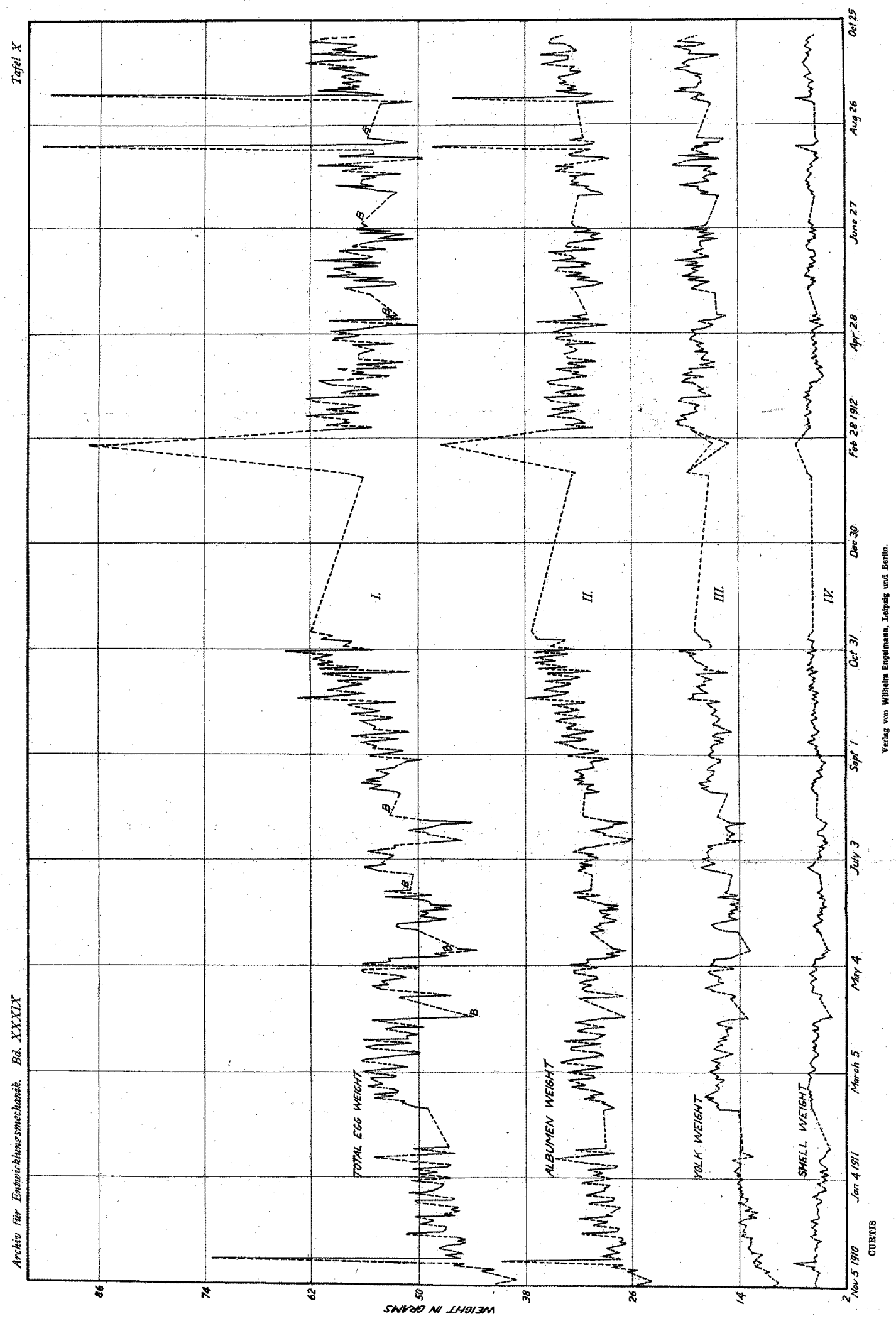


A Biometrical Study of Egg Production in the Domestic Fowl. IV. 327

\section{Plate VIII.}

A photograph of two series of eggs laid by bird No. 478. For the significance of the numbers on the labels see the explanation of Plate VI. $\times 1 / 2$.

\section{Plate IX.}

A photograph of the first eggs laid by a three months old Barred Plymouth Rock pullet. Eggs No. 1, 4,5 and probably 2 (see table 30) were double yolked. $\times 2 / 3$.

Plate $\mathbf{X}$.

Diagram showing the weight in gms. of the whole egg and of each part on every day on which an egg was laid by bird No. 218. The line I represents egg weight; the line II albumen weight; the line III yolk weight and the line IV shell weight. $B$ indicates the day on which the bird became broody. 